\title{
Investigating hypoxia in aquatic environments: diverse approaches to addressing a complex phenomenon
} Z. Erdem ${ }^{7, b}$, M. Geraga ${ }^{10}$, A. Gilli ${ }^{11}$, M. T. Gomoiu ${ }^{12}$, P. O. J. Hall ${ }^{13}$, D. Hansson ${ }^{14}$, Y. He ${ }^{1, \mathrm{c}}$, M. Holtappels ${ }^{3}$, M. K. Kirf ${ }^{15}$, M. Kononets ${ }^{13}$, S. Konovalov ${ }^{16}$, A. Lichtschlag ${ }^{3, d}$, D. M. Livingstone ${ }^{17}$, G. Marinaro ${ }^{8}$, S. Mazlumyan ${ }^{6}$, S. Naeher ${ }^{15, \text { e }}$, R. P. North $^{17, f}$, G. Papatheodorou ${ }^{10}$, O. Pfannkuche ${ }^{5}$, R. Prien ${ }^{18}$, G. Rehder $^{18}$, C. J. Schubert $^{15}$, T. Soltwedel ${ }^{2}$, S. Sommer ${ }^{5}$, H. Stahl ${ }^{4}$, E. V. Stanev ${ }^{1}$, A. Teaca ${ }^{12}$, A. Tengberg ${ }^{13}$, C. Waldmann ${ }^{19}$, B. Wehrli ${ }^{15}$, and F. Wenzhöfer ${ }^{2,3}$

${ }^{1}$ Helmholtz Zentrum Geesthacht Center for Materials and Coastal Research, Max-Planck Str. 1, 21502 Geesthacht, Germany

${ }^{2}$ Alfred Wegener Institute Helmholtz Center for Polar and Marine Research, Am Handelshafen 12, 27570 Bremerhaven, Germany

${ }^{3}$ Max Planck Institute for Marine Microbiology, Celsiusstr. 1, 28359 Bremen, Germany

${ }^{4}$ Scottish Association for Marine Science, Oban, Argyll, PA37 1QA, UK

${ }^{5}$ GEOMAR Helmholtz Center for Ocean Research Kiel, Wischhofstrasse 1-3, 24148 Kiel, Germany

${ }^{6}$ A. O. Kovalevskiy Institute of Biology of Southern Seas, Nakhimov Av. 2, 99011 Sevastopol, Ukraine

${ }^{7}$ Istanbul Technical University, EMCOL and Department of Geological Engineering, Maslak Sarıyer, 34469 İstanbul, Turkey

${ }^{8}$ Istituto Nazionale di Geofisica e Vulcanologia, Sezione Roma 2, Via di Vigna Murata 605, 143 Rome, Italy

${ }^{9}$ Faculty of Environmental Science and Engineering, Babes-Bolyai University, Cluj-Napoca, Romania

${ }^{10}$ Laboratory of Marine Geology and Physical Oceanography, Department of Geology, University of Patras, 26504, Greece

${ }^{11}$ ETH Zurich, Geological Institute, Sonneggstrasse 5, 8092 Zurich, Switzerland

${ }^{12}$ National Institute of Marine Geology and Geoecology, 304 Mamaia Boulevard, 8700 Constanta, Romania

${ }^{13}$ University of Gothenburg, Dept. of Chemistry and Molecular Biology, Marine Chemistry, 412 96, Gothenburg, Sweden

${ }^{14}$ Swedish Institute for the Marine Environment, Seminariegatan 1F, 405 30, Gothenburg, Sweden

${ }^{15}$ Eawag, Swiss Federal Institute of Aquatic Science and Technology, Department of Surface Waters - Research and Management, Seestrasse 79, 6047 Kastanienbaum, Switzerland

${ }^{16}$ Marine Hydrophysical Institute, Dept. Marine Biogeochemistry, Kapitanskaya St. 2, 99011 Sevastopol, Ukraine

${ }^{17}$ Eawag, Swiss Federal Institute of Aquatic Science and Technology, Department of Water Resources and Drinking Water, Überlandstrasse 133, 8600 Dübendorf, Switzerland

${ }^{18}$ Leibniz Institute for Baltic Sea Research Warnemünde, Seestr. 15, 18119 Rostock, Germany

${ }^{19}$ Bremen University/MARUM, Leobener Str., 28359 Bremen, Germany

a Joint first authorship (these authors have contributed equally to the manuscript).

${ }^{b}$ present address: GEOMAR Helmholtz Center for Ocean Research Kiel, Wischhofstrasse 1-3, 24148 Kiel, Germany

${ }^{c}$ present address: University of Kiel, Institute of Geosciences, Ludewig-Meyn-Str. 10, 24118 Kiel, Germany

${ }^{\mathrm{d}}$ present address: National Oceanography Centre, University of Southampton Waterfront Campus, European Way,

Southampton, SO14 3ZH, UK

epresent address: Curtin University, WA-Organic and Isotope Geochemistry Center, G.P.O. Box U1987, Perth, WA 6845, Australia

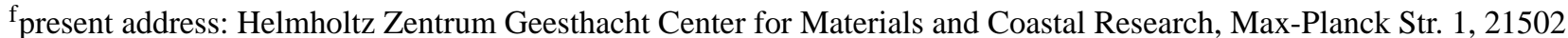

Geesthacht, Germany

Correspondence to: J. Friedrich (jana.friedrich@hzg.de) and F. Janssen (felix.janssen@awi.de)

Received: 12 July 2013 - Published in Biogeosciences Discuss.: 5 August 2013

Revised: 16 December 2013 - Accepted: 28 December 2013 - Published: 27 February 2014 
Abstract. In this paper we provide an overview of new knowledge on oxygen depletion (hypoxia) and related phenomena in aquatic systems resulting from the EU-FP7 project HYPOX ("In situ monitoring of oxygen depletion in hypoxic ecosystems of coastal and open seas, and landlocked water bodies", www.hypox.net). In view of the anticipated oxygen loss in aquatic systems due to eutrophication and climate change, HYPOX was set up to improve capacities to monitor hypoxia as well as to understand its causes and consequences.

Temporal dynamics and spatial patterns of hypoxia were analyzed in field studies in various aquatic environments, including the Baltic Sea, the Black Sea, Scottish and Scandinavian fjords, Ionian Sea lagoons and embayments, and Swiss lakes. Examples of episodic and rapid (hours) occurrences of hypoxia, as well as seasonal changes in bottom-water oxygenation in stratified systems, are discussed. Geologically driven hypoxia caused by gas seepage is demonstrated. Using novel technologies, temporal and spatial patterns of watercolumn oxygenation, from basin-scale seasonal patterns to meter-scale sub-micromolar oxygen distributions, were resolved. Existing multidecadal monitoring data were used to demonstrate the imprint of climate change and eutrophication on long-term oxygen distributions. Organic and inorganic proxies were used to extend investigations on past oxygen conditions to centennial and even longer timescales that cannot be resolved by monitoring. The effects of hypoxia on faunal communities and biogeochemical processes were also addressed in the project. An investigation of benthic fauna is presented as an example of hypoxia-devastated benthic communities that slowly recover upon a reduction in eutrophication in a system where naturally occurring hypoxia overlaps with anthropogenic hypoxia. Biogeochemical investigations reveal that oxygen intrusions have a strong effect on the microbially mediated redox cycling of elements. Observations and modeling studies of the sediments demonstrate the effect of seasonally changing oxygen conditions on benthic mineralization pathways and fluxes. Data quality and access are crucial in hypoxia research. Technical issues are therefore also addressed, including the availability of suitable sensor technology to resolve the gradual changes in bottom-water oxygen in marine systems that can be expected as a result of climate change. Using cabled observatories as examples, we show how the benefit of continuous oxygen monitoring can be maximized by adopting proper quality control. Finally, we discuss strategies for state-of-the-art data archiving and dissemination in compliance with global standards, and how ocean observations can contribute to global earth observation attempts.

\section{Introduction}

Oxygen concentrations in the open ocean and in coastal areas are decreasing worldwide (Diaz, 2001; Diaz and Rosenberg, 2008, Rabalais and Gilbert, 2009). Ocean models predict declines of $1-7 \%$ in the global ocean oxygen inventory over the next century (Keeling et al., 2010) and the analysis of open-ocean oxygen recordings already indicates a decrease in oxygen in the ocean interior (Stramma et al., 2008). Oxygen depletion and "hypoxia" develop wherever the consumption of oxygen by organisms or chemical processes exceeds the supply of oxygen from adjacent layers of water, from the atmosphere, and from photosynthesizing organisms.

Both natural and anthropogenic drivers can be responsible for oxygen depletion. Specific hydrodynamic conditions - i.e., enclosed and semi-enclosed water bodies with limited water exchange and long water retention times, windshielded fjords and lakes or freshwater lenses in coastal seas near river mouths - may make aquatic systems naturally prone to oxygen depletion. In addition, oxygen decline is often related to the oxidation of organic matter and reduced substances, to a lack in oxygen supply due to density stratification, and to the advective intrusion of oxygen-poor waters from deeper layers or adjacent water bodies. Geologically driven hypoxia or anoxia caused by the release of gases (e.g., methane or carbon dioxide) is less common but has been reported from African lakes, the Cariaco Basin, from offshore Namibia, from the Gulf of Mexico and from tectonically active areas of western Greece (Nayar, 2009; Ward et al., 1987; Kessler et al., 2005, 2011; Monteiro et al., 2006; Ferentinos et al., 2010).

Warming induced by climate change adds to oxygen depletion as it reduces the solubility of oxygen in water, and enhances microbial activity. Warming of the upper water column and an increase in precipitation strengthens watercolumn stratification, impeding mixing and hindering the transport of oxygenated water to greater ocean depths. In lakes analogous processes occur. Global warming also results in rising lake surface water temperatures (Adrian et al., 2009) and an increase in the intensity and duration of thermal stratification (Stefan et al., 1998; Peeters et al., 2002; Livingstone, 2003). During winter and spring - when temperate lakes typically undergo deep mixing - shorter periods of homothermy, or their complete absence, will reduce or inhibit deep-water renewal, resulting in lower deep-water oxygen concentrations (Stefan et al., 1996; Livingstone, 1997; Peeters et al., 2002; Jankowski et al., 2006; Rempfer et al., 2009, 2010). Climate warming is therefore likely to lead to an increase in the occurrence of hypoxia in lakes (Stefan and Fang, 1994; Jankowski et al., 2006). Locally, however, global change may give rise to opposite effects. For example, increasing wind speeds enhance mixing in both marine and freshwater systems. Alterations in the freshwater balance may reduce density gradients (Neumann, 2010). 
Anthropogenic drivers - e.g., agriculture, industry, and urbanization - impose pressures upon aquatic ecosystems, like the pollution of coastal seas with fertilizers and sewage leading to persistent algal blooms ("eutrophication"), and affect both the supply and uptake of oxygen. Planktonic photosynthesis may temporarily increase oxygen concentrations in the upper water layers until the organic matter eventually settles from the sunlit surface layer. Upon microbial degradation of the organic material below the euphotic zone and at the seafloor, oxygen is utilized and deep-water oxygen concentrations decrease. If bottom-water oxygen drops significantly, ecosystems undergo successive deterioration, eventually turning into permanently anoxic environments where microorganisms replace all higher life. This collapse of aquatic communities leads to a dramatic decline in ecosystem functioning and services such as biodiversity, fisheries, aquaculture and tourism (Levin et al., 2009; Zhang et al., 2010). Remediation measures in coastal ecosystems, however, do not always lead to ecosystem recovery; ecosystem responses tend rather to follow nonlinear trends that may include hysteresis and time lags (Kemp et al., 2009), as observed, for example, in the northwestern Black Sea (Mee et al., 2005, BSC, 2008).

In many aquatic systems, the effects of warming and eutrophication may coincide. In the Baltic Sea, for example, the projected decrease in oxygen concentration is expected to be caused by a reduced oxygen supply from the atmosphere due to increasing temperatures in combination with intensified nutrient availability from runoff and internal cycling (Meier et al., 2011).

Oxygen availability may affect the behavior, physiology, and mortality of organisms of any size and has an influence on the activity of microorganisms and on the prevailing biogeochemical processes (Levin et al., 2009; Middelburg and Levin, 2009; Riedel et al., 2012). Hypoxia thus substantially affects ecosystem functioning, with strong implications for all ecosystem components, biodiversity, biologically mediated cycling of matter, and ecosystem services such as fisheries and tourism. In general, oxygen-stressed ecosystems tend to have a lower diversity of long-lived species and reduced trophic complexity, and instead show a shift toward smaller opportunistic species (Pearson and Rosenberg, 1978; Nilsson and Rosenberg, 2000). Because of the plurality of ecosystem components and their individual reactions it is evident that the term "hypoxia" must refer to a processor biota-specific grade of low-oxygen stress rather than to some general concentration threshold. Vaquer-Sunyer and Duarte (2008) showed that oxygen depletion induces significant mortality even when oxygen concentrations are 2.3 times above the threshold of $62.5 \mu \mathrm{mol} \mathrm{L}^{-1}$ conventionally used for hypoxia in the literature. This indicates that organisms may be suffering from oxygen limitation in areas not presently designated as hypoxic. It has been suggested that thresholds for hypoxia in coastal ecosystems are higher than previously thought and are not static, but regulated by lo- cal and global processes. They are particularly sensitive to warming (Steckbauer et al., 2011), and are also dependent on other parameters such as $p \mathrm{CO}_{2}$ (Brewer and Peltzer, 2009; Hofmann et al., 2011). In this paper, the term "hypoxia" is not assigned to a specific concentration threshold but rather to an environmentally significant degree of oxygen depletion that depends on the effect or process being studied.

The importance of the long-term monitoring of oxygen concentrations has been recognized for many decades. The earliest systematic records of coastal hypoxia from Europe and North America date back to the 1910s (Zhang et al., 2010; Petersen, 1915; Sale and Skinner, 1917).

Oxygen monitoring is typically carried out annually, seasonally, or monthly during ship-based surveys. Long-term time-series measurements are critical for identifying the relative influence of climate variability and anthropogenic pressures. Ship-based monitoring, however, cannot cover the spatial extent of hypoxia, or its temporal dynamics on shorter timescales, or stochastic and episodic low-oxygen events. As ecosystem responses depend on the frequency, duration, spatial extent, and severity of hypoxia events, continuous monitoring of oxygen is required. The need for an improved and continuous monitoring of oxygen is made even clearer by predictions of generally declining oxygen concentrations in the future (Keeling et al., 2010). Observations with an improved spatio-temporal coverage also facilitate the identification of hypoxia drivers and help constrain numerical models. The need to develop new observational tools and models to support integrated research of biogeochemical dynamics and ecosystem behavior that will improve confidence in remediation management strategies for coastal hypoxia has also been highlighted by SCOR working group 128 on natural and human-induced hypoxia and its consequences for coastal areas (Zhang et al., 2010).

The core objective of the EU-FP7 project HYPOX ("In situ monitoring of oxygen depletion in hypoxic ecosystems of coastal and open seas, and landlocked water bodies", www.hypox.net) was to better understand the causes of hypoxia formation and improve the predictive capability of models. To this end, HYPOX initiated a comprehensive, state-of-the-art program for monitoring oxygen and related parameters in a variety of European aquatic systems that differ in oxygen status or in their sensitivity to change. HYPOX working areas (Fig. 1 and Table 1) are subject to a large variety of natural and anthropogenic causes of oxygen depletion and show a wide range in the severity of oxygen deficiency. They are located in coastal and open seas, including the North Atlantic-Arctic Ocean transition (Fram Strait), four contrasting sites in the Black Sea (Bosporus outlet area, Romanian Shelf, Crimean Shelf, Black Sea basin), and two Baltic Sea sites (Gotland Basin and Boknis Eck in Eckernförde Bay). Several lagoons and embayments in the subtropical/Mediterranean Greek Ionian Sea were also studied, as well as fjord systems (Koljoe Fjord in Sweden and Loch Etive in Scotland). Swiss lakes were investigated as examples 
Table 1. HYPOX study sites, temporal occurrence and drivers of oxygen depletion, monitoring approaches, processes investigated, and references to the sections containing more detailed descriptions.

\begin{tabular}{|c|c|c|c|c|c|}
\hline $\begin{array}{l}\text { Location/ } \\
\text { related section }\end{array}$ & Frequency and duration & Natural driver & Anthropogenic driver & $\begin{array}{l}\text { Type of in-situ observatory/ } \\
\text { monitoring approach }\end{array}$ & Processes studied \\
\hline \multicolumn{6}{|c|}{ Open and shelf seas } \\
\hline $\begin{array}{l}\text { Baltic Sea } \\
\text { Gotland basin/ } \\
3.1,3.2\end{array}$ & $\begin{array}{l}\text { Persistent anoxia } \\
>200 \mathrm{~m} \text {, during stag- } \\
\text { nation periods anoxia } \\
>110 \mathrm{~m} \text {, wind driven } \\
\text { oxycline dynamics at } \\
\text { time-scales of hours to } \\
\text { weeks }\end{array}$ & $\begin{array}{l}\text { Density-driven strati- } \\
\text { fication, baroclinic or } \\
\text { barotrophic inflows and } \\
\text { internal waves }\end{array}$ & $\begin{array}{l}\text { Climate warming stabi- } \\
\text { lizes stratification }\end{array}$ & $\begin{array}{l}\text { Profiling mooring GODESS } \\
\text { and benthic observatories } \\
\text { with } \mathrm{O}_{2} \text { optodes, benthic flux } \\
\text { chambers, seafloor mapping }\end{array}$ & $\begin{array}{l}\text { Short-term fluctuations at } \\
\text { pelagic redoxcline, three- } \\
\text { dimensional system, fast redox } \\
\text { fluctuations at the sediment- } \\
\text { water interface, organic matter } \\
\text { mineralization and nutrient re- } \\
\text { lease at the seafloor at changing } \\
\text { bottom-water } \mathrm{O}_{2}\end{array}$ \\
\hline $\begin{array}{l}\text { Baltic Sea } \\
\text { Boknis Eck/ } \\
3.4,5.2 .2\end{array}$ & $\begin{array}{l}\text { Seasonal bottom-water } \\
\text { hypoxia }\end{array}$ & Summer stratification & $\begin{array}{l}\text { Eutrophication due to } \\
\text { anthropogenic nutrient } \\
\text { input and nutrient re- } \\
\text { cycling at the seafloor, } \\
\text { climate warming stabi- } \\
\text { lizes stratification }\end{array}$ & $\begin{array}{l}\text { 50-yr time-series based on } \\
\text { monthly CTD casts with } \\
\text { Clark-type } \mathrm{O}_{2} \text { sensors and } \\
\text { Winkler titration, pore water } \\
\text { geochemistry, ex situ core } \\
\text { incubations }\end{array}$ & $\begin{array}{l}\text { Long-term trends in } \mathrm{O}_{2} \text { and } \\
\text { nutrients, pathways of benthic } \\
\text { organic matter mineralization } \\
\text { and nutrient fluxes at changing } \\
\text { bottom-water } \mathrm{O}_{2}\end{array}$ \\
\hline $\begin{array}{l}\text { Black Sea Basin/ } \\
3.5,4.1\end{array}$ & $\begin{array}{l}\text { Persistent anoxia below } \\
\text { pycnocline }\end{array}$ & $\begin{array}{l}\text { Density-driven stratifi- } \\
\text { cation between saline } \\
\text { deep waters and less } \\
\text { saline surface waters, } \\
\text { interactions with local } \\
\text { shelf topography }\end{array}$ & $\begin{array}{l}\text { Interplay of climate } \\
\text { variability and eutroph- } \\
\text { ication leads to rising } \\
\text { of the suboxic zone }\end{array}$ & $\begin{array}{l}\text { Drifting ARGO-type profiling } \\
\text { observatories with } \mathrm{O}_{2} \text { optodes, } \\
90 \text { yr of } \mathrm{O}_{2} \text { time-series observa- } \\
\text { tions based on CTD casts with } \\
\text { Clark-type } \mathrm{O}_{2} \text { sensors and Win- } \\
\text { kler titration }\end{array}$ & $\begin{array}{l}\text { Seasonal and local variability } \\
\text { of the chemocline position and } \\
\text { fine structure, long-term trends }\end{array}$ \\
\hline $\begin{array}{l}\text { Black Sea } \\
\text { Bosporus outflow/ } \\
4.3,5.1 .3,5.2 .1\end{array}$ & $\begin{array}{l}\text { Episodic injection of } \\
\mathrm{O}_{2} \text { into permanently } \\
\text { anoxic deep waters }\end{array}$ & $\begin{array}{l}\text { Permanent thermo- } \\
\text { haline stratification, } \\
\text { hypoxic conditions in } \\
\text { otherwise anoxic deep } \\
\text { waters due to inflow } \\
\text { of saline water of } \\
\text { Mediterranean origin }\end{array}$ & $\begin{array}{l}\text { Wastewater/nutrient } \\
\text { input from NW shelf } \\
\text { and Bosporus may } \\
\text { influence water-column } \\
\text { biogeochemistry }\end{array}$ & $\begin{array}{l}\text { Pump-CTD casts, with Clark- } \\
\text { type electrodes }\end{array}$ & $\begin{array}{l}\text { Water-column biogeochem- } \\
\text { ical processes at permanent } \\
\text { redoxcline and in oxic/hypoxic } \\
\text { "Bosporus plume" waters at } \\
\sim 300 \mathrm{~m} \text { depth, consequences } \\
\text { of } \mathrm{O}_{2} \text { depletion for benthic } \\
\text { fauna along depth } / \mathrm{O}_{2} \text { transect }\end{array}$ \\
\hline $\begin{array}{l}\text { Black Sea a } \\
\text { North-western shelf/ } \\
3.4,5.1 .1,5.1 .2,5.2 .2\end{array}$ & $\begin{array}{l}\text { Seasonal bottom-water } \\
\text { hypoxia }\end{array}$ & $\begin{array}{l}\text { Seasonal thermohaline } \\
\text { stratification due to } \\
\text { freshwater-seawater } \\
\text { confluence }\end{array}$ & $\begin{array}{l}\text { Agriculture, coastal } \\
\text { urbanization, fisheries, } \\
\text { eutrophication due to } \\
\text { nutrient input from } \\
\text { River Danube and } \\
\text { non-point sources }\end{array}$ & $\begin{array}{l}\text { Static three month mooring } \\
\text { with } \mathrm{O}_{2} \text { optodes, benthic flux } \\
\text { chambers }\end{array}$ & $\begin{array}{l}\text { Pathways of benthic organic } \\
\text { matter mineralization at chang- } \\
\text { ing } \mathrm{O}_{2} \text {, formation of bottom- } \\
\text { water hypoxia, consequences of } \\
\text { hypoxia for benthic ecosystem }\end{array}$ \\
\hline $\begin{array}{l}\text { Black Sea } \\
\text { Crimean shelf/ } \\
3.2,5.1 .3\end{array}$ & $\begin{array}{l}\text { Oscillating, from hours } \\
\text { to weeks, perhaps also } \\
\text { longer }\end{array}$ & $\begin{array}{l}\text { Permanent thermo- } \\
\text { haline stratification, } \\
\text { oscillations of the } \\
\text { chemocline depth (ed- } \\
\text { dies, internal waves), } \\
\text { interactions with local } \\
\text { shelf bathymetry, local } \\
\mathrm{CH}_{4} \text { seepage }\end{array}$ & $\begin{array}{l}\text { Local eutrophication, } \\
\text { long-term trends in } \\
\text { chemocline depth }\end{array}$ & $\begin{array}{l}\text { CTD profiles with Clark-type } \\
\mathrm{O}_{2} \text { sensors, static mooring ar- } \\
\text { rays, areal surveys (manned } \\
\text { submersible, towed observa- } \\
\text { tories), benthic observatories } \\
\text { (benthic chambers, micro pro- } \\
\text { filers, BBL studies) with } \mathrm{O}_{2} \text { op- } \\
\text { todes and Clark-type micro sen- } \\
\text { sors, seafloor mapping }\end{array}$ & $\begin{array}{l}\text { Benthic } \mathrm{O}_{2} \text { uptake, mineraliza- } \\
\text { tion pathways, distribution of } \\
\text { benthic communities }\end{array}$ \\
\hline $\begin{array}{l}\text { North Atlantic } \\
\text { Fram Strait/ } \\
6.1,6.2\end{array}$ & $\begin{array}{l}\text { Oxic conditions, poten- } \\
\text { tially slight long-term } \\
\mathrm{O}_{2} \text { decrease }\end{array}$ & $\begin{array}{l}\text { Potential decrease in } \\
\text { deep-water } \mathrm{O}_{2} \text { re- } \\
\text { sulting from global } \\
\text { warming and changes } \\
\text { in deep-water forma- } \\
\text { tion / thermohaline } \\
\text { circulation }\end{array}$ & & $\begin{array}{l}\text { Long-term moorings with } \mathrm{O}_{2} \\
\text { optodes, Winkler titration, } \\
\text { time-series of } \mathrm{O}_{2} \text { microprofiles }\end{array}$ & $\begin{array}{l}\text { Detection of gradual, small, } \\
\text { long-term changes in deep wa- } \\
\text { ter oxygenation }\end{array}$ \\
\hline
\end{tabular}


Table 1. Continued.

\begin{tabular}{|c|c|c|c|c|c|}
\hline $\begin{array}{l}\text { Location/ } \\
\text { related section }\end{array}$ & Frequency and duration & Natural driver & Anthropogenic driver & $\begin{array}{l}\text { Type of in-situ observatory/ } \\
\text { monitoring approach }\end{array}$ & Processes studied \\
\hline \multicolumn{6}{|c|}{ Landlocked water bodies } \\
\hline $\begin{array}{l}\text { Scotland } \\
\text { Loch Etive/ } \\
3.6,6.2\end{array}$ & $\begin{array}{l}\text { Long stagnation peri- } \\
\text { ods with hypoxia or } \\
\text { anoxia, episodic deep- } \\
\text { water renewal and oxy- } \\
\text { genation only at low } \\
\text { freshwater input, spring } \\
\text { tides, and favorable } \\
\text { winds }\end{array}$ & $\begin{array}{l}\text { Density-driven } \\
\text { stratification due to } \\
\text { freshwater-seawater } \\
\text { confluence, strong tidal } \\
\text { influence }\end{array}$ & $\begin{array}{l}\text { Global change related } \\
\text { changes in wind and } \\
\text { precipitation patterns } \\
\text { will influence inflow } \\
\text { events, anthropogenic } \\
\text { regulation of river } \\
\text { runoff }\end{array}$ & $\begin{array}{l}\text { Cabled observatory with } \mathrm{O}_{2} \text { op- } \\
\text { todes, long-term bottom moor- } \\
\text { ings }\end{array}$ & $\begin{array}{l}\text { Hydrophysical and meteoro- } \\
\text { logical prerequisites of inflow } \\
\text { events }\end{array}$ \\
\hline $\begin{array}{l}\text { Swedish west coast } \\
\text { Koljoe Fjord/ } \\
6.2\end{array}$ & $\begin{array}{l}\text { Long stagnation peri- } \\
\text { ods with hypoxia or } \\
\text { anoxia, episodic deep- } \\
\text { water renewal events } \\
\text { due to wind-induced in- } \\
\text { flow of saline waters }\end{array}$ & $\begin{array}{l}\text { Density-driven } \\
\text { stratification due to } \\
\text { freshwater-seawater } \\
\text { confluence }\end{array}$ & $\begin{array}{l}\text { Changes in wind and } \\
\text { precipitation patterns } \\
\text { related to global change } \\
\text { will influence inflow } \\
\text { events }\end{array}$ & $\begin{array}{l}\text { Time-series since } 1935 \text { with } \\
\text { Clark-type } \mathrm{O}_{2} \text { sensors and Win- } \\
\text { kler titration, cabled observa- } \\
\text { tory with } \mathrm{O}_{2} \text { optodes }\end{array}$ & $\begin{array}{l}\text { Physical processes of mixing, } \\
\text { hydrophysical and meteoro- } \\
\text { logical prerequisites of inflow } \\
\text { events }\end{array}$ \\
\hline $\begin{array}{l}\text { Greek lagoons and } \\
\text { embayments } \\
\text { Amvrakikos Gulf/ } \\
\text { 3.7, 5.1.1 }\end{array}$ & Seasonal anoxia & $\begin{array}{l}\text { Mediterranean fjord- } \\
\text { type system, seasonal } \\
\text { thermohaline stratifica- } \\
\text { tion, limited exchange } \\
\text { with open sea, low and } \\
\text { episodic gas seepage } \\
\text { from pockmarks }\end{array}$ & $\begin{array}{l}\text { Eutrophication due to } \\
\text { fish farms and fertilizer } \\
\text { runoff from agriculture }\end{array}$ & $\begin{array}{l}\text { Areal surveys with towed } \\
\text { observatory MEDUSA (CTD, } \\
\mathrm{O}_{2}, \mathrm{CH}_{4} \text { and } \mathrm{H}_{2} \mathrm{~S} \text { sensors), } \\
\text { organic biomarkers, benthic } \\
\text { foraminifera }\end{array}$ & $\begin{array}{l}\text { Drivers of hypoxia and anoxia, } \\
\text { role of gas seepage }\end{array}$ \\
\hline $\begin{array}{l}\text { Greek lagoons and } \\
\text { embayments Aetoliko } \\
\text { Lagoon/ } \\
3.7,5.1 .1\end{array}$ & $\begin{array}{l}\text { Persistent bottom water } \\
\text { anoxia }\end{array}$ & $\begin{array}{l}\text { Semi-enclosed lagoon, } \\
\text { limited exchange with } \\
\text { open sea, persistent } \\
\text { thermohaline stratifica- } \\
\text { tion, low and episodic } \\
\text { gas seepage from } \\
\text { pockmarks }\end{array}$ & $\begin{array}{l}\text { Increased freshwater } \\
\text { discharge, limited } \\
\text { water exchange due to } \\
\text { technical works }\end{array}$ & $\begin{array}{l}\text { Areal surveys with towed ob- } \\
\text { servatory MEDUSA (CTD, } \mathrm{O}_{2} \text {, } \\
\mathrm{CH}_{4} \text { and } \mathrm{H}_{2} \mathrm{~S} \text { sensors) }\end{array}$ & $\begin{array}{l}\text { Temporal and spatial dynamics } \\
\text { of gas seepage, gas origin, sea- } \\
\text { sonal dynamics in pycnocline } \\
\text { depth, relation of fish kills to } \\
\text { meteorological conditions }\end{array}$ \\
\hline $\begin{array}{l}\text { Greek lagoons and } \\
\text { embayments Katakolo } \\
\text { Bay/ } \\
3.7\end{array}$ & $\begin{array}{l}\text { Hypoxia around seep- } \\
\text { age sites (physical } \mathrm{O}_{2} \\
\text { stripping - maybe also } \\
\text { oxidation of reduced } \\
\text { gases) }\end{array}$ & $\begin{array}{l}\text { Gas seepage from } \\
\text { tectonically active } \\
\text { area (geogenic driver), } \\
\text { permanently strong } \\
\text { seepage of thermogenic } \\
\text { methane and } \mathrm{H}_{2} \mathrm{~S} \text { from } \\
\text { pockmarks }\end{array}$ & & $\begin{array}{l}\text { Areal surveys with towed ob- } \\
\text { servatory MEDUSA (CTD, } \mathrm{O}_{2} \text {, } \\
\mathrm{CH}_{4} \text { and } \mathrm{H}_{2} \mathrm{~S} \text { sensors), 3- } \\
\text { month deployment of benthic } \\
\text { observatory GMM (with CTD, } \\
\mathrm{O}_{2} \text { optode, } \mathrm{CH}_{4} \text { and } \mathrm{H}_{2} \mathrm{~S} \text { sen- } \\
\text { sors) }\end{array}$ & $\begin{array}{l}\text { Temporal and spatial dynamics } \\
\text { of gas seepage and its relation } \\
\text { to hypoxia }\end{array}$ \\
\hline $\begin{array}{l}\text { Switzerland } \\
\text { Lake Zurich/ } \\
4.2,4.3\end{array}$ & $\begin{array}{l}\text { Long-term trend } \\
\text { from monomictic to } \\
\text { oligomictic, seasonal to } \\
\text { annual stagnation with } \\
\text { bottom-water hypoxia }\end{array}$ & $\begin{array}{l}\text { Seasonal/ multiannual } \\
\text { thermal stratification }\end{array}$ & $\begin{array}{l}\text { Climate warming is im- } \\
\text { peding overturning in } \\
\text { winter, counteracted by } \\
\text { decreasing eutrophica- } \\
\text { tion }\end{array}$ & $\begin{array}{l}\text { 70-yr monthly time series based } \\
\text { on CTD casts with Clark-type } \\
\mathrm{O}_{2} \text { sensors and Winkler titra- } \\
\text { tion, time-series analysis, redox } \\
\text { sensitive metals in the sediment } \\
\text { record }\end{array}$ & $\begin{array}{l}\text { Effect of climate variability } \\
\text { on stratification stability and } \\
\text { bottom-water } \mathrm{O}_{2} \text {, Internal load- } \\
\text { ing of deep water with P re- } \\
\text { lease from sediments during } \\
\text { bottom water hypoxia, bottom- } \\
\text { water oxygenation history }\end{array}$ \\
\hline $\begin{array}{l}\text { Switzerland } \\
\text { Lake Rotsee/ } \\
3.3,4.3\end{array}$ & $\begin{array}{l}\text { Monomictic, annual } \\
\text { stagnation and bottom- } \\
\text { water anoxia }\end{array}$ & $\begin{array}{l}\text { Thermal stratification, } \\
\text { wind-shielded }\end{array}$ & $\begin{array}{l}\text { Eutrophication due to } \\
\text { wastewater and fertil- } \\
\text { izer runoff from agri- } \\
\text { culture in the past }\end{array}$ & $\begin{array}{l}\text { Optimized amperometric } \mathrm{O}_{2} \\
\text { sensing with Clark-type sen- } \\
\text { sors, fiberoptical trace optodes, } \\
\text { biomarkers in the sediment } \\
\text { record }\end{array}$ & $\begin{array}{l}\text { Fine structure of the submicro- } \\
\text { molar oxic-anoxic interface at } \\
\text { nanomolar resolution, eutroph- } \\
\text { ication and oxygenation history }\end{array}$ \\
\hline
\end{tabular}

of landlocked freshwater systems. For several of the sites, including the North Atlantic, Boknis Eck, Lake Zurich, Koljoe Fjord, and Loch Etive, multidecadal long-term monitoring data exist for oxygen and related parameters - e.g., Bange et al. (2011) (Boknis Eck: www.bokniseck.de); Zimmermann et al. (1991) (Lake Zurich); http://produkter.smhi.se/pshark/ datamap_bohuskusten.php (Koljoe Fjord area).

To gain deeper insights into the various drivers and mechanisms of hypoxia formation, the core part of the HYPOX project was dedicated to the development of monitoring strategies for oxygen and associated parameters tailored to the types of oxygen depletion found at the respective sites.
In addition, we looked for fingerprints of past hypoxia in the sediment record using organic and inorganic proxies. In order to extend the knowledge gained in space (i.e., generalization of the findings) and time (i.e., extrapolation of current observations into the future), modeling was an intrinsic part of our approach. These generalizations and forecasting capabilities facilitate an examination of the effects of future climate and eutrophication scenarios on oxygen availability and ecosystem functioning. Observations of oxygen availability and the response of animal communities and ecosystems to hypoxia are needed, not only to improve our understanding of the potential loss of ecosystem functioning and ecosystem services 


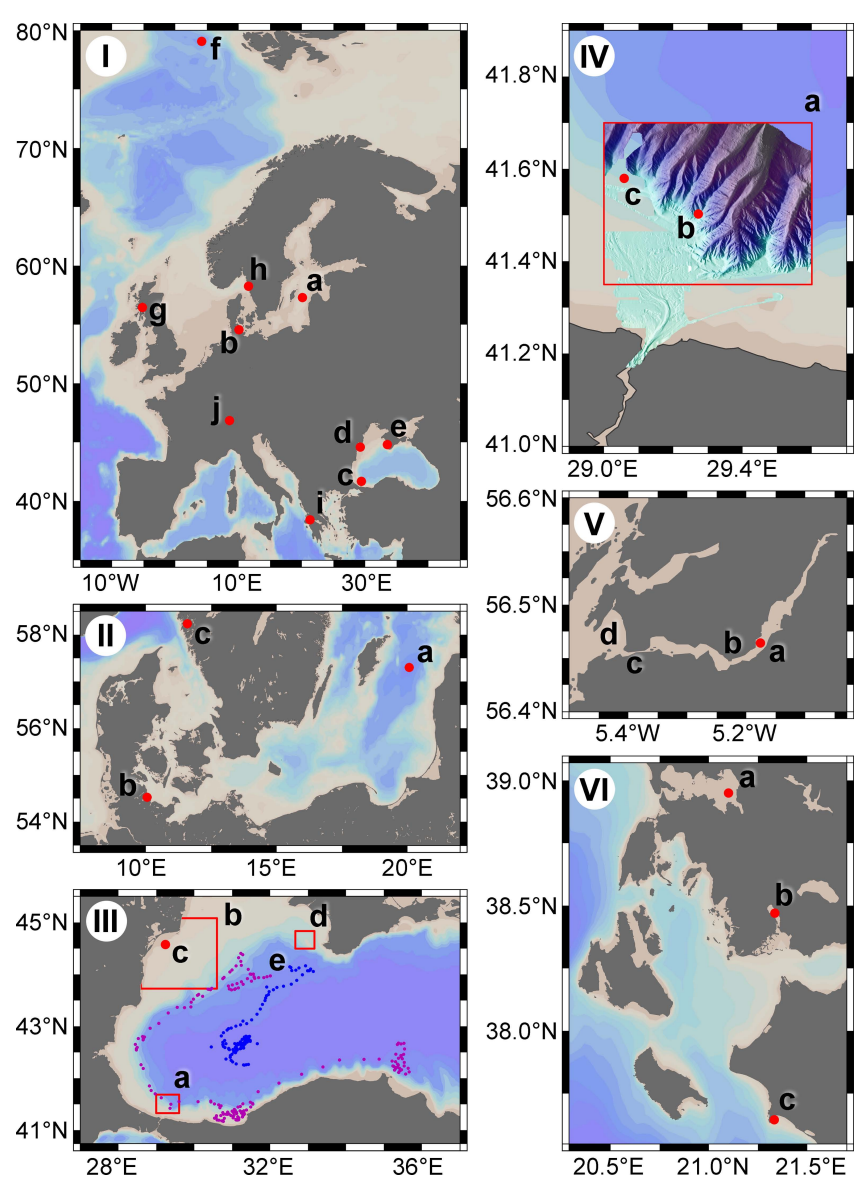

Fig. 1. Panel I, overview of study area: (Ia) Gotland Basin, (Ib) Eckernförde Bay/Boknis Eck, (Ic) Bosporus outlet, (Id) northwestern Black Sea shelf, (Ie) western Crimean shelf, (If) Fram Strait/HAUSGARTEN observatory, (Ig) Loch Etive, (Ih) Koljoe Fjord, (Ii) Ionian Sea lagoons and embayments, (Ij) Swiss lakes. Panel II, Baltic Sea and adjacent study area: (IIa) Gotland Basin observatory, (IIb) Eckernförde Bay/Boknis Eck time-series station, (IIc) Koljoe Fjord observatory. Panel III, Black Sea study area: (IIIa) Bosporus outlet study area, (IIIb) northwestern shelf study area, (IIIc) Portita Bay/northwestern shelf observatory (IIId) western Crimean shelf study area, (IIIe) deployment area of NEMO Floats 144 and 145 (profiling locations/drift track: blue and purple dots). Panel IV, Bosporus outlet study area: (IVa) coring and water sampling area, (IVb) core MSM015-192, (IVc) core MSM015-311. Panel V, Loch Etive study area: (Va) Loch Etive cabled observatory, (Vb) Bonawe Sill, (Vc) "Falls of Lora" sill, (Vd) Ardmucknish Bay. Panel VI, Ionian Sea study sites: (VIa) Amvrakikos Gulf, (VIb) Aetoliko Lagoon, (VIc) Katakolo Bay.

as a consequence of global warming and eutrophication but also to identify early warning indicators and tipping points in the wider ecosystem.

The intention behind this paper is to provide an overview of the new knowledge on oxygen and oxygen-related phenomena in aquatic systems resulting from the HYPOX project and the specific monitoring approaches applied. The paper is arranged into seven sections. Following this introduction (Sect. 1), Sect. 2 briefly introduces the study sites. In Sect. 3 we describe our approaches to observing hypoxia at appropriate scales with a focus on the temporal dynamics and spatial scales of hypoxia. Section 4 reports on investigations on long-term changes in present and past hypoxia. Section 5 is dedicated to the effects of hypoxia on faunal patterns and biogeochemical processes. Section 6 tackles the questions of how to improve data quality, access to the monitoring data, and data dissemination. Finally, conclusions and recommendations based on three years of hypoxia research in HYPOX are provided in Sect. 7.

\section{Description of study sites}

Table 1 provides an overview of the individual HYPOX study sites that provided data for this paper, along with some brief information on the temporal occurrence and drivers of oxygen depletion, monitoring approaches, and processes investigated.

\subsection{Open and shelf seas}

In the Baltic Sea our focus of work was on the temporal dynamics of the oxic-anoxic interface in the Gotland Basin. This interface is located between low-density surface waters and more dense and saline deep waters that originate from climate-controlled events involving the inflow of North Sea waters. Additional investigations focused on the effect of hypoxia on the release of reduced substances and phosphate from the sediments in Boknis Eck. Currently, the release of phosphorus from sediments is estimated to be an order of magnitude larger than the anthropogenic input (Conley et al., 2009), and may be an important driver of harmful algal blooms and subsequent oxygen depletion at depth. The Baltic Sea is the second-largest brackish water system in the world: it has a mean depth of $52 \mathrm{~m}$ (max. $460 \mathrm{~m})$, an area of $\sim 413000 \mathrm{~km}^{2}$ and a volume of $\sim 22000 \mathrm{~km}^{3}$ (Feistel et al., 2008). The Baltic Sea consists of several deep basins (Arkona Basin, Bornholm Basin, Eastern and Western Gotland Basin, Gulf of Finland, Gulf of Bothnia, Bothnian Bay) which are separated by shallow sills (e.g., Drodgen Sill and Darss Sill). These sills restrict the propagation of saline North Sea waters at depth, and also restrict deep-water exchange between the basins. The largest basin (Gotland Basin) in particular is thus naturally prone to permanent haline stratification, long residence times, and oxygen deficiency in the deeper water layers. In the basins of the Baltic Sea, hypoxia has been occurring repeatedly for natural reasons ever since the Baltic Sea was formed at about $8000 \mathrm{yr}$ BP. Such natural hypoxia occurred during several periods in the Holocene, including the medieval warm period (Leipe et al., 2008), but anthropogenic eutrophication has increased the spatial extent and intensity of oxygen depletion (Conley et al., 2009). This situation is 
exacerbated by the large drainage basin of the Baltic and by its anthropogenic nutrient surplus (Feistel et al., 2008). The Baltic Sea is surrounded by industrialized countries with intensive agricultural activity and, with a catchment area of $>1700000 \mathrm{~km}^{2}$, experiences significant freshwater runoff over the entire basin. The Baltic Sea is thus affected by both natural and anthropogenic drivers and pressures, and is very sensitive to eutrophication (HELCOM, 2009). Nutrient concentrations peaked during the 1980s and have since declined as a result of the success of efforts to reduce nutrient loading from the land. However, only 13 areas (2 open basins and 11 coastal sites) in the Baltic Sea are classified as "areas not affected by eutrophication", whereas 176 areas (15 open basins and 161 coastal sites) remain "areas affected by eutrophication" (HELCOM, 2009). Nutrient input from the sediments ("internal nutrient loading") is also a serious problem and more significant than terrestrial inputs to the Gulf of Finland (Pitkanen et al., 2001) and the Baltic proper (Viktorsson et al., 2013). In addition, projected climatic changes, which are stronger for the Baltic Sea than the global average (BACC, 2008), will affect both the freshwater balance and the seasonal extent of ice cover in the northern part of the Baltic.

Bottom waters in the central part of the Gotland Basin (a on panel I of Fig. 1) have been hypoxic or anoxic for more than half of the past $50 \mathrm{yr}$. Since the late 1970s, the frequency of major inflow events of oxygenated saline water from the North Sea has declined, with only two short ventilation episodes occurring, in 1993 and 2003. Yet, the resupply of saline water leads to a stabilization of the permanent stratification and slight uplift of the halocline, which results in an extension of the area exposed to hypoxic conditions (Conley et al., 2009). Some of the shallower, yet mostly stratified basins of the Baltic Sea (i.e., the Bornholm and Arkona basins) experience hypoxic or anoxic conditions on shorter timescales with a clear seasonality (Feistel et al., 2008). The Baltic Sea thus provides an ideal natural laboratory to study the impact of intermittent oxygen deficiency on different timescales.

Boknis Eck is a narrow channel located at the northern entrance of Eckernförde Bay in the southwestern Baltic Sea $\left(54^{\circ} 31^{\prime} \mathrm{N}, 10^{\circ} 20^{\prime} \mathrm{E}\right.$, b on panel I of Fig. 1), and has a maximum water depth of about $28 \mathrm{~m}$. The hydrography of Boknis Eck is dominated by the regular inflow of North Sea water through the Kattegat and the Danish straits, while riverine input is negligible. The higher salinity of the inflowing North Sea water in combination with a temperature increase at the surface lead to a pronounced summer stratification and the development of a pycnocline at about $15 \mathrm{~m}$ water depth. Phytoplankton blooms in autumn (September-November) and spring (February-March) are followed by the pronounced sedimentation of organic material (Smetacek et al., 1984). While stratification restricts vertical mixing, the organic matter supply causes an increase in benthic activity and oxygen demand in the deep layer (Graf et al., 1983). These fac- tors cause pronounced seasonal hypoxia and, in more recent times, have resulted in anoxia during late summer (Bange et al., 2011; Hansen et al., 1999). In addition, low oxygen concentrations are accompanied by elevated benthic fluxes of phosphate and ammonium (Balzer et al., 1983; Dale et al., 2013). Storms and a decrease in surface-water temperature cause mixing of the water column and ventilation of the deeper water in autumn (Bange et al., 2011; Hansen et al., 1999).

The Black Sea suffers from the combined effects of anthropogenic eutrophication, overfishing and climate forcing (Oguz and Gilbert, 2007; Mee et al., 2005), and thus allows many aspects of natural and man-made hypoxia to be studied. Consequently, studies of the Black Sea conducted within HYPOX included investigations of oxygen fluctuations in bottom waters (Romanian shelf, Crimean shelf), the effects of oxygen on benthic fauna and biogeochemical cycles (Bosporus outlet area, Romanian shelf, Crimean shelf), ecosystem recovery following a reduction in anthropogenic nutrient load (Romanian shelf), and studies of past redox conditions (Bosporus outlet area).

The Black Sea is a semi-enclosed basin that has contained the world's largest volume of naturally permanently anoxic waters at depths below approximately $200 \mathrm{~m}$ since about $7500 \mathrm{yr}$ BP (Jones and Gagnon, 1994). The sea is climatologically strongly influenced by the North Atlantic Oscillation (NAO) (Oguz et al., 2006) and its biological productivity is linked strongly to climate forcing (Oguz and Gilbert, 2007). The basin is largely isolated from the world ocean and only limited water exchange with the Mediterranean takes place via the Bosporus Strait and the Sea of Marmara. Precipitation and evaporation are roughly balanced. The Black Sea receives a strong freshwater input from the Danube, Dnieper and Dniester rivers, which discharge into the surface layers on the western shelf, and from numerous smaller rivers that discharge along the southern, eastern and northern coasts. This freshwater input results in a strong, natural, thermohaline stratification, which restricts vertical transport and is responsible for the lack of oxygen at depth. The rivers collect wastewater from more than 100 million people in the catchment, which has led to elevated nutrient inputs from the major rivers and resulted in high-productivity regimes (Oguz and Gilbert, 2007). The Black Sea has been recognized as a natural laboratory for studying various effects of climate forcing and anthropogenic drivers and pressures over the last decades. Before the onset of eutrophication, changes in the distribution of oxygen were attributed to seasonal variations in the solubility of oxygen and in the depth of the upper boundary of the sulfidic layer (Skopintsev, 1975). Apart from the inflow of Mediterranean water, the Bosporus outlet area (c on panel I of Fig. 1) is characterized by a rim current at the shelf margin and hypoxia below $\sim 100 \mathrm{~m}$ water depth. The mean inflow of Mediterranean water through the Bosporus has been estimated from salt and water budgets to be $310 \mathrm{~km}^{3} \mathrm{yr}^{-1}(\sim 0.01 \mathrm{~Sv}$, Ünlüata et al., 1990). 
Field studies (Latif et al., 1991) suggest a continuous inflow of Mediterranean water, which is occasionally interrupted for short durations (2-3 days) under strong and persistent northerly winds. The oxic, warm, and saline Mediterranean water cascades down the continental shelf to greater depths, where it mixes with the adjacent anoxic waters, detaches from the slope and forms the so-called "Bosporus Plume". After oxygen is consumed, the Bosporus Plume waters can still be detected by temperature anomalies, which have been measured up to $\sim 80$ nautical miles off the Bosporus mouth (Konovalov et al., 2003).

The Romanian shelf is part of the broad western Black Sea shelf and receives most of the river runoff ( $d$ on panel I of Fig. 1). The freshwater input leads to strong natural thermohaline stratification and also to seasonally restricted ventilation of deeper water layers on the shelf. This represents a natural driver for hypoxia and makes the western shelf prone to oxygen deficiency near the seafloor, particularly during summer. During autumn and winter, the thermohaline stratification is eroded by frequent storms and the water column is re-oxygenated. Strong, small-scale anticyclonic eddies that are present on the shallow shelf (Beckers et al., 2002) keep nutrient-rich water in the area and allow high primary productivity. Oxygen depletion as a consequence of anthropogenic eutrophication seriously affected the shelf from the early 1970s to the mid-1990s (Mee, 1992; Zaitsev, 1992; Tolmazin, 1985). More frequent and intense algal blooms (particularly of non-siliceous species as a result of the construction of dams, e.g., Humborg et al., 1997), red tides (i.e., blooms of Noctiluca scintillans and Prorocentrum cordatum) and changes in phytoplankton species composition led to deposition of surplus organic matter on the seafloor, causing frequent hypoxic and even anoxic events during the summer for more than $20 \mathrm{yr}$, with serious consequences for pelagic and benthic ecosystem structure and functioning, as well as for living resources, tourism, and recreation (BSC, 2008; Mee et al., 2005). During eutrophication-induced hypoxia, the sediments on the western shelf released half as much phosphorus as the entire input from the River Danube during the same period of time (Friedrich et al., 2002), thereby internally fuelling eutrophication. Statistical models indicate that the proportions of the interannual variability of hypoxia induced by eutrophication and climate are similar (Capet et al., 2013). As a result of degradation, the benthic ecosystem of the northwestern Black Sea shelf showed a significant reduction in species diversity, an increase in the abundance and biomass of invasive zoobenthic species that are tolerant of low oxygen conditions (e.g., Mya arenaria, Rapana venosa), a reduction in biofilter strength because of the loss of filterfeeder populations (e.g., Mytilus galloprovincialis), as well as the flourishing of opportunistic species such as worms and ascidians. Following the economic collapse of the eastern European countries during the 1990s, riverine nutrient loads decreased and the ecosystem is now showing signs of slow recovery, such as a decrease in the frequency and duration of hypoxic events (Langmead et al., 2009). Yet, the estimated load of nutrients and phytoplankton biomass remained high in the 1990s in comparison to the pre-eutrophication period (Yunev et al., 2007).

At the Crimean shelf of the Black Sea (e on panel I of Fig. 1) the position and structure of the chemocline is strongly influenced by anticyclonic gyres located outside of the main Rim Current, as well as by internal waves and the synoptic variability of the Black Sea's circulation pattern (Filonov, 2000). Quasi-periodic and incidental vertical fluctuations of the oxycline and the oxic-anoxic interface have been observed to occur at the Crimean shelf (Luth et al., 1998). The temporal changes in the depth of the oxygensulfide interface cover a range of 130-165 m, corresponding to lateral intrusions of up to $1 \mathrm{~km}$ distance along the shelf seafloor. This may occasionally aerate the seafloor below the average pycnocline depth, or flush the lower part of the oxic seafloor areas with anoxic waters. The temporal dynamics and intensity of these disturbances, as well as their intermediate effect on benthic communities and biogeochemical processes, remain poorly resolved.

Long-term monitoring of oxygen in the deep-sea at the North Atlantic-Arctic transition in Fram Strait is crucial to understanding the effects of global warming and changes in deep-sea circulation (Soltwedel et al., 2005) and their potential effects on the oxygenation of the deep ocean. Fram Strait is the only deep connection between the central Arctic Ocean and the Nordic Seas, where exchange of intermediate and deep waters takes place (Rudels et al., 2000; Fahrbach et al., 2001). The so-called "HAUSGARTEN" area in Fram Strait, west of Spitsbergen (f on panel I of Fig. 1), is characterized by the inflow of relatively warm, nutrientrich Atlantic Water into the central Arctic Ocean (Manley, 1995). In recent years a strong increase in the annual mean net heat transport within the waters of the West Spitsbergen Current has occurred, especially in the Yermak Branch (Schauer et al., 2004). Circulation patterns in Fram Strait result in a variable sea-ice cover, with permanent ice-covered areas in the west, permanent ice-free areas in the southeast, and seasonally varying ice conditions in the central and northeastern parts; i.e., in the wider HAUSGARTEN area. The dramatic decrease in summer sea-ice extent observed over the last few decades will cause an ongoing northward shift of the primary production that is associated with the ice edge. Satellite remote sensing over the last $30 \mathrm{yr}$ has revealed a continuous decrease in the Arctic summer minimum sea-ice area by approximately $10 \%$ per decade, which is attributable to global warming. Further alterations in sea-ice cover, water temperature, and primary production are expected, but the consequences for the wider ecosystem are largely uncertain (Weslawski et al., 2009). In order to understand the impact of large-scale environmental changes on the Arctic marine ecosystem, the German Alfred Wegener Institute for Polar and Marine Research (AWI) established the deep-sea observatory HAUSGARTEN in 1999 (Soltwedel 
et al., 2005). Today, the observatory includes 17 permanent sampling sites along a bathymetric transect covering water depths between $1000-5500 \mathrm{~m}$, and along a latitudinal transect following the $2500 \mathrm{~m}$ isobath. Multidisciplinary research activities at HAUSGARTEN cover almost all compartments of the marine ecosystem from the pelagic zone to the benthic realm. Although the marine ecosystem in the Fram Strait system is far from being classified as hypoxic, the observatory serves as a model site to study a possible link between climate change, bottom-water circulation changes, and oxygen supply in the open ocean.

\subsection{Landlocked water bodies}

Loch Etive is a Scottish fjord $0.2-2 \mathrm{~km}$ wide and $30 \mathrm{~km}$ long. It has 6 shallow sills $7-13 \mathrm{~m}$ below the water surface, and a glacially deepened hollow in its inner part ( $\mathrm{g}$ on panel I of Fig. 1; Fig. 9). Located on the Scottish west coast, it is well exposed to the Northern Atlantic and characterized by relatively low industrial and agricultural pressure. Previous modeling studies suggested that the oxygen depletion occurring in the inner deep basin of Loch Etive is mainly dominated by natural factors (Edwards and Edelsten, 1977). Tidally forced exchange through a complicated geometry of narrow straits combined with water-column stratification generates nonlinear 3-D dynamical features such as reversing tidal jets with $\mathrm{V}$-shape leading edges, standing lee waves, and internal tides. The interaction of several factors such as current velocity, stratification, sill geometry, and tidal oscillation frequency is required to displace the isopycnals to depths below the interface that separates deep stagnant waters from the upper, well-mixed layer. Renewal events take place only if the density of arriving water intrusions is higher than the density of the resident bottom waters in the inner part of the basin. Investigations in Loch Etive, and in the Swedish Koljoe Fjord described below, aimed to resolve temporal dynamics and drivers of episodic water-renewal events that occasionally aerate stagnating, and hence oxygen-depleted, deep waters. In both systems, deep-water exchange was known to be partly wind-driven but the processes controlling ventilation events had not been entirely resolved (Nordberg et al., 2001; Edward and Edelsten, 1977).

Koljoe Fjord is a fjord basin within the Orust-Tjörn fjord system on the Swedish west coast (h on panel I of Fig. 1). It is sandwiched between the open Skagerrak in the west and the adjacent fjord basin Havstensfjord in the east. Havstensfjord itself is connected to a series of basins further south that eventually also open up to the Skagerrak. Narrow sills of intermediate depth separate Koljoe Fjord from the other water bodies. The deepest part of the basin reaches $45 \mathrm{~m}$. The fjord is stratified, with a surface layer approximately $10 \mathrm{~m}$ thick. A halocline at $13 \mathrm{~m}$ water depth prevents windinduced mixing from oxygenating the water below. Oxygen concentrations in the deep waters therefore quickly decline after renewal events, and the fjord is prone to long stagnation periods with hypoxic or anoxic conditions (e.g., Nordberg et al., 2001). Sinking organic matter from terrestrial sources, runoff, and algal blooms worsen the situation. A coastal monitoring program has been in place for several years in the fjord system. Stations are located at three places within the fjord system, and at the southern entrance. Since 1990, monitoring has generally been undertaken on a monthly basis.

In the lagoons along the Ionian coast of western Greece, locally constrained low-oxygen zones are observed to occur episodically around gas seepages. The Ionian coast represents the main petroliferous area in Greece. Active tectonics and salt diapirism induce important onshore and offshore gas and oil seepages (Papatheodorou et al., 1993; Hasiotis et al., 2002; Etiope et al., 2006; Karakitsios and Rigakis, 2007; Kamberis et al., 2000). We hypothesize that gas seepage represents a geogenic driver for hypoxia events. Investigations carried out at these sites focused on the influence of gas seepages on the occurrence of seasonal and permanent anoxia. The combined effects of hydrographic setting, sewage, fertilizer input, and the release of reduced compounds from the sediments were also taken into account. We focus on three areas: Aetoliko Lagoon, Amvrakikos Gulf, and Katakolo Bay (panel VI of Fig. 1).

Aetoliko Lagoon is situated at the northern part of the Messolonghi-Aetoliko Lagoon complex (b on panel VI of Fig. 1). It represents the largest and most important wetland area in Greece and is protected under the Ramsar convention (Dassenakis et al., 1994). Fishery is a traditional activity in the lagoons and fundamental to the local economy. The southern part of the lagoon is connected with the open sea (Patras Gulf) through the shallow Messolonghi Lagoon. The northern part of Aetoliko Lagoon represents the deepest part of the lagoon complex. The lagoon exhibits permanent thermohaline stratification as a result of low water circulation and limited exchange with the open sea. Below the well-oxygenated surface water layer the water is permanently anoxic, with hydrogen sulfide concentrations of up to $176 \mu \mathrm{mol} \mathrm{L}^{-1}$.

Amvrakikos Gulf is a shallow, marine, seasonally anoxic embayment connected to the open Ionian Sea by narrow, shallow straits (a on panel VI of Fig. 1). It is considered to be the only Mediterranean fjord-type system (Ferentinos et al., 2010; Kountoura and Zacharias, 2011). The seafloor of the gulf is covered by fine-grained sediments and a thin veneer of black muddy sediments. The vertical distribution of dissolved oxygen seems to be largely controlled by the density stratification of the water column, which is comprised of a brackish surface layer and a saline bottom layer (Ferentinos et al., 2010). Hypoxia related to gas seepage from pockmarks in the southeastern part of the gulf (Amphilochia Bay) was investigated as part of this study.

Katakolo Bay, an open embayment on the west coast of the Peloponnese (c on panel VI of Fig. 1), hosts one of the largest offshore thermogenic methane seeps in Europe (Etiope et al., 2006, 2013). Gas seepage, made obvious by the widespread 
occurrence of plumes of bubbles over a shallow, $94200 \mathrm{~m}^{2}$ area (5.5-16 m water depth), may lead to localized, episodic hypoxia.

The Swiss lakes addressed in our study ( $\mathrm{j}$ on panel I of Fig. 1) are deep, wind-sheltered water bodies which are typically monomictic; i.e., they mix completely once a year. Recent climate change has caused shifts towards less frequent mixing (oligomixis) (Livingstone, 1993), which can result in deep-water hypoxia (Livingstone, 1997; Rempfer et al., 2010) and the release of phosphorus from the sediment (North et al., 2014). Current conditions in the lakes, as well as the impact of climate change and the history of hypoxia, were addressed by a combination of measurements and time-series analyses. Many lakes on the Swiss Plateau underwent strong eutrophication in the early 1970s as a result of phosphate input from detergents and agricultural runoff. The trophic status of most deep Swiss lakes has improved markedly over the past few decades as a result of measures to combat anthropogenic eutrophication. However, global warming is leading to increased lake surface temperatures worldwide (Schneider and Hook, 2010), which can affect many aspects of lake ecosystems (Adrian et al., 2009). For example, less vigorous mixing paired with a longer duration of stratification (Livingstone, 2003) is likely to result in lower hypolimnetic oxygen concentrations and an increase in the thickness of the hypoxic zone (Livingstone and Imboden, 1996). These climate effects might counteract the benefits of the measures introduced to improve lake trophic status. In Switzerland, the availability of long, high-quality lake profile data, especially from Lake Zurich, allows attempts to be made to quantify the effect of recent climate change on deep-water oxygen concentrations (e.g., Livingstone, 1997; Jankowski et al., 2006; Rempfer et al., 2009, 2010; North et al., 2014).

Lake Zurich is a medium-sized perialpine lake with a surface area of $65 \mathrm{~km}^{2}$, a volume of $3.3 \mathrm{~km}^{3}$ and a maximum depth of $136 \mathrm{~m}$ (Livingstone, 2003). Although typically monomictic, Lake Zurich can also behave as a dimictic or oligomictic lake depending on the winter weather (Rempfer et al., 2010). The recent shift towards oligomixis, a situation in which the lake does not mix completely in some years (Livingstone, 1993), has resulted in some occurrences of extremely low deep-water oxygen concentrations (Livingstone, 1997). Lake Zurich underwent strong eutrophication until the early 1980s. As a consequence of the construction of wastewater treatment plants in the 1970s and 1980s, and the nationwide banning of phosphates in detergents in the 1980s, the total phosphorus concentration in the lake decreased rapidly and the lake is now considered to be weakly eutrophic or mesotrophic (Jankowski et al., 2006).

Lake Rotsee is a small, monomictic, eutrophic lake with a surface area of $0.46 \mathrm{~km}^{2}$, a volume of $3900 \mathrm{~m}^{3}$ and a maximum depth of $16 \mathrm{~m}$. During most of the year, the water column exhibits a highly stable stratification with a chemocline located between about 6 and $10 \mathrm{~m}$ depth (Schubert et al.,
2010). Since around 1850, the trophic state has increased as a result of sewage input, and in 1920 the lake was classified as polytrophic (Bloesch, 1974; Stadelmann, 1980). Numerous blooms of Planktothrix rubescens, which turned the lake water red, were observed (Züllig, 1985). In an attempt to restore the lake, a canal to the Reuss River was constructed in 1922 to increase the input of fresh water to the lake (Kohler et al., 1984). However, because of the continued supply of nutrients from a nearby disposal site, the occasional drying up of the canal, and the inability of the water inflow from the canal to initiate mixing (Bachmann, 1931; Stadelmann, 1980), the trophic status of the lake barely changed. Recovery of the lake started slowly after the construction of an interceptor sewer in 1969 and a sewage treatment plant in 1974 (Stadelmann, 1980).

\section{Observing hypoxia at appropriate temporal and spatial scales}

Oxygen concentrations in aquatic systems, especially in areas with strong oxygen gradients, may vary over different temporal and spatial scales. Temporal variability can result from periodic seasonal or hydrodynamic effects (e.g., summer stratification, tides, internal waves), but can also be of episodic nature (e.g., due to meteorologically triggered intrusions or overflow events). Spatial variability may occur over large areas, such as entire basins and water bodies, or affect the distribution of oxygen and redox-sensitive species on a scale of centimeters within perturbed pelagic redoxclines. Changes in oxygen concentrations might involve the full scale from well-oxygenated to almost anoxic conditions, or be restricted to a narrow range between anoxic conditions and the availability of trace amounts of oxygen. Such minute changes may still have severe implications for marine biota, as for many aquatic organisms oxygen can be either mandatory or toxic. In this chapter, we report on investigations of oxygen distribution that address these different scales. Special emphasis is put on a description of the measurement/monitoring strategies and the chosen methodological and technological approaches.

\subsection{Short-term changes in oxygen concentration in the pelagic redoxcline - an example from the Baltic Sea}

Strong stratification of the deep Baltic Sea water column results in the formation of a pelagic redoxcline - a transition zone with strong vertical redox gradients. Similar situations are observed in the Black Sea and in other stratified marine systems (e.g., in many fjords). Oxygen and other major electron acceptors (e.g., nitrate) that are abundant in the upper water layer oxidize reduced species (e.g., sulfide and reduced metal species) that accumulate in deeper waters. Consequently, pelagic redoxclines are prime locations of biogeochemical redox transformations that depend on the 

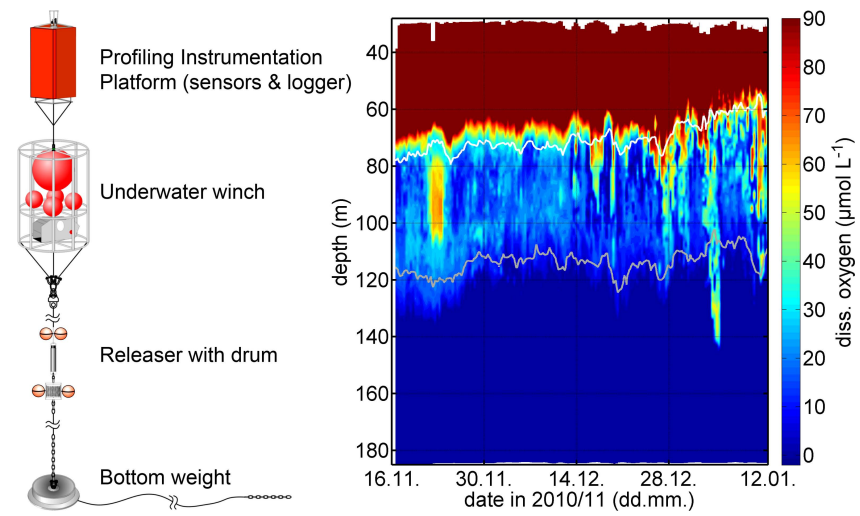

Fig. 2. Left-hand panel: sketch of the GODESS profiling mooring with profiler, underwater winch, releaser with recovery line and bottom weight (from top to bottom) in the Gotland Basin. Righthand panel: dissolved-oxygen concentration for a 56-day deployment in the central part of Eastern Gotland Basin (16 November 2010 to 11 January 2011), measured with a Rinko III oxygen optode from JFE Advantech Co., Ltd. (Japan). All concentrations above $90 \mu \mathrm{mol} \mathrm{L}^{-1}$ are plotted in red. White and gray lines denote the $8.0 \mathrm{~kg} \mathrm{~m}^{-3}$ and $9.5 \mathrm{~kg} \mathrm{~m}^{-3}$ isopleths, respectively, of the density anomaly.

vertical transport of reduced and oxidized species across this layer. Traditionally, redoxclines have been viewed as gradually evolving, layered systems with steady turbulent diffusion as the sole mechanism of vertical solute transport. There is increasing evidence, however, that redoxcline systems in the Baltic and the Black Sea show more complex structure and variability on short timescales (Dellwig et al., 2010; Konovalov et al., 2003; Glazer et al., 2006). Direct observations of the dynamic properties of pelagic redoxclines cannot be addressed by traditional ship-based monitoring, but require continuous measurements. For this reason, a profiling mooring was built within the framework of HYPOX (Prien and Schulz-Bull, 2011), which allowed, for the first time, the temporal evolution of redox conditions in the water column of the central Eastern Gotland Basin to be observed (lefthand panel of Fig. 2). An underwater winch equipped with a positively buoyant instrumentation platform was moored at a depth of about $185 \mathrm{~m}$ (a on panel II of Fig. 1). At regular time intervals the winch released the cable and the instrumentation platform ascended at a speed of about $0.37 \mathrm{~m} \mathrm{~s}^{-1}$, recording profiles of oxygen and standard oceanographic parameters, as well as chlorophyll $a$, fluorescence, turbidity, oxidation reduction potential, and $\mathrm{pH}$. The right-hand panel of Fig. 2 shows the dissolved oxygen concentration assembled from 171 profiles recorded every eight hours over a 56day winter deployment. This sampling interval is appropriate in the Baltic Sea because of the absence of tides. In other marine systems with semi-diurnal tides, a shorter sampling interval would be necessary to avoid tidal aliasing of the low frequency signals. However, there is a tradeoff between sampling interval and deployment duration, as the energy in the batteries limits the number of profiles that can be measured. The measurement series reveals not only fast changes in oxygen concentrations of more than $5 \mu \mathrm{mol} \mathrm{L}^{-1} \mathrm{~h}^{-1}$ in a layer several tens of meters thick between the oxycline and the anoxic deep layer, but also frequent intrusions of oxygenated water into deeper water layers with low oxygen concentrations. This high temporal variability is indicative of a complex, three-dimensional structure of the redoxcline created by the lateral import of different water masses as a result of complex hydrodynamic processes (e.g., baroclinic and barotrophic inflows, internal waves, upwelling, and boundary mixing; Reissmann et al., 2009).

These complex, dynamic conditions have important implications. Increased turbulent mixing of, for example, oxic or nitrate-bearing waters with sulfidic waters will most likely enhance biogeochemical transformation processes and alter microbial community composition. Large changes in redoxcline stability and structure may lead to strong shifts in the nitrogen and manganese cycles (Hannig et al., 2007; Dellwig et al., 2010). At the same time these processes will determine major transport schemes across the oxic-anoxic boundary. One example is the transport of phosphate from deeper waters towards the sunlit surface layer of the Baltic, where it may facilitate the blooming of cyanobacteria. Based on these findings the redoxcline appears as a dynamic, threedimensional system, controlled or strongly modified by intermittent lateral transport processes and vertical oscillations rather than by continuous vertical diffusion. This provides an exciting new perspective for explaining observations that have so far remained enigmatic, such as the absence of microbial communities under favorable growth conditions and the occurrence of chemical intermediates in the water column that are decoupled from the redox conditions at the time of observation.

\subsection{Fast redox fluctuations at the seawater sediment interface - examples from the Gotland Basin (Baltic Sea) and the Crimean shelf (Black Sea)}

Where temporally dynamic and spatially complex redoxclines impinge on the seafloor (see previous section), bottomwater oxygen conditions are likely to show similarly pronounced short-term fluctuations. Such fluctuations can be expected to have a strong impact on sessile benthic fauna (see Sect. 5.1.3). Even under spatially uniform redox conditions in a stratified water column, hydrodynamic displacement of isopycnal interfaces may cause rapid changes in oxygen availability at the seafloor. Oxygen time-series data were collected in the lowermost part of the water column in the Eastern Gotland Basin (a on panel II of Fig. 1) and the southwestern Crimean shelf ( $\mathrm{d}$ on panel III of Fig. 1) to investigate the variability of bottom-water oxygenation in permanently stratified systems. 

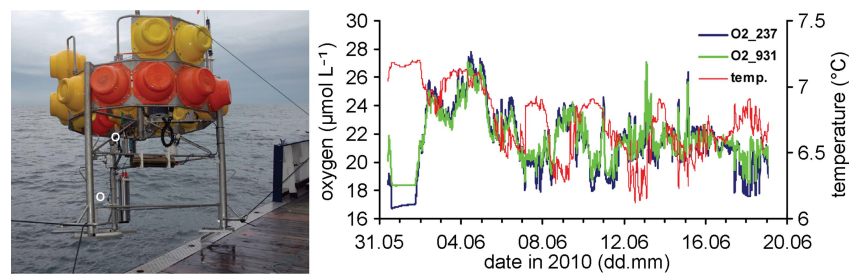

Fig. 3. Left-hand panel: photograph of the GEOMAR benthic observatory. White circles denote oxygen optodes attached 0.3 and $1 \mathrm{~m}$ (serial numbers 237 and 931, respectively) above the seafloor. Right-hand panel: time series of bottom-water oxygen concentration and temperature measured $0.3 \mathrm{~m}$ (blue line) and $1 \mathrm{~m}$ (green line) above the seafloor at a 90 m-deep station in the Gotland Basin during summer 2010 (Alkor cruise AL355).

Stand-alone benthic observatories (left-hand panel of Fig. 3) were deployed at the seafloor of the Gotland Basin at the depth of the redoxcline $(90 \mathrm{~m})$. The right-hand panel of Fig. 3 shows persistent fluctuations in the range of $17-$ $28 \mu \mathrm{mol} \mathrm{L}^{-1}$ as they occurred in summer 2010 in the eastern Gotland Basin during calm weather. Measurements obtained at the same station during turbulent meteorological conditions in autumn 2009 showed much larger fluctuations, with episodic oxygenation events of up to $200 \mu \mathrm{mol} \mathrm{L}^{-1}$. Similar conditions were observed at the southwestern Crimean shelf during calm weather in April-May 2010. Here, oxygen concentrations $1 \mathrm{~m}$ above the seafloor were generally highly variable and occasionally dropped from $>150 \mu \mathrm{mol} \mathrm{L}^{-1}$ to almost anoxic condition within less than two hours (Fig. 4b). A compilation of oxygen measurements carried out by various instruments showed that sediments at water depths of $130-145 \mathrm{~m}$ on the southwestern Crimean shelf were exposed to bottom waters alternating between oxic, hypoxic, and anoxic conditions. Variations in oxygen concentration and water density were strongly correlated, revealing that the observed changes in bottom-water oxygen were indicative of dynamic shifts of the pycnocline. In general, the driving forces behind the variability can be manifold, ranging from small-scale processes to large-scale processes such as internal waves, the passage of mesoscale eddies, Ekman pumping, atmospheric pressure oscillations, and tides. The stronger the gradients in the pycnocline and oxycline, the greater is the impact of their vertical displacement on benthic oxygen conditions. Although tidal sea-level changes are only a few centimeters in the Black Sea, the up-and-down shifts of the water column caused an oxygen variability of up to $20 \mu \mathrm{mol} \mathrm{L}^{-1}$ in the oxycline at the Crimean shelf.

The examples from the Gotland Deep and the Black Sea show that continuous recordings at high frequency are needed in order to accurately characterize benthic oxygen levels in stratified waters at the depth of the redoxcline. The pronounced oscillations in bottom-water oxygenation are expected to have severe effects on the benthic communities living there (see Sect. 5.1.3) and may affect the remineralization

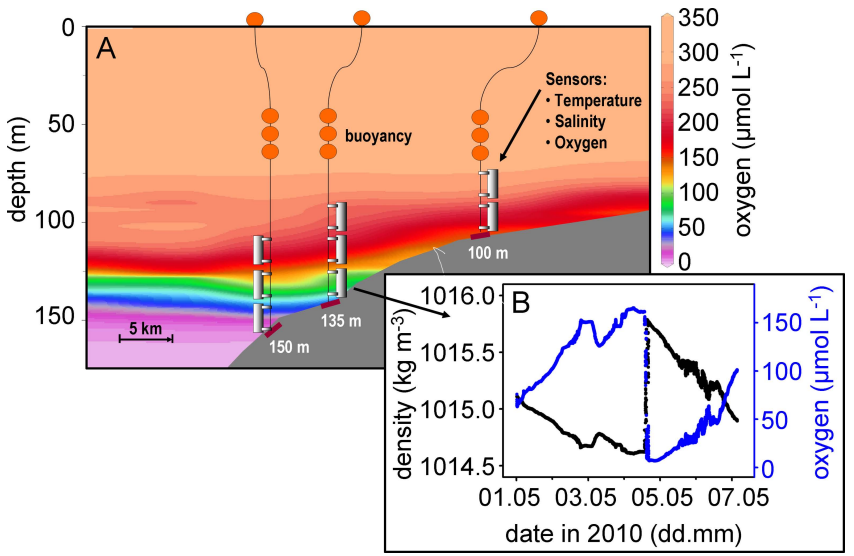

Fig. 4. (A) Three moorings were deployed at the southwestern Crimean shelf (Black Sea) from 1 to 7 May 2010 at 100, 135 and $150 \mathrm{~m}$ depth, measuring temperature, salinity and oxygen concentration. The average distribution of oxygen is compiled from 16 CTD profiles taken between 24 April and 7 May. (B) Time series of density and oxygen from the lowermost CTD at $135 \mathrm{~m}$ depth. Oxygen correlates with density, showing a gradual increase in oxygen over several days followed by a sudden drop in oxygen concentration of more than $150 \mu \mathrm{mol} \mathrm{L}^{-1}$ within two hours.

of organic matter and the redox cycling of major elements, as well as the associated nutrient release from the underlying sediments.

\subsection{Fine structure of the lower oxycline-examples from Swiss lakes}

The Baltic Sea profiling mooring described in Sect. 3.1 revealed the strong spatio-temporal dynamics of redoxclines in stratified marine basins. Of particular significance for redox cycling is the oxic-anoxic interface, since the rates of many biogeochemical processes are determined by the presence or absence of oxygen (e.g., Canfield et al., 2005). Standard oxygen sensors are not able to detect oxygen down to the trace concentrations required to fully understand the distribution of biogeochemical processes and redox species in the environment (Stolper et al., 2010; Thamdrup et al., 2012). To resolve redoxcline oxygen distributions at the relevant scales of concentration and time, oxygen sensors need to be sensitive and respond quickly. The recently developed self-calibrating switchable trace oxygen (STOX) sensor resolved the problem of drift in amperometric oxygen sensors and lowered the detection limit to trace levels $\left(2 \mathrm{nmol} \mathrm{L}^{-1}\right)$ (Revsbech et al., 2009). However, the time needed for calibration cycles ( $15 \mathrm{~s}$ in especially fast cycling sensors, a few minutes for regular sensors; Revsbech et al., 2011) limits speed or vertical resolution in profiling applications. Investigations within HYPOX revealed that standard (i.e., nonswitchable) amperometric and optical oxygen microsensors are both suitable to fully characterize the fine-scale structure of the oxic/anoxic interface in stratified water columns 

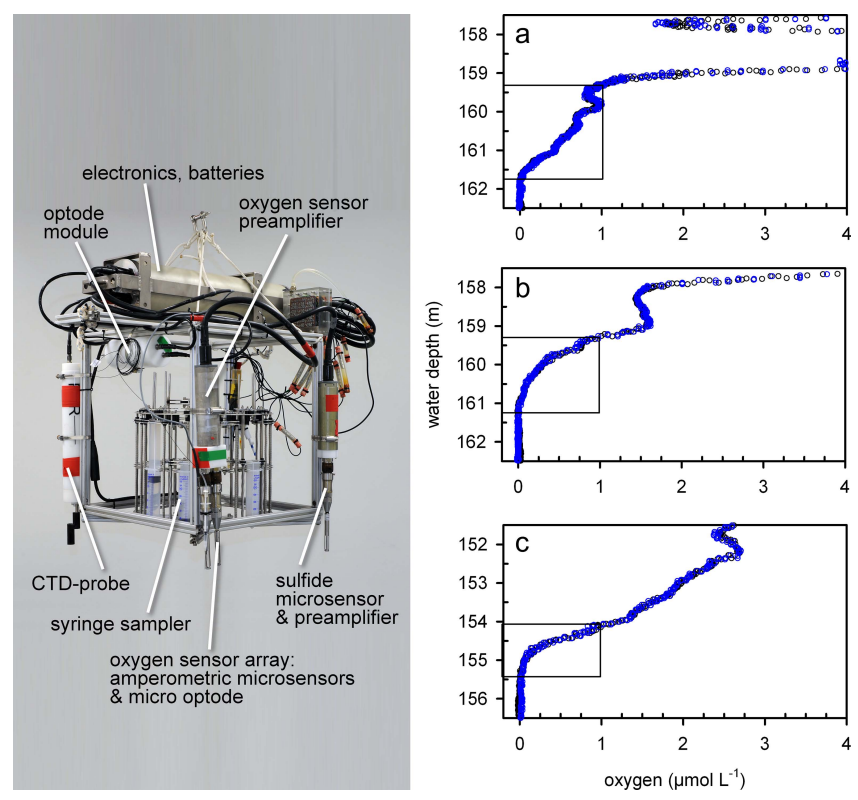

Fig. 5. Left-hand panel: sampling platform "PIA" for the highresolution measurement of nanomolar oxygen concentrations. Right-hand panel: three examples of high-resolution oxygen profiles measured within $3 \mathrm{~h}$ on 7 July 2010 in the south basin of Lake Zug, Switzerland. Oxygen concentrations were derived in parallel from a microoptode (blue) and an amperometric microsensor (black, after in situ recalibration based on optode data). Boxes indicate sub-micromolar oxygen concentrations.

(right-hand panels of Fig. 5). Utilizing the deep anoxic water layer as an in situ calibration point solved issues of drift and offset for the amperometric sensors. Combined with novel signal amplification techniques, this allowed the detection limit to be reduced to $<10 \mathrm{nmol} \mathrm{L}^{-1}$ at a signal resolution of $<0.1 \mathrm{nmol} \mathrm{L}^{-1}$ per bit (for a detailed description of the method see Kirf et al. 2014a). The optical microsensor also showed good performance with no measurable drift, a detection limit of $<20 \mathrm{nmol} \mathrm{L}^{-1}$, and smallest increments of $4 \mathrm{nmol} \mathrm{L}^{-1}$. During parallel use, the two independent sensor systems recorded virtually identical profiles and both proved able to resolve sub-micromolar oxygen concentrations at the bottom of the oxycline. The sensor systems were integrated into the custom-built "Profiling In situ Analyzer" (PIA) platform to combine high-resolution in situ sensing and sampling capabilities with online data transfer (left-hand panel of Fig. 5).

The application of the new sensor array to the water column of the permanently stratified Swiss Lake Zug revealed hitherto unobserved extensive meter-scale sub-micromolar zones (right-hand panels of Fig. 5). The existence of these extended layers of trace oxygen concentrations are not resolved with traditional CTD surveys using standard electrochemical or optical macro sensors. Similarly, extrapolation from the upper part of the oxycline (e.g., between 200 and $\left.10 \mu \mathrm{mol} \mathrm{L}{ }^{-1}\right)$ to zero oxygen underestimates the true thick- ness of the layer of trace oxygen concentrations and cannot account for the observed small-scale variability. In Lake Zug and Lake Rotsee the depth of the oxic-anoxic interface, as well as the spatial distribution of oxygen concentrations in the low micromolar to sub-micromolar range, varied between casts and within a single cast between sensors separated laterally by as little as $25 \mathrm{~cm}$. This indicates pronounced smallscale variability in redoxcline conditions. Given the low diapycnal mixing in the two lakes, this small-scale variability can persist over timescales that are relevant for microbial processes, and may create transitional habitats where specific microorganisms can thrive. The significance of trace oxygen concentrations for microorganisms, and hence for biogeochemical processes, was confirmed by parallel sampling at the lower end of the oxycline (Kirf et al., 2014b). This showed that the apparent gaps between the oxic zone and the layers of intense $\mathrm{CH}_{4}$ and $\mathrm{Mn}^{2+}$ oxidation were characterized by sub-micromolar oxygen concentrations, and that oxidation had therefore occurred in the presence of traces of oxygen. Similarly it could be shown that $\mathrm{NO}_{2}^{-}$peaks in Lake Zug are associated with the (temporally dynamic) depth of the true oxic-anoxic interface. Results obtained in the water column of the Swiss lakes are again challenging the traditional view of the pelagic oxycline as a stable and uniform habitat with a sharp, stationary, two-dimensional oxicanoxic interface (see also Sect. 3.1). Investigations on appropriate scales are needed for an improved understanding of the spatio-temporal nature of the lower oxycline.

\subsection{Seasonal changes in oxygen - examples from the western Black Sea shelf and western Baltic Sea}

To monitor the seasonal evolution of bottom-water hypoxia on the western Black Sea shelf for a better understanding of the drivers that caused the catastrophic decline of the benthic ecosystem, a stand-alone benthic mooring was deployed at $28 \mathrm{~m}$ water depth off Constanta (Romanian shelf) from May to August 2010 (c on panel III of Fig. 1 and Fig. 6c). This provided the first long-term, in situ time series of bottomwater oxygen, temperature, turbidity, salinity, and current velocity on the western Black Sea shelf and allowed biological and hydrophysical controls on oxygen to be identified. During cold weather in May and June in 2010 that coincided with low biological activity, bottom-water oxygen remained constant (Fig. 6a), and CTD profiles revealed the absence of a thermocline (data not shown). From mid-June to mid-July, oxygen concentrations decreased from 230 to $100 \mu \mathrm{mol} \mathrm{L}-1$, while bottom-water turbidity remained low. The presence of a thermocline likely reduced bottom-water ventilation. Small peaks in bottom current speed were accompanied by increases in bottom-water temperature (Fig. 6b) and by small increases in oxygen superimposed on the general downward trend in bottom-water oxygen. During the heat wave in July 2010, fish kills resulting from bottom-water hypoxia were observed at the Romanian coast (see Sect. 5.1.1). Later 

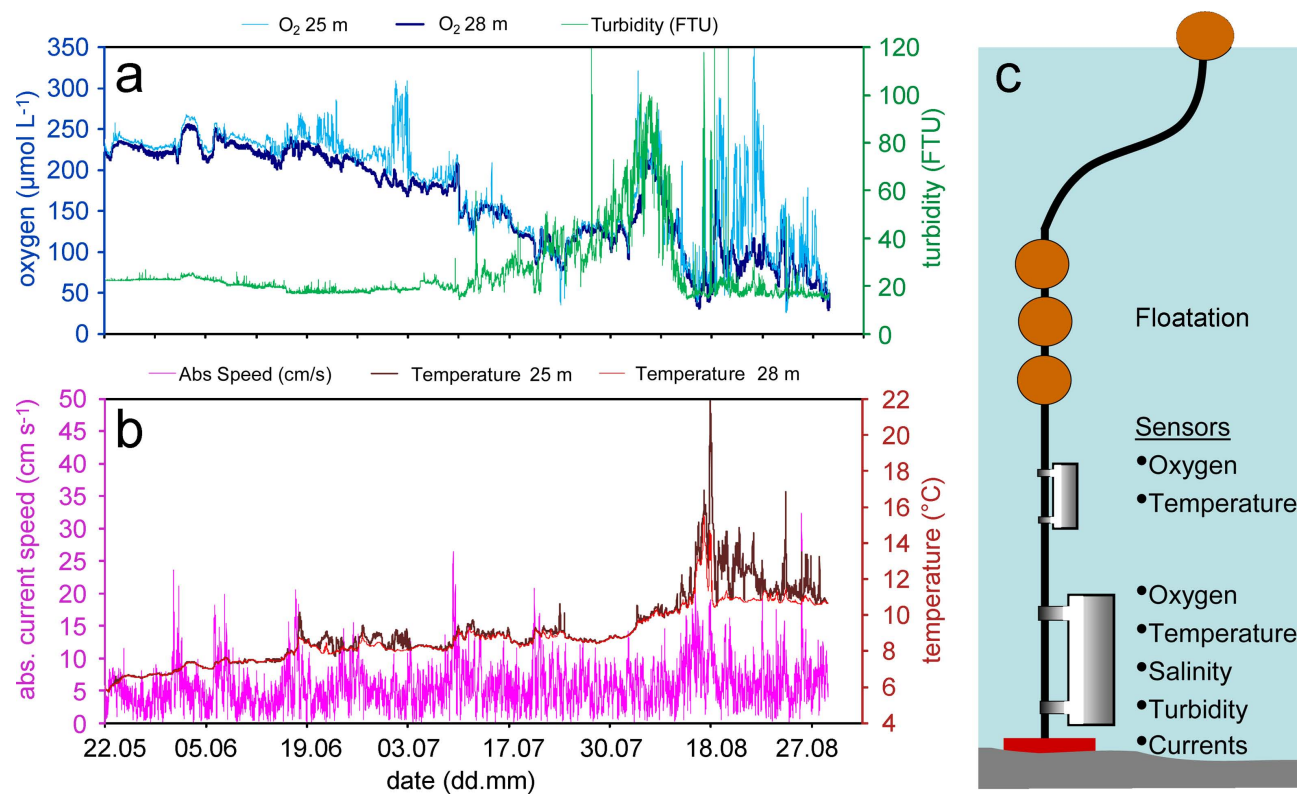

Fig. 6. Left-hand panel: time series of (a) oxygen concentration $\left(\mu \mathrm{mol} \mathrm{L}{ }^{-1}\right)$ and turbidity (Formazin Turbidity Units, FTU), and (b) temperature $\left({ }^{\circ} \mathrm{C}\right)$ in 25 and $28 \mathrm{~m}$ water depth and absolute current speed $\left(\mathrm{cm} \mathrm{s}^{-1}\right)$ above the seafloor. Data were collected from May to August 2010 on the Romanian Black Sea shelf $\left(44^{\circ} 34.681^{\prime}\right.$ N, $29^{\circ} 14.620^{\prime}$ E) with a recording current meter (Type RCM9, AADI, Bergen, Norway). Right-hand panel (c): schematic of the mooring.

in July, oxygen and turbidity increased and then sharply decreased. This could be explained as the result of: (i) the sinking of a senescent phytoplankton bloom leading to the initial increase in turbidity and oxygen; and (ii) subsequent sedimentation and decomposition of the detrital material giving rise to oxygen consumption and a decrease in turbidity. From mid-August, oxygen concentrations appeared to be again dominated by hydrophysical controls. Warm, lowsalinity and probably low-oxygen water from the Danube plume was transported to the target area by strong southwestward currents (data on current directions not shown), which resulted in bottom-water hypoxia. This short, intense mixing event led to slight ventilation, and hence to increases in oxygen. When stratification was restored, oxygen concentrations in the bottom water decreased again to about $100 \mu \mathrm{mol} \mathrm{L}^{-1}$. These results show that for the monitoring of seasonal hypoxia in shallow waters, long-term moorings consisting of optodes, a CTD, current meters, turbidity sensors, and, ideally, an ADCP for vertical velocities and a fluorometer for chl $a$, are appropriate tools to resolve short-term temporal variability in oxygen and to identify both the hydrophysical and biological drivers of hypoxia. The formation of a stable thermohaline stratification during summer decreases bottomwater ventilation on the wide, shallow shelf. This implies that the northwestern shelf's hydrodynamic setting makes it naturally prone to bottom-water hypoxia. Brief occurrences of bottom-water hypoxia during the warm season may therefore have been common phenomena on the northwestern Black Sea shelf even before eutrophication set in. The study of

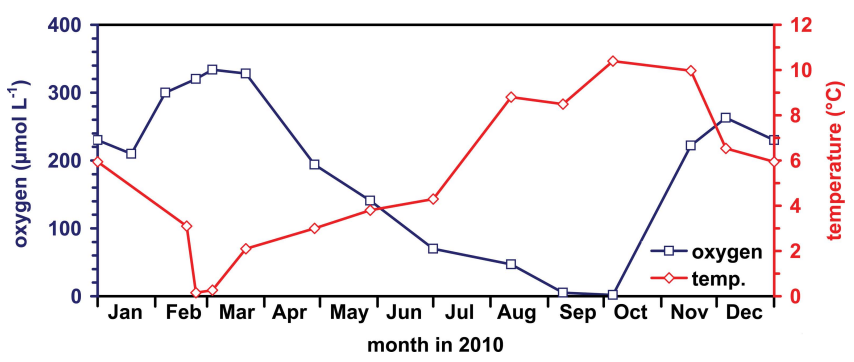

Fig. 7. Time series of temperature and dissolved oxygen in the bottom water $(25 \mathrm{~m})$ measured at Boknis Eck in 2010.

Capet et al. (2013) stresses the urgent need for dedicated oxygen monitoring on the northwestern shelf, since the recovery process from hypoxia had been overestimated based solely on spot measurements in areas and months not typically affected by hypoxia. Our new high-resolution oxygen time series during the summer season represents a first step in improving our understanding of the dynamics of hypoxia, and in making a realistic assessment of the ecosystem recovery process on the northwestern shelf.

As part of the HYPOX project, a time series of bottomwater oxygen concentration at the long-term monitoring station Boknis Eck in the western Baltic Sea was collected in 2010 by making monthly CTD casts (b on panel II of Fig. 1 and Fig. 7). The existence of an overall seasonal trend in this data set is clear, although short-term fluctuations in oxygen, as observed on the Romanian shelf, may well be missed by 
monthly sampling. The major oxygen and temperature dynamics in 2010 reflect bottom-water ventilation in winter related to wind-induced mixing, and thermal stratification and oxygen consumption in summer. Similar seasonal patterns are also found in long-term time series of oxygen and associated parameters obtained from the monthly sampling program established at Boknis Eck in 1957 (Bange et al., 2011; www.bokniseck.de). On decadal timescales the data show a general increase in the number of summer anoxic events with bottom-water oxygen concentrations $<2 \mu \mathrm{mol} \mathrm{L}^{-1}$, as well as increasing sea surface temperatures (Bange et al., 2011). While only one anoxic event was recorded during the period 1957-1983, ten such events occurred between 1986 and 2010. Annual mean bottom-water oxygen concentrations have also been decreasing year-on-year. These features may result from (i) intensified nutrient recycling (see also Sect. 5.2.2), and (ii) enhanced and prolonged summer stratification resulting from a warming of the surface waters and a shift of strong wind events and breakup of stratification from autumn to winter/early spring during the period 1988-2007 (Lennartz, 2013; Lehmann et al., 2011). Thus, both local and larger-scale processes may affect the interannual and intra-annual trends in oxygen concentration at this site (Bange et al., 2011; Lennartz, 2013).

\subsection{Large-scale patterns in water-column oxygenation - an example from the Black Sea}

Argo floats are autonomous profiling sensor platforms that drift with oceanic currents at pre-programmed depths (www. argo.net/). They are able to change their buoyancy by modifying the total volume of the device, enabling them to move vertically within the water column. The fleet of floats currently profiling the world's oceans has greatly improved our understanding of physical oceanography, and the suggestion has already been made to add oxygen sensors to extend the scope of these floats more in the direction of ocean biogeochemistry (Gruber et al., 2007). However, of the more than 3000 profiling Argo floats presently drifting in the world's oceans, only about 200 are equipped with oxygen sensors. Because the Black Sea is a deep basin, the use of Argo floats is an optimal solution not only for physical variables (Korotaev et al., 2006), but also for oxygen.

The data used in this study were collected by Navigating European Marine Observer (NEMO) profiling floats. These are Argo-type floats manufactured by Optimare Sensorsysteme AG (Bremerhaven, Germany) and equipped with oxygen optodes (type 3830, AADI, Bergen, Norway). During cruise leg MSM15/1 of R/V MARIA S. MERIAN, NEMO floats 0144 and 0145 were deployed as the first profiling floats equipped with oxygen sensors ever to operate in the Black Sea (Stanev et al., 2013). Deployments took place on 7 May 2010 in the northern Black Sea at $44^{\circ} 10^{\prime} \mathrm{N}, 32^{\circ} 30.01^{\prime} \mathrm{E}$ (NEMO-0144) and $44^{\circ} 0.02^{\prime} \mathrm{N}$, $32^{\circ} 4.92^{\prime} \mathrm{E}$ (NEMO-0145). NEMO-0144 ended operations at the end of December 2011, while NEMO-0145 continued operation until the end of November 2012. The data from both floats are accessible in the oceanography data base Corio$\operatorname{lis}^{1}$. The trajectories of the two floats diverged rapidly after their initial deployment (e on panel III of Fig. 1). NEMO0144 (blue dots) entered the open Black Sea, while NEMO0145 (pink dots) followed the upper continental slope. Both floats were programmed to rise from $500 \mathrm{~m}$ depth to the sea surface at intervals of five days and to transmit the conductivity, temperature, pressure, and oxygen measurements that were collected during each ascent in Short Burst Data (SBD) packages via the IRIDIUM satellite system. Between profiles, measurements were carried out twice a day at a parking depth of $450 \mathrm{~m}$.

About 120000 observations of oxygen in the Black Sea, taken between 1910 and 1999, are available via the MEDiterranean ACCess based system for exploration and visualization of the marine cast data (MEDACC; http://isramar.ocean. org.il/isramar2009/medacc/). Most of the measurements are restricted to the upper water layer, were recorded irregularly in time and space, and often lack proper quality control. The oxygen measurements collected by NEMO-0144 and NEMO-0145 comprise about $20 \%$ of the total number of oxygen measurements available today. The data are plotted in Fig. 8 and demonstrate the power of continuous observations for understanding oxygen dynamics in coastal and open ocean areas. Surface oxygen maxima were formed in winter in parallel with the cold intermediate water. Later in the year, however, a subsurface core of oxygen-rich water was observed in the upper $50 \mathrm{~m}$ - clearly above the intermediate low-temperature core known as the cold intermediate layer (Stanev et al., 2013). There are further indications that the evolution of oxygen and the evolution of temperature were governed by different processes, implying that the oxygenation of the upper water column was to some extent decoupled from the formation of cold intermediate water. Consecutive temperature profiles show that the penetration of cold water into the intermediate layer represents a convective process, which occurs only during short periods of time in winter. Clearly, the downward convection of cold, oxygen-rich water from the surface will provide oxygen to deeper layers. However, in contrast to temperature, the penetration of oxygen is not restricted to short periods but represents a more continuous process. This is reflected in a progressive increase in the oxygen content of the upper water layer until the water starts to warm up in late spring. It can be concluded that diffusive fluxes play an important role in providing oxygen to the upper water column of the Black Sea. The progressive decrease in the oxygen content of the surface mixed layer in summer results from the increase in water temperature, which in turn reduces oxygen solubility. However, concurrently with the

\footnotetext{
${ }^{1}$ NEMO-0144: www.ifremer.fr/co-argoFloats/float?ptfCode $=$ 7900465; NEMO-0145: www.ifremer.fr/co-argoFloats/float? ptfCode $=7900466$
} 


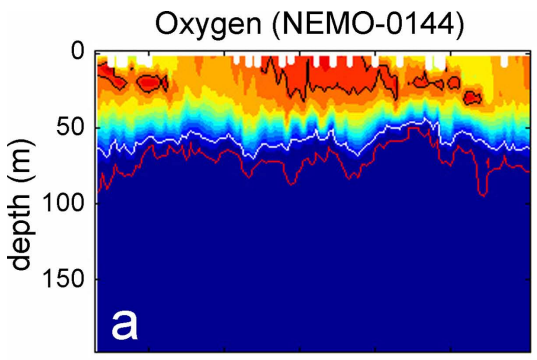

09.1012 .1003 .1106 .1109 .1112 .11

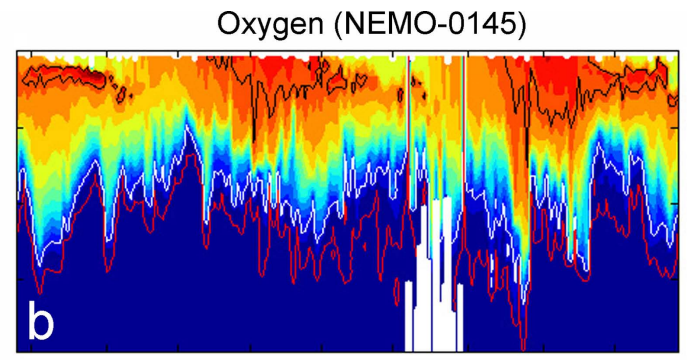

06.1009 .1012 .1003 .1106 .1109 .1112 .1103 .1206 .12

date (mm.yy)

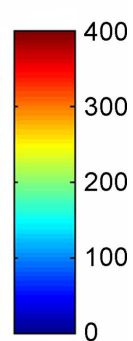

300

200

100

Fig. 8. Temporal evolution of oxygen (in $\mu \mathrm{mol} \mathrm{L}^{-1}$ ) as measured by NEMO-0144 (a) and NEMO-0145 (b). These plots illustrate the evolution of the subsurface oxygen maximum and the mesoscale variability of the interface between oxic and anoxic waters. The white and red isolines depict oxygen concentrations of 50 and $5 \mu \mathrm{mol} \mathrm{L}-1$, respectively. Note that in the basin interior (NEMO-0144) the temporal evolution of the depth of the isopycnals is very small. White vertical strips illustrate missing data resulting either from sensor malfunction or from the sensor reaching the bottom.

loss of oxygen from warming surface waters in summer, an oxygen maximum evolves just below the surface, with concentrations exceeding those observed at the surface in winter. This indicates that the enhanced photosynthetic productivity in the photic layer acted as a major source of oxygen in summer. Similar subsurface features in the oxygen distribution have been revealed by Argo floats in other ocean basins (Riser and Johnson, 2008). The Black Sea subsurface oxygen maximum persisted until the seasonal thermocline disappeared in October/November, when the oxygen concentration at depth again decreased due to the diffusive loss of oxygen to the anoxic layer below.

The characteristics and dynamics of the oxygen distribution differed strongly between the upper continental slope (NEMO-0145, Fig. 8b) and the open Black Sea (NEMO0144, Fig. 8a). The oxygenated layer in the open basin was about half as thick as that at the upper continental slope, and the temporal variations of its thickness were very small (about $20 \mathrm{~m}$ ). In contrast, the depth of the oxic-anoxic water interface around the continental slope (represented by the $5 \mu \mathrm{mol} \mathrm{L}{ }^{-1}$ isoline) underwent changes of more than $75 \mathrm{~m}$ within a period of only a few weeks. These changes closely tracked the vertical displacement of the pycnocline, which was dominated by mesoscale oscillations. These "bursts" of low-oxygen or high-oxygen waters demonstrate the importance of mesoscale processes for the oxygen dynamics of the Black Sea shelf.

\subsection{Episodic hypoxia and ventilation in fjords - an example from Loch Etive}

Fjord systems are characterized by silled entrances and limited exchange with neighboring water bodies. This often results in density stratification, prolonged deep-water residence times, and the development of hypoxic conditions at depth, conditions similar to those characterizing the Black Sea and the Baltic. For this reason, investigations in Koljoe Fjord and the fjord-like Loch Etive serve as model studies for deepwater renewal in stratified systems with topographically restricted exchange with the open ocean. Cabled observatories with a land-based power supply and online data access were installed in both Koljoe Fjord and Loch Etive (c on panel II of Fig. 1 and a on panel V of Fig. 1, respectively). The availability of real-time data allowed numerical modeling studies to be conducted concurrently.

This section focuses on the monitoring and modeling carried out in Loch Etive (panel V of Fig. 1). Some of the results obtained in the geographically and hydrographically more complex Koljoe Fjord system are covered in Sect. 6.2. Time series of density, delay-mode thermistors and oxygen concentration recorded at $124 \mathrm{~m}$ depth in Loch Etive show that stagnant periods with gradually decreasing oxygen concentrations represent the standard case for the deep water in the inner basin of the fjord (period after July 2010 in the lower panel of Fig. 9). In Loch Etive, vertical mixing and lateral exchange with the neighboring sea are largely controlled by tides. Under normal conditions, tidal forcing is unable to induce deep mixing or to push saline deep waters across the main sill ("Bonawe Sill", see b on panel V of Fig. 1) into the deep inner basin, and as a result only slight mixing with oxic and shallow low-salinity waters occurs. This mixing manifests itself as a slow decrease in deep-water salinity and density, but oxygen intrusions do not balance oxygen consumption, leading to the establishment of almost hypoxic conditions at depth near the end of the recording period (oxygen concentrations $<62.5 \mu \mathrm{mol} \mathrm{L}{ }^{-1}$, light gray area in the lower panel of Fig. 9). In the winter and early summer of 2010, however, three bottom-water renewal events appear as sudden increases in oxygen and density (black dashed vertical lines in Fig. 9). Analyzing tides and weather data for the respective periods and feeding them into a 3-D hydrodynamic model (a localized version of the Finite Volume Coastal Ocean Model FVCOM; Chen et al., 2003) revealed that specific meteorological and oceanographic conditions 


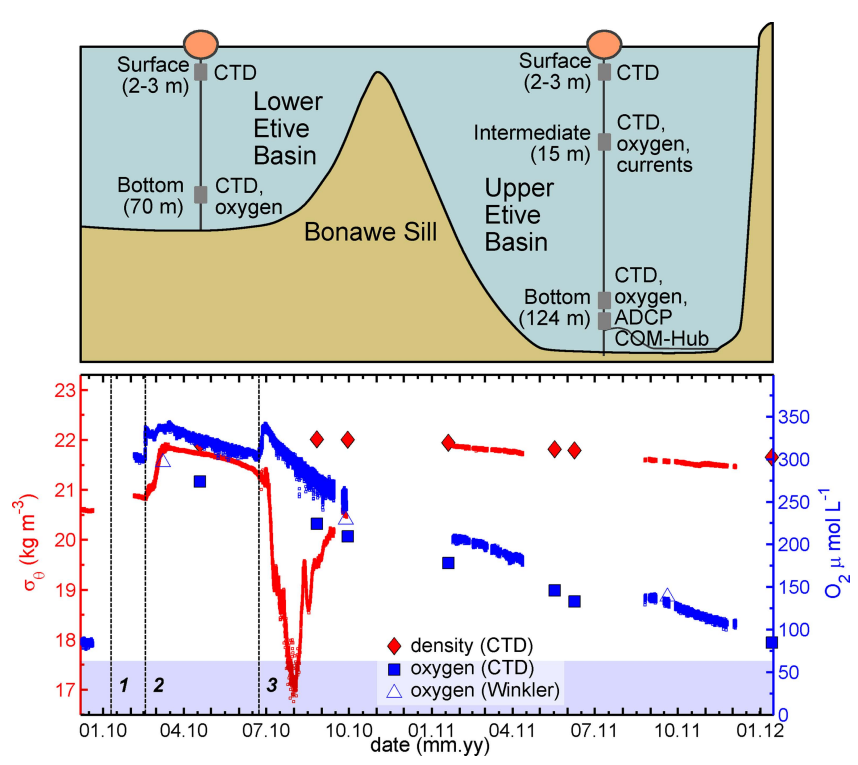

Fig. 9. Upper panel: schematic of the Loch Etive Cabled Observatory ("LECO", mooring depicted on the right-hand side) and the autonomous installation, including delay mode thermistors (NERC Diving Unit), installed in the lower basin seawards of the Bonawe Sill (depicted on the left-hand side). The time series in the lower panel originate from LECO's lowermost sensor unit. Lower panel: potential density (red line) and dissolved oxygen measured with an oxygen optode (type 3835, AADI, Bergen, Norway; blue line) at the HYPOX mooring site in upper Loch Etive at $124 \mathrm{~m}$ water depth. Blue squares and red diamonds represent validation data from CTD casts obtained with various instruments (SBE19+, SBE16, SBE9, equipped with SBE oxygen sensors, Seabird Electronics, Bellevue, WA, USA). The blue triangles represent oxygen concentrations in samples measured by Winkler titration. The three overturning events observed ( $\sim 10$ January, 17-23 February, 23-30 June 2010) are indicated by dashed vertical lines. Gaps in the records resulted from cable connection/instrument failure, repair and redeployments. During the third renewal event, vertical stratification was destroyed and surface waters were transported to the bottom. Stratification recovered with the occurrence of heavy rains in early July; however, bio-fouling in the conductivity cell led to the apparent extended presence of low-density waters at depth. The gray area denotes hypoxic conditions with oxygen concentrations below $62.5 \mu \mathrm{mol} \mathrm{L}-1$.

are needed for deep-water renewal events to occur. All events happened at spring tide and coincided with a drop in air pressure of $30-50 \mathrm{hPa}$ that led to an additional sea level rise of $0.3-0.5 \mathrm{~m}$. This inverse barometer effect exaggerated the tidal oscillations and helped to force dense waters upward and across the sill. Reduced freshwater input due to low precipitation and low discharge from a nearby hydroelectric station, coupled with the frequent occurrence of temperatures below freezing during winter, minimized the outflow of brackish surface water from the inner fjord. These exceptionally dry, cold conditions facilitated the accumulation of dense, saline, oxic waters at the entrance of Loch

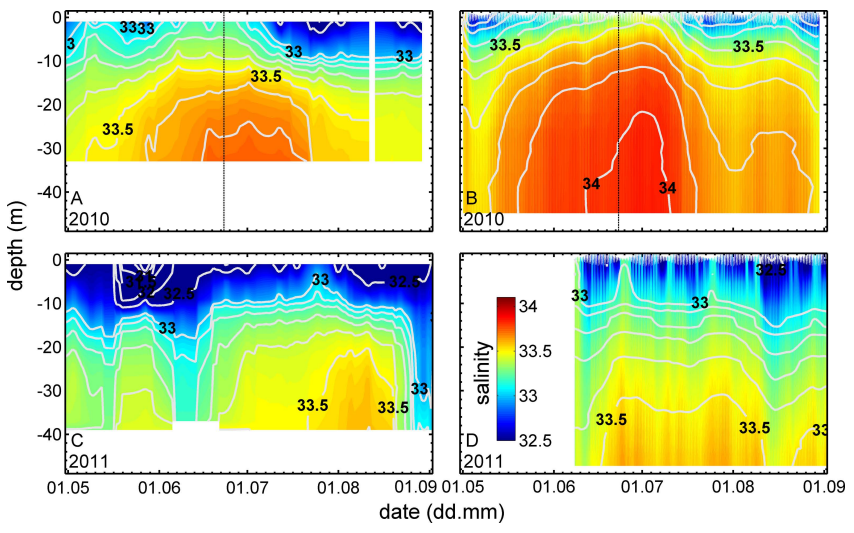

Fig. 10. Weekly time series of salinity profiles at Lynn of Lorne in Ardmucknish Bay $\left(56^{\circ} 28.91^{\prime} \mathrm{N}, 5^{\circ} 30.10^{\prime} \mathrm{W}\right)$ from CTD casts (left-hand panel) and calculated with the FVCOM model (righthand panel) for the summers of 2010 (a, b) and 2011 (c, d). The onsets of the overturning events in the deep basin of Loch Etive are indicated by dashed vertical lines. The presence of a pool of highdensity (high-salinity) water at the entrance to Loch Etive in 2010 and its absence in 2011 is reproduced well by the model.

Etive in the Lynn of Lorne/Ardmucknish Bay area (d on panel V of Fig. 1). This important precondition for deepwater renewal in the upper basin was captured with high accuracy by the FVCOM model (Fig. 10). Inflow events were further supported by east-southeasterly "down-fjord" winds (Bell, 1973) that pushed stratified surface layers away from the lower loch, thereby enhancing estuarine circulation and the delivery of dense water toward the entrance of the inner basin. After the deep-water renewal events, the weather reverted back to long-term average conditions, with higher temperatures and more precipitation. This resulted in the presence of a pool of low-salinity water at the entrance to Loch Etive (Fig. 10c, d) and impeded further renewal events from summer 2010 until the end of the recorded data series in the winter of 2011/2012.

Continuous fixed-point observations proved feasible to track the evolution of hypoxia at depth and to detect rare bottom-water renewal and ventilation events. Online data access facilitated the concurrent analysis of the hydrographic conditions that invoke inflow. Furthermore it allows the implementation of hypoxia early warning tools for the deep water of Loch Etive, which is considered to be particularly prone to hypoxia (Gillibrand et al., 2006). Numerical simulations allowed the hydrodynamic mechanisms that govern inflow events to be identified and demonstrated the complexity of the conditions required to bring about deep-water renewal. By applying the knowledge gained from combined online monitoring and modeling, it may be possible to provoke inflow events manually by reducing the supply of fresh water to the loch from the hydro-electric power station when natural conditions are favorable, and thereby to mitigate deep-water hypoxia. 

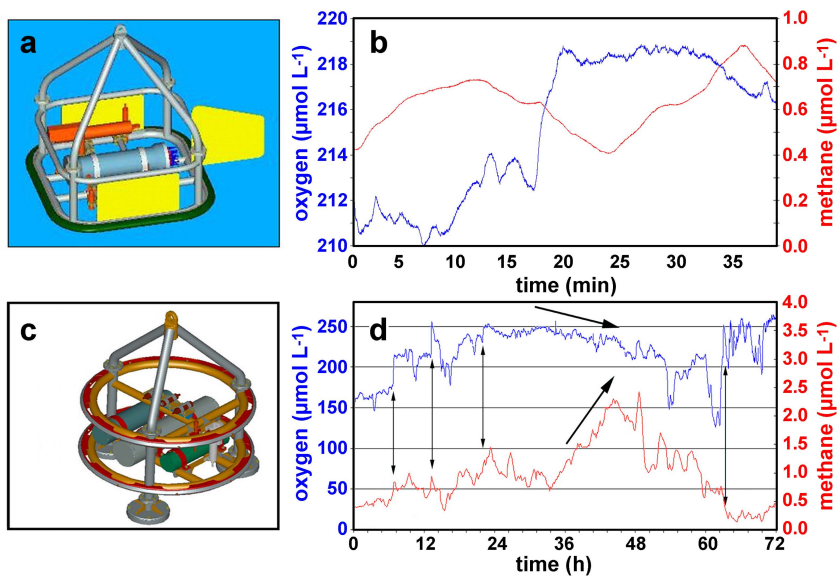

Fig. 11. Left-hand panels: MEDUSA system (a) and GMM benthic observatory (c) used for spatial surveying and temporal monitoring, respectively, in Katakolo Bay. Right-hand panels: illustrative records showing the inverse relationship between $\mathrm{O}_{2}$ and $\mathrm{CH}_{4}$ : oxygen depletion related to an increase in the concentration of methane over a submarine bubble seep as recorded by the MEDUSA towing system (b) and short-term and long-term changes in oxygen concentration accompanied by inverse changes in methane concentration recorded over a period of three days in a submarine seep by the GMM (d).

\subsection{Hypoxia driven by gas seepage - examples from Greek lagoons and embayments}

In Katakalo Bay, Amvrakikos Gulf, and Aetoliko Lagoon on the Ionian coast of western Greece (panel VI in Fig. 1) hypoxia was studied in relation to geogenic drivers; i.e., to the seepage of reducing gases from the seafloor $\left(\mathrm{CH}_{4}\right.$ and $\mathrm{H}_{2} \mathrm{~S}$ originating from deep sedimentary rocks). Two different observation systems were used: the benthic Gas Monitoring Module (GMM) for time-series monitoring (Marinaro et al., 2004) and the towed Module for Environmental Deep Under Sea Analysis (MEDUSA) for spatial surveys (Marinaro et al., 2011). GMM and MEDUSA were equipped with a CTD and sensors for oxygen, $\mathrm{CH}_{4}$ and $\mathrm{H}_{2} \mathrm{~S}$. In addition, GMM carried turbidity and current sensors, while MEDUSA was equipped with video camera and altimeter.

Katakolo Bay is affected by a considerable active and permanent seepage of methane and sulfide of thermogenic origin along a series of faults (Etiope et al., 2006, 2013). MEDUSA was used for a thorough survey of the Katakolo Bay gas-bubble fields. Based on the survey, GMM was then deployed very close to a shallow seep field at $\sim 8 \mathrm{~m}$ water depth for a 101-day monitoring period of oxygen and reducing gases. Drops in oxygen concentration were observed to coincide with elevated concentrations of dissolved $\mathrm{CH}_{4}$ related to seepage from the seabed. This trend of oxygen decrease and $\mathrm{CH}_{4}$ increase was observed both by spatial surveys (oxygen decrease upon passage of the MEDUSA module over bubble seeps) and in time-series data obtained with

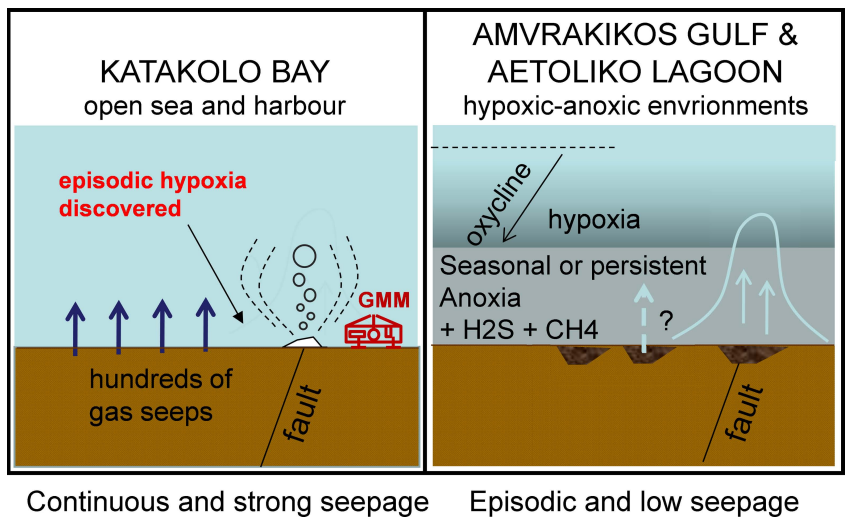

Fig. 12. Simplified graphical representation of the drivers of hypoxia/anoxia in Katakolo Bay (left-hand panel), and in Amvrakikos Gulf and Aetoliko Lagoon (right-hand panel). "GMM" indicates the benthic observatory used for the time-series monitoring of dissolved gases: see text for explanation).

the GMM observatory. Figure $11 \mathrm{~b}$ and d shows one example from each instrument. In Katakolo Bay, the seepage of gas apparently acted as a geogenic driver that was able to decrease oxygen concentrations even under relatively exposed hydrographic conditions and in the absence of strong stratification or a permanent oxycline.

In Amvrakikos Gulf and Aetoliko Lagoon, where strong stratification and fertilizer input from land results in seasonal or even permanent anoxia at depth, no clear indication for seepage-related oxygen depletion was observed. In the southeastern sector of Amvrakikos Gulf, MEDUSA surveys indicated weak seepage at a large, apparently fault-controlled pockmark, while no seepage was detected in the rest of the Gulf. Some pockmarks were identified in Aetoliko Lagoon but isotopic gas analyses suggest that sulfide and methane were of microbial origin and thus most likely not indicative of seepage, but rather a product of sulfate reduction and methanogenesis taking place in anoxic sediments.

In conclusion, the results from the Greek locations provide evidence for the potential of strong gas seepage to act as a geogenic driver that reduces oxygen availability even at relatively exposed sites. Similar processes may also take place in other areas with intense gas seepage. Under conditions of low, episodic gas seepage, hypoxia in the Ionian Sea lagoons and embayments seems to be controlled mainly by oceanographic and anthropogenic drivers, although weak oxygen depletion in bottom waters related to local seepage cannot be ruled out (Fig. 12). The combination of temporal monitoring and spatial surveys proved to be an effective approach to study seepage-related hypoxia. 

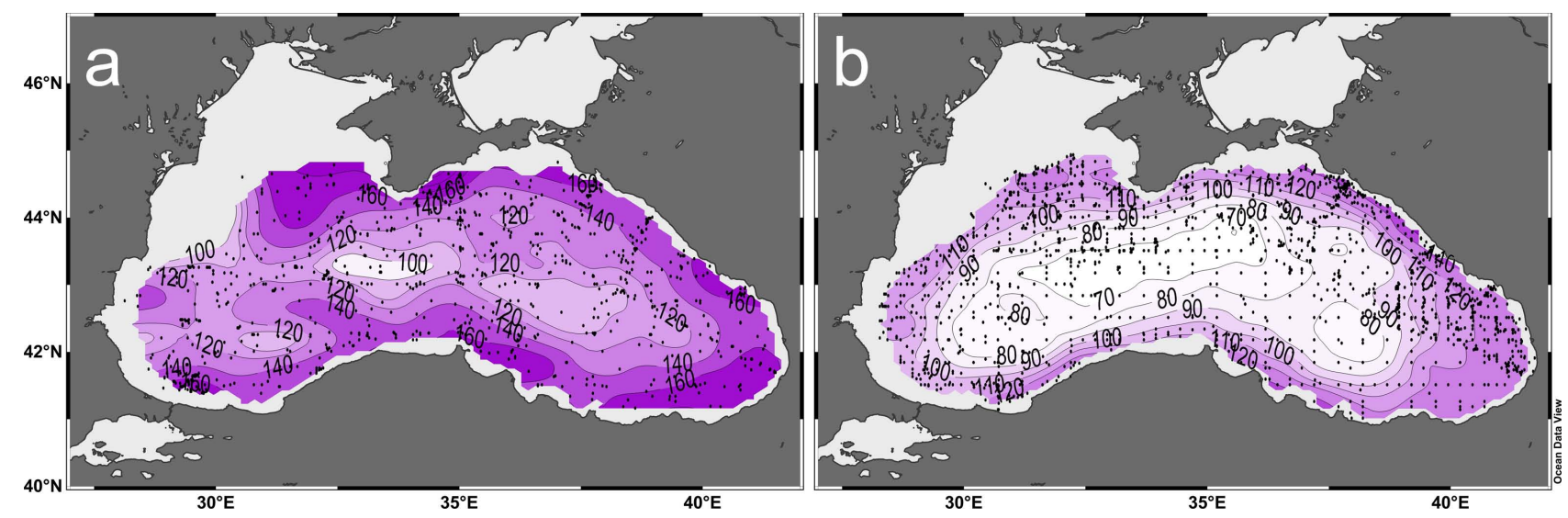

Fig. 13. The mean depth of the upper boundary of the suboxic zone (UBSOZ) in the Black Sea for the periods 1955-1976 (a) and 1987-2011 (b).

\section{Investigating long-term changes in present and past hypoxia}

In this section, we demonstrate ways of investigating longterm trends in oxygen in aquatic systems. Trends and variability in the occurrence of hypoxia on a decadal timescale are addressed by analyzing existing monitoring data from two very different systems - the permanently stratified water column of the Black Sea, and deep Lake Zurich, in which mixing of variable intensity regularly occurs in winter. As in the case of the Baltic Sea (see Sect. 3.4 and Feistel et al., 2008), both the Black Sea and Lake Zurich (along with many other lakes) have been affected by variability in climate forcing and long-term eutrophication. Temperature and oxygen profiles, which have been measured for several decades at these sites, are used to separate out the confounding effects of climatic forcing and eutrophication. During the last few decades, nutrient availability in the Black Sea has increased, while it has declined in Lake Zurich. Similar to the western Baltic Sea (see Sect. 5.2.2.), Lake Zurich shows a general trend toward increasing stratification as a result of the warming of the upper water column. For the Black Sea, oscillations in climatic conditions and winter vertical mixing were found to control the downward flux of oxygen, while the dramatic shoaling in the upper boundary of the hypoxic zone seems to be associated mainly with eutrophication. To look further into the history of oxygen and hypoxia, inorganic and organic proxies from the sediment record were studied in some Swiss lakes and in the Bosporus outflow area of the Black Sea. Manganese, in combination with sulfur and/or iron, proved to be suitable as a proxy for past oxygenation for both deep Lake Zurich and the Bosporus outflow area. In the Bosporus outflow area, manganese profiles in sediment cores revealed the history and dynamics of the Mediterranean inflow and its ventilation effects on the seafloor over the past several thousand years. Biomarkers provided valuable insights into past hypoxia and the eutrophication of Swiss lakes.

\subsection{Multidecadal hypoxia trends in stratified basins - an example from the Black Sea}

In recent years, much insight has been gained into the biogeochemical and physical processes driving the oxygen distribution in the Black Sea and its variability (e.g., Konovalov and Murray, 2001; Konovalov et al., 2003, 2005, 2006; Glazer et al., 2006). Two important questions concerning the long-term (decadal) variations in oxygen distribution that still remain open are related to identifying the main drivers and distinguishing between the influence of climate change and the influence of direct anthropogenic pressure (eutrophication). Profiles of oxygen distribution for the Black Sea are relatively scarce (a total of 3240 profiles up until 2011). However, they date back to 1923 and have been collected systematically since 1955 . This analysis focuses on long-term variations in the depth of the upper boundary of the suboxic zone (UBSOZ) and on identifying the respective roles played by climate forcing and eutrophication in engendering these variations. In agreement with earlier work (Konovalov and Murray, 2001) the UBSOZ is defined as the $20 \mu \mathrm{mol} \mathrm{L}^{-1}$ isopleth.

The basin-wide distribution of the depth of the UBSOZ shows a temporally variable but spatially consistent "bellshaped" pattern (Fig. 13). For the entire period covered by oxygen measurements (i.e., 1923-2011) the mean depth of the UBSOZ generally increases from $80 \mathrm{~m}$ in the central Black Sea to $165 \mathrm{~m}$ at the shelf slope, with a maximum depth in the Bosporus Strait region. In addition, the depth of the UBSOZ exhibits seasonal fluctuations of up to $50 \mathrm{~m}$, synoptic fluctuations of up to $25 \mathrm{~m}$ and diel fluctuations of up to $15 \mathrm{~m}$ (data not shown). Despite this variability on shorter temporal scales, pronounced changes on decadal timescales are clearly recognizable (Fig. 13). During the period of relatively low eutrophication in 19551976, the UBSOZ depth generally ranged between 95-220 m (Fig. 13a). After 1976, the suboxic zone has shoaled progres- 


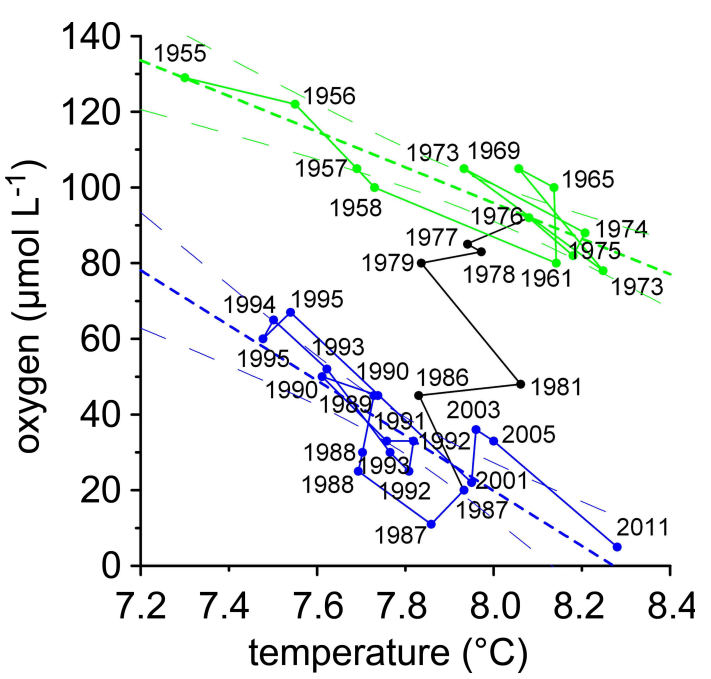

Fig. 14. Relationship between basin-averaged oxygen concentration and water temperature in the main pycnocline of the Black Sea (sigma- $t=15.4$ ) from 1955-2011. Individual points represent the mean oxygen concentrations measured during individual cruises; thus they are available only for years when cruises were carried out. The dashed lines with short dashes represent linear regressions of the data from 1955-1979 and 1981-2011, and the dashed lines with long dashes represent the corresponding confidence intervals.

sively, exposing shallower seafloor areas to hypoxia. By the most recent period (1987 to the present), which is characterized by high productivity levels and intense climatic variability, it had risen further to $60-160 \mathrm{~m}$ (Fig. 13b). Hence, for the major part of the Black Sea, the long-term decrease in the depth of the UBSOZ from 1955 onwards is in the range of $20-50 \mathrm{~m}$.

To recognize the nature of these changes it is necessary to distinguish between the influences of biogeochemical and physical processes. The temporal evolution of oxygen concentrations in the core of the main pycnocline (sigma- $t=$ 15.4) as a function of temperature allows temporal trends in basin oxygenation to be traced while eliminating the influence of changes in water-column stratification (Fig. 14). The pycnocline temperature can be regarded as a proxy for the climate-driven intensity of vertical ventilation in winter and, hence, for the supply of oxygen. Consequently, at least within the observed range of temperatures, the oxygen concentration in the main pycnocline is expected to scale inversely approximately linearly with temperature as long as the rate of oxygen consumption stays largely constant. This is the case for the low-level eutrophic period from 1955-1976 and - at generally lower pycnocline oxygen concentrations - also for the highly eutrophic period from 1987-2011. High concentrations of oxygen in the main pycnocline during 1955-1976 are consistent with the particularly deep oxygen penetration in that period (Figs. 14 and 13a), while low oxygen concentrations in the pycnocline during 1987-2011 are associated with the shallowest depth of the UBSOZ (Figs. 14 and 13b).
This is in agreement with a change from relatively low rates of primary production and nutrient supply during the first period to high trophic conditions in more recent times (e.g., Sorokin, 1964; Cociasu et al., 1996; Konovalov and Murray, 2001; Yunev et al., 2002). The intermediate period of the most intense eutrophication from the late 1970s to the second half of the 1980s is characterized by a completely different pattern of pycnocline oxygenation (Fig. 14). In these years, relatively stable temperatures indicate a steady rate of ventilation of the Black Sea, but the associated oxygen supply was clearly insufficient to compensate for the increasing oxygen consumption. Consequently, concentrations of oxygen in the main pycnocline dropped by about $80 \mu \mathrm{mol} \mathrm{L}^{-1}$, with the difference in the dependence of oxygen on temperature before 1976 and after 1987 exceeding the confidence intervals in the observed range of data (Fig. 14). This decrease in oxygen at largely constant temperatures reveals the strong impact of eutrophication, while the effect of climatic forcing was less pronounced. However, it seems that the higher eutrophication level also increased the sensitivity of the system to climate change. Compared to the situation before 1976, the slope of the quasilinear response of the pycnocline oxygenation to changing temperatures increased at the $90 \%$ confidence level. As a result, the range of oxygen variability increased twofold for the same range of temperatures and oxygen concentrations, revealing an excursion to almost anoxic conditions from 2005-2011.

In summary, the analysis of long-term monitoring data allows the quantification of spatial and temporal changes in the distribution of oxygen and the respective effects of eutrophication and climate change on oxygen conditions. The identified long-term trends, combined with seasonal and diel fluctuations, are expected to affect redox conditions at the shelf slope at depths ranging from $100-250 \mathrm{~m}$ on different timescales. Consequently, bottom waters, as well as the upper sediment layers and the faunal communities at these depths, are expected to experience variable redox conditions, including oxic, suboxic and even anoxic/sulfidic environments. When the effects of eutrophication and climate change are resolved (Fig. 14), projections of climate-driven trends become possible. For example, the very cold winter of 2011-2012 may have caused an increase in the depth of oxygen penetration and the stock of oxygen in the Black Sea. Yet, variations in eutrophication are presently hard to predict. Thus, long-term monitoring remains crucial and new tools for the timely warning of dramatic changes, in particular the development of hypoxia, are of utmost importance.

\subsection{Multidecadal trends in lake hypoxia - an example from Lake Zurich}

From the approximately $70 \mathrm{yr}$ time series of monthly instrumental data from Lake Zurich, the period 1972-2010 was selected for analysis. During this period, monitoring was carried out consistently by the City of Zurich Water Supply, with 

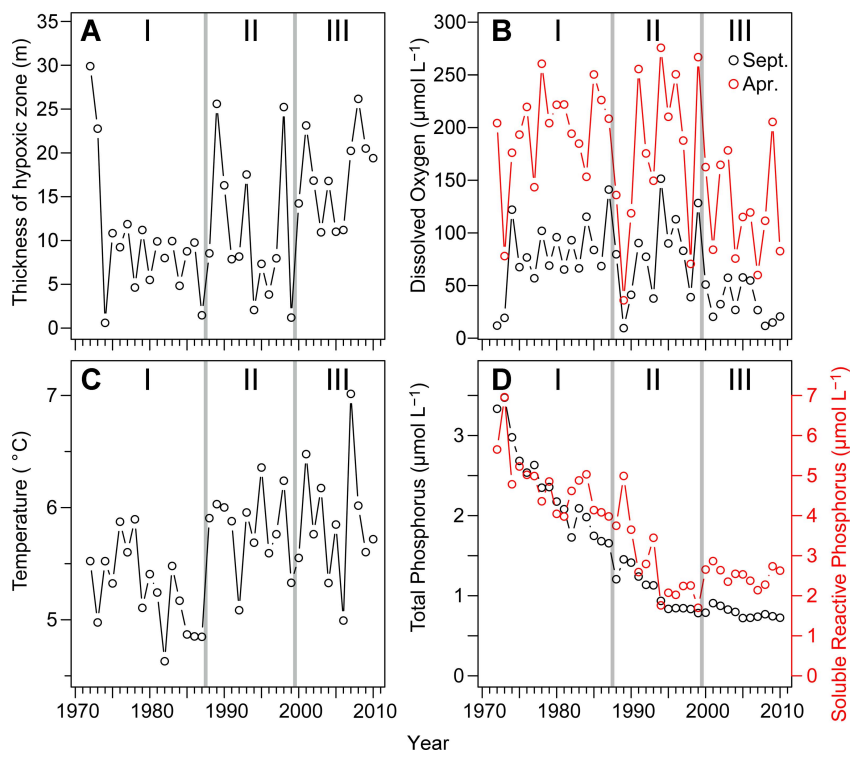

Fig. 15. Lake Zurich data set (1972-2010). (A) Thickness of the hypoxic zone (oxygen concentrations $<62.5 \mu \mathrm{mol} \mathrm{L}-1 /<2 \mathrm{mg} \mathrm{L}^{-1}$ ) in September. (B) Mean volume-weighted deep-water (120-136 m) oxygen concentration in September (black) and in the previous April (red). (C) Mean volume-weighted temperature of the uppermost $20 \mathrm{~m}$ of the lake from December to April. (D) Mean annual volume-weighted concentration of total phosphorus (black) in the entire lake (0-136 m) and of soluble reactive phosphorus (red) in the deep water (120-136 m). For further information see North et al. $(2013,2014)$.

measurement accuracies of $0.1 \mathrm{~K}$ and $10 \mu \mathrm{mol} \mathrm{L} \mathrm{L}^{-1}$ or better for temperature and oxygen, respectively (O. Köster, personal communication, 2012). For details on the Lake Zurich data set see Zimmermann et al. (1991), Livingstone (2003), Jankowski et al. (2006), and North et al. (2013, 2014). Watercolumn profiles of temperature and of the concentrations of oxygen, total phosphorus and soluble reactive phosphorus were measured at the location of the deepest point of the lake $(136 \mathrm{~m})$. A two-stage process using linear and cubic spline interpolation was used to transform the measured profiles into spatially and temporally uniform data with depth intervals of $1 \mathrm{~m}$ and time intervals of one month. From these interpolated data, mean temperatures and concentrations of oxygen, total phosphorus and soluble reactive phosphorus (volume-weighted for different layers of the lake) were calculated, as well as the thickness of the hypoxic zone (from $62.5 \mu \mathrm{mol} \mathrm{O} \mathrm{O}_{2} \mathrm{~L}^{-1} / 2 \mathrm{mg} \mathrm{L}^{-1}$ down to the maximum depth of the lake) and the Schmidt stability (a measure of the lake's thermal stability; Schmidt, 1928; Idso, 1973).

Minimum oxygen concentrations at depth - and consequently also the maximum thickness of the hypoxic zone - are typically reached at the end of the summer stratification period in September (Jankowski et al., 2006). Based on the temporal evolution of deep-water oxygen concentrations and the thickness of the hypoxic zone in September
(Fig. 15a and b) the study period can be divided into three segments $^{2}$ (North et al., 2014). In Segment I (1972-1987), with the exception of the first two years, the mean deep-water oxygen concentration (i.e., below $120 \mathrm{~m}$ water depth) is generally at or above $62.5 \mu \mathrm{mol} \mathrm{L}-1$ and the hypoxic zone is rarely thicker than $11 \mathrm{~m}$. By contrast, in Segment III (20002010), the hypoxic zone is consistently thicker than $11 \mathrm{~m}$. Segment II (1988-1999) represents a transitional phase during which deep-water oxygen concentrations and the thickness of the hypoxic zone are extremely variable. The longterm decrease in deep-water oxygen concentrations and the increase in the extent of the hypoxic zone clearly cannot be the result of eutrophication: the decrease in mean total phosphorus concentration from $>3 \mu \mathrm{mol} \mathrm{L}^{-1}$ in the early 1970 s to $<1 \mu \mathrm{mol} \mathrm{L}^{-1}$ in the past decade shows that Lake Zurich underwent oligotrophication during the study period (Fig. 15d).

To a large degree, the mean deep-water oxygen concentration in September mirrors that in the preceding April (Fig. 15b), when deep-water oxygen concentrations in deep Swiss perialpine lakes are generally at their annual maximum after mixing and ventilation in winter and spring (Livingstone and Imboden, 1996). This tight coupling implies that minimum deep-water oxygen concentrations in September are directly related to the intensity of mixing, and hence climatic forcing, in winter and spring (Livingstone and Imboden, 1996). Computation of the Schmidt stability confirmed that the thermal stability of the water column in winter and spring increased from Segment I to Segment III, inhibiting deep mixing in the lake. This was primarily due to an increase in water temperature in the uppermost $20 \mathrm{~m}$ of the lake (Fig. 15c), which reflects a similar increase in regional air temperature in winter and spring. Most of the increase in both water and air temperatures occurred abruptly from 1987-1988 as a result of the late 1980s climate regime shift (CRS) (North et al., 2013), which is known to have affected temperatures in oceans (e.g., Conversi et al., 2010) and lakes (e.g., Anneville et al., 2004, 2005), and which appears to have resulted ultimately from a shift in the Arctic Oscillation (Rodionov and Overland, 2005). Thus the reason for the long-term increase in the extent of hypoxia appears to be at least partially associated with changes in the large-scale climatic regime (North et al., 2014).

One clear impact of the increase in the extent of hypoxia has been on the soluble reactive phosphorus concentration in the deep water of the lake, which exhibited an abrupt increase from Segment II to Segment III despite a fairly consistent decline in the mean total phosphorus concentration in the lake since the early 1970s (Fig. 15c). This indicates that the increase in the extent of hypoxia apparent in Segment III is likely to have resulted in an increase in the dissolution of phosphorus from the sediment; i.e., in an increase in internal

\footnotetext{
${ }^{2}$ Here we adopt the common hypoxia threshold of $2 \mathrm{mg} \mathrm{L}^{-1} / 62.5 \mu \mathrm{mol} \mathrm{L}{ }^{-1}$.
} 
phosphorus loading that is ultimately the result of a longterm change in climatic forcing (North et al., 2014).

Despite the success achieved in fighting eutrophication in Swiss lakes, the recent increase in hypoxia in Lake Zurich demonstrates that the effects of climate warming might slow down or even reverse this process. An increase in deep-water hypoxia as a result of less vigorous lake mixing is in itself a negative ecological development, but this is likely to be compounded by a concomitant increase in internal phosphorus loading. More detailed research in various lakes is needed to fully understand how reduced mixing affects internal phosphorus loading. Long-term monitoring data are essential to address this question as well as many other aspects of the impact of climate and other non-stationary drivers on lake ecology. Lake monitoring thus needs to be continued and where possible intensified - especially in case of lakes that already have long historical data sets or are sources of drinking water (to over 1 million people in the case of Lake Zurich). The recent trend toward decreasing the frequency of monitoring in some Swiss lakes for financial reasons needs to be reversed if we want to understand how - and how fast - lake systems are changing.

\subsection{Long-term oxygenation history - examples from Swiss lakes and the Bosporus outflow area in the Black Sea}

Organic and redox-sensitive inorganic markers in the sediment enable the reconstruction of environmental conditions related to hypoxia farther back into the past than is possible using only multidecadal instrumental time series. In lakes and semi-enclosed seas, seasonal to millennial redox changes in the hypolimnion strongly modify the cycling of $\mathrm{Fe}$ and $\mathrm{Mn}$ (Davison, 1993). Reducing conditions become established, for instance as a result of oxygen consumption during the remineralization of organic matter, leading to the release of Fe and Mn (Nealson and Saffarini, 1994; O'Sullivan and Reynolds, 2005). After oxygenation at the chemocline following partial or total mixing of the water column, Fe and $\mathrm{Mn}$ precipitates are deposited and can potentially be preserved in the sediment (Haworth et al., 1984; Schaller and Wehrli, 1996). The concentration and types of biomarkers in the sediment relate to shifts in plankton and microbial communities in the water column, depending on environmental conditions. Here we present the $\mathrm{Mn} / \mathrm{Fe}$ ratio as a semiquantitative proxy for the intensity of past spring oxygenation, and lipid biomarkers for reconstructing eutrophication and hypoxia in Swiss lakes. The redox-sensitive elements $\mathrm{Fe}$, $\mathrm{Mn}$, and S are employed to reconstruct the history of the Mediterranean inflow to the Black Sea and its role in ventilating the Bosporus outflow area.

Seasonal hypolimnion oxygenation events in Lake Zurich from the past century were reconstructed based on a $110 \mathrm{~cm}$ long core from the deepest part of the lake. The core was analyzed with an Avaatech X-ray fluorescence (XRF) core

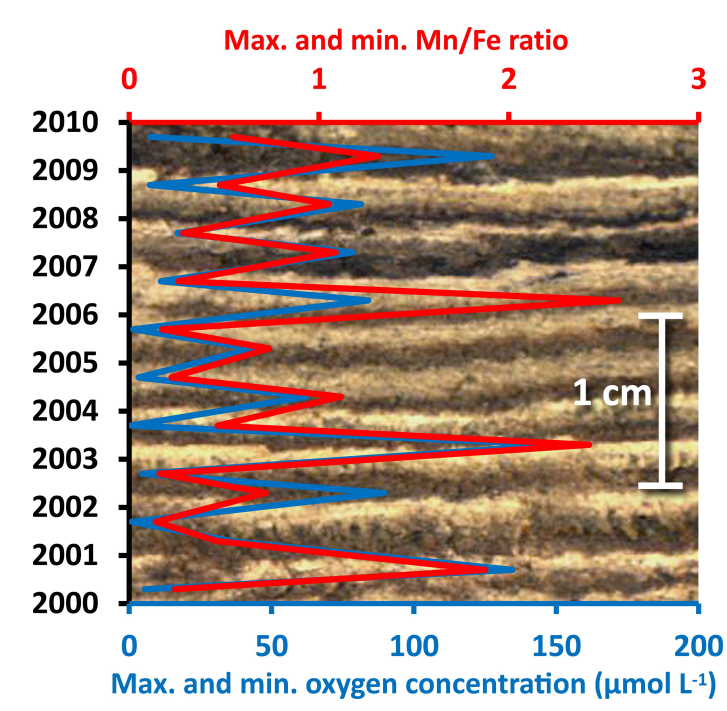

Fig. 16. Detail of the laminated sediment core from Lake Zurich covering the period 2000-2010. The profiles show seasonal changes in the $\mathrm{Mn} / \mathrm{Fe}$ ratio (based on maximum and minimum XRF counts in the respective layers of the core, red line) and in the bottom-water oxygen concentration at $135 \mathrm{~m}$ water depth (maxima and minima of a 3-month running mean of the monitoring data, blue line).

scanner ( $30 \mathrm{~s}$ at 10 and $30 \mathrm{kV}$ at $0.3 \mathrm{~mm}$ spatial resolution). The age model was based on organic varve counting, where the minima in the calcium signal occur in winter, and are attributed to the beginning of each calendar year. The laminated part of the core (Fig. 16) spanned the period 18952010, which could be resolved seasonally by the XRF analysis. The relative trace metal concentrations determined in the core were compared with the oxygen concentrations measured in the water column to assess the potential of trace metals as indicators of deep-water hypoxia. Manganese (Mn) peaks in the sediment clearly tend to occur in late winter and spring, coinciding with the spring deep-water oxygen maxima, whereas iron (Fe) exhibits peaks in autumn and winter (Naeher et al., 2013b, and references therein). Naeher et al. (2013b) showed that the Fe signal is mainly governed by calcite dilution. The maximum Mn XRF counts, when normalized by the Fe XRF data measured at the same depth, correlated well with the maximum three-month running mean oxygen concentrations in the water column at $135 \mathrm{~m}$ (Fig. 16). Although some deviation exists between predicted and monitored oxygen concentrations, the $\mathrm{Mn} / \mathrm{Fe}$ ratio clearly represents a semi-quantitative proxy for reconstructing spring maximum oxygenation from the sedimentary record. This proxy was also applied to the period 18951936 in order to reconstruct bottom-water oxygenation for the period before oxygen monitoring began in Lake Zurich (Naeher et al., 2013b). However, sediment and geochemical focusing limits the application of the proxy to the deepest part of the lake. In addition, there are some instances of especially low $\mathrm{Mn} / \mathrm{Fe}$ ratios at high oxygen concentrations that 

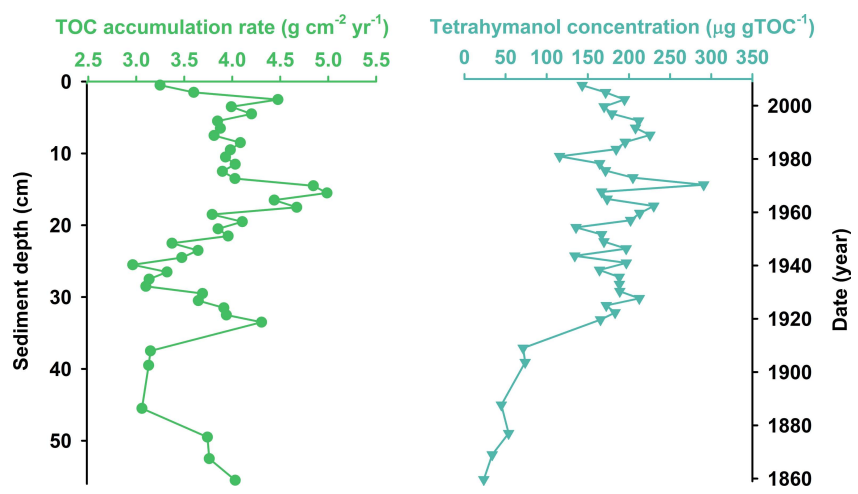

Fig. 17. Profiles of TOC accumulation rate and tetrahymanol concentrations in Lake Rotsee as a function of sediment depth $(\mathrm{cm})$ and date (year).

suggest that the supply of Mn to the sediment may diminish after several consecutive years of high deep-water oxygen concentrations (Naeher et al., 2013b).

Lipid biomarkers in the sediments of the Swiss Lake Rotsee were used to reconstruct eutrophication and hypoxia over the last $150 \mathrm{yr}$, based on a $56 \mathrm{~cm}$-long core taken at $16 \mathrm{~m}$ water depth, at the deepest point of the lake (Naeher et al., 2012). The procedures and analytical instruments used for the determination of lipid biomarkers are reported in Naeher et al. (2012). Eutrophication in the lake led to an increase in productivity and subsequently in total organic carbon (TOC) accumulation rates in the 1920s and 1960s (green curve in Fig. 17), (Naeher et al., 2012). This increased supply of organic matter to the sediment presumably led to higher organic matter mineralization rates, accompanied by increased oxygen demand, finally leading to hypoxic/anoxic conditions. The increase in the abundance of tetrahymanol since the 1920s (turquoise curve in Fig. 17) might have been associated with intensified stratification in line with observations at other sites (e.g., Sinninghe Damsté et al., 1995). The presumed increase in the supply of organic matter also led to a higher biomass of methanogens (based on glycerol dialkyl glycerol tetraethers, $\delta^{13} \mathrm{C}$ values of cleaved ethers and microbial data), followed by a temporal delay of aerobic methanotrophic bacteria (based on $17 \beta$ $21 \beta$-bishomohopanoic acid, diploptene, $\delta^{13} \mathrm{C}$ values) (Naeher et al., 2014). More robust markers for hypoxia originate from phototrophic sulfur bacteria (Chromatiaceae, Chlorobiaceae; Brocks and Summons, 2003), which live under photic-zone euxinia and anoxia. The detection of isorenieratene, okenone, methyl-isobutyl-maleimide and methyl- $n$ propyl-maleimide indicated the presence of Chromatiaceae and Chlorobiaceae, implying the occurrence of photic-zone euxinia in Lake Rotsee (Naeher et al., 2013a). In conclusion, lipid biomarkers in sediments can indicate past environmental changes, such as for instance eutrophication, productivity, organic matter mineralization/degradation, stratification and oxygen depletion based on microbial community changes
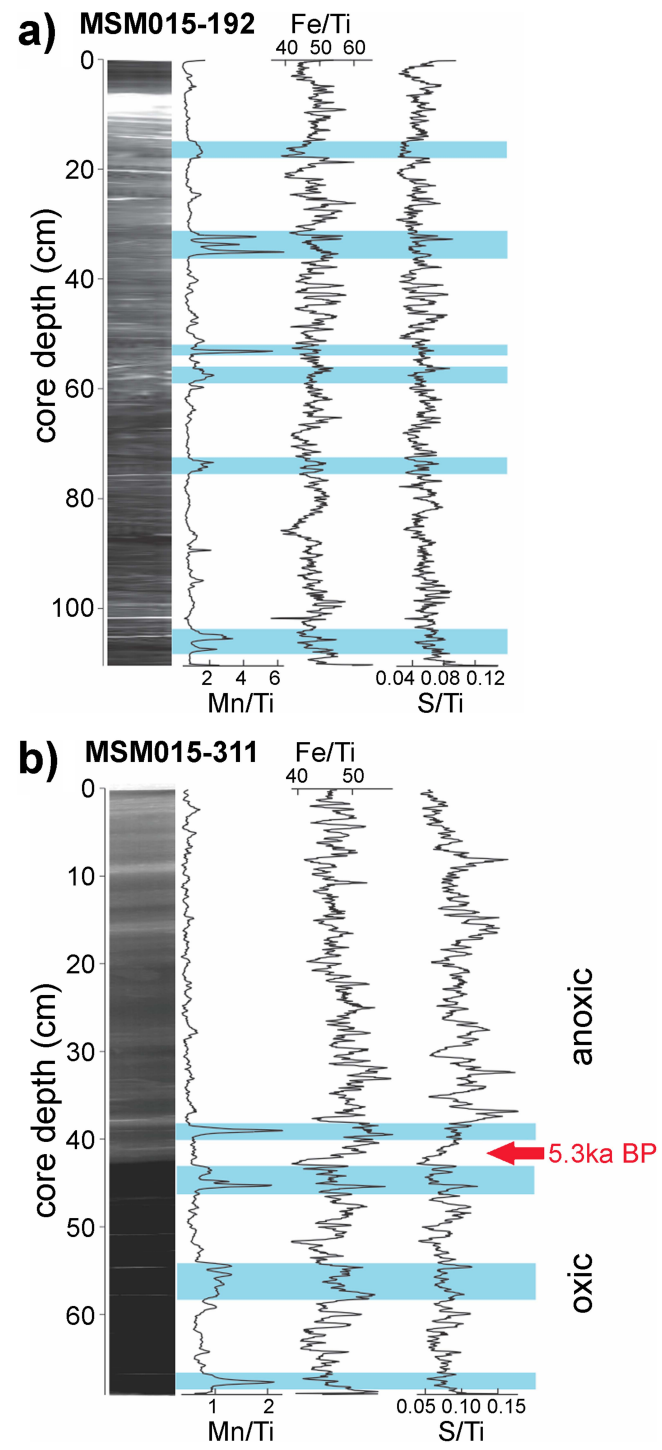

Fig. 18. X-ray radiographic images and XRF element (Mn, Fe, S) /Ti profiles of sediment cores in the Bosporus outflow area of the Black Sea (see Fig. 1 for location). Positive Mn/Ti peaks reflect oxic conditions, whereas positive $\mathrm{S} / \mathrm{Ti}$ peaks indicate anoxic conditions at the time of deposition. The cores were taken at $307 \mathrm{~m}$ water depth, which is below the present oxic/anoxic interface. The Mediterranean Water ventilation effect is indicated by positive $\mathrm{Mn} / \mathrm{Ti}$ peaks (marked by blue bands). (a) Core MSM015-192 is located in the eastern part of the area $\left(41^{\circ} 30.143^{\prime} \mathrm{N}, 29^{\circ} 16.340^{\prime} \mathrm{E}\right)$. This core shows high $\mathrm{Mn} / \mathrm{Ti}$ throughout the core, indicating the ventilating role of the Mediterranean water. (b) Core MSM015-311 is located in the western part of the area $\left(41^{\circ} 34.7842^{\prime} \mathrm{N}, 29^{\circ} 03.462^{\prime} \mathrm{E}\right)$. The $\mathrm{X}$-ray radiographic image of this core shows an abrupt change in density at $42 \mathrm{~cm}$, dated at $5.3 \mathrm{ka} \mathrm{BP}$. This change is accompanied by the termination of positive $\mathrm{Mn} / \mathrm{Ti}$ peaks, suggesting that the ventilation by Mediterranean water in the western part of the area ceased around $5.3 \mathrm{ka} \mathrm{BP}$.

and/or the adaptation of microorganisms to the changed environmental conditions. 
$\mathrm{Fe}$ and $\mathrm{Mn}$, in conjunction with $\mathrm{S}$, were also applied as inorganic proxies to reconstruct oxygenation events by Mediterranean water in the Bosporus outlet area of the Black Sea on timescales of several millennia. Sediment cores taken in 2009 from R/V ARAR and in 2010 from R/V MARIA S. MERIAN (Leg MSM15/1) along transects from $75 \mathrm{~m}$ to $307 \mathrm{~m}$ water depth on the shelf and upper slope (a on panel IV of Fig. 1) were analyzed by Itrax XRF core scanner and dated by the radiocarbon method using Acceleration Mass Spectrometry (AMS). Manganese normalized to titanium proved to be a good proxy for the warm, saline, oxygen-bearing Mediterranean water mass in sediment cores. The ventilation effect of Mediterranean water on the seafloor is marked by peaks in $\mathrm{Mn} / \mathrm{Ti}$ on the XRF scanner profile throughout the entire sedimentary record of core MSM015-192 (Fig. 18a), which was taken in the eastern part of the outlet area at $307 \mathrm{~m}$ depth (b on panel IV of Fig. 1). Such Mn anomalies in upper slope cores, not associated with $\mathrm{Fe}$ and $\mathrm{S}$ anomalies, are most probably formed by the deposition of Mn(II) from the water column under oxic conditions. High Mn counts throughout the core from the eastern site indicate oxic bottom-water conditions during the deposition of the core sequence (Fig. 18a). The core located in the western part of the outflow area (MSM015-311, c on panel IV of Fig. 1) shows high $\mathrm{Mn}$ counts below $40 \mathrm{~cm}$ core depth, which indicates the prevalence of oxic bottom-water conditions in the period before $5.3 \mathrm{kyr}$ BP (Fig. 18b). Such geochemical evidence, in combination with seafloor morphological features, indicate that the Mediterranean inflow initially also used the northwest trending main channel, transporting oxygenated waters to the western part of the area. Around 5.3 kyr BP, this western transport of Mediterranean water shifted completely eastward, leading to the occurrence of bottom-water anoxia in the western area until the present. This transition from oxic to anoxic conditions in the western area is also reflected in lithological changes; e.g., in mud color changing from gray-green through gray and dark gray to black, indicating Mn deposition, as well as by a transition to lower sediment densities in the radiographic image at $5.3 \mathrm{kyr}$ BP (Fig. 18b). CTD surveys obtained during the same cruises indicate that today's Bosporus plume is still located to the east of the Bosporus channel (see Sect. 5.2.1). Our study in the Bosporus outlet area has shown that we can use Mn as an effective proxy for investigating the history and changing dynamics of the inflow of Mediterranean water into the Black Sea.

\section{Effects of hypoxia on faunal patterns and biogeochemical processes}

\subsection{Effects on faunal patterns}

Rapidly changing oxygen concentrations and the occurrence of hypoxia impose stress on aquatic organisms, and the

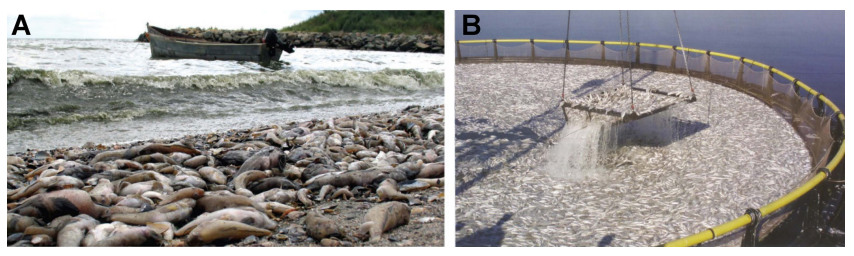

Fig. 19. (A) Mass mortality of benthic fauna in July 2010 in a semienclosed bay on Constanta beach (Photo: Adrian Teaca). (B) Dead fish floating in a cage after a massive fish kill in fish farms at Amvrakikos Gulf (February 2008).

physiological responses and survival strategies of the biota are very complex (Vaquer-Sunyer and Duarte, 2008; Zhang et al., 2010; Levin, 2003; Ekau et al., 2010). When oxygen concentrations decrease, pelagic organisms may escape vertically, develop migration strategies to avoid hypoxic areas, or develop adaptation mechanisms (Ekau et al., 2010). Benthic invertebrates may initially show aberrant behavior before they finally undergo mass mortality (Zhang et al., 2010). All these responses lead to changes in community structure and functioning, and typically to a reduction in species diversity accompanied by the dominance of a few oxygentolerant species (Levin, 2003). Recent studies indicate that water-column oxygenation determines the diel vertical migration patterns of zooplankton. This, in turn, may intensify oxygen depletion, especially in oxygen minimum zones (Bianchi et al., 2013). Hypoxia affects ecosystem functions related to macrofauna, such as bioirrigation and bioturbation (Middelburg and Levin, 2009), which may indirectly affect benthic biogeochemical processes that depend on faunamediated oxygen transport (e.g., denitrification). Ecosystem responses to hypoxia and pathways of recovery from hypoxia are typically nonlinear and may be characterized by specific thresholds of hypoxia duration and severity, by the sudden collapse of communities and functions, and by extended and complex pathways of recovery if oxygen conditions improve. In most cases the ecosystem is affected by a combination of several stressors that accompany hypoxia (Zhang et al., 2010). In this section we show the effects of hypoxia based on the examples of fish kills in the northwestern Black Sea (Romanian shelf) and in Greek lagoons, and on the examples of benthic ecosystem decline and pathways of recovery on the Romanian Black Sea shelf. We also focus on changes in the species distribution of benthic organisms along depth gradients and rapidly varying oxygen concentrations in the Bosporus outlet and on the Crimean shelf.

\subsubsection{Fish kills as a drastic consequence of hypoxia - examples from the northwestern Black Sea and Greek lagoons}

The most drastic effect of hypoxia is the mass mortality of pelagic and benthic organisms. When oxygen levels drop, animals relocate, show reduction in growth and reproduction, 
or die (Levin et al., 2009). The response depends on the species and on the severity and spatial extent of hypoxia. The paleontological record reveals an extreme example of this: during a warm period 250 million years ago a drastic drop in oxygen levels resulted in the extinction of more than $90 \%$ of all marine species (Benton, 2005). Fish kills are the most obvious signs of "dead zones". We report here exemplarily on the mass mortalities of pelagic and benthic organisms caused by hypoxia resulting from geogenic, hydrological, meteorological, and anthropogenic drivers in the northwestern Black Sea and in Greek lagoons.

In the northwestern Black Sea (c on panel III of Fig. 1), mass mortalities of benthic organisms, including demersal fish, were most dramatic during a period of anthropogenically driven eutrophication in the 1980s and 1990s. Today, such mass mortalities still occur occasionally during hot summers when water-column stratification prevents ventilation of the bottom water. The construction of a large number of littoral defense works to protect beaches and to stop coastal erosion along the beaches created so-called "littoral cells" where eutrophication thrives during the summer. In the early years of eutrophication, demersal fish kills occurred following blooms of Prorocentrum cordatum that reached 10 to 50 million cells $\mathrm{L}^{-1}$ in the Romanian coastal sea off the Danube Delta (Skolka and Cautis, 1971; Gomoiu, 1977). The fish died as a result of blocking of their respiratory apparatus; i.e., from clogging of the gills by algae and detritus in suspension and from asphyxiation due to hypoxia. The species most affected by hypoxia were Neogobius melanostomus (75.5\% mortality), Gobius niger (7.5\%), Mesogobius batrachocephalus (1.5\%), Pomatoschistus microps (2.5\%), Symphodus ocellatus (3\%), S. tinca, S. cinereus (1\%), S. roissali $(0.5 \%)$, Parablennius sanguinolentus $(5 \%)$, and $P$. tentacularis (2\%). The most dramatic hypoxia-related fish kills along the Romanian coast were recorded in 1969, 1975 and 1989. Despite recovery from large-scale eutrophication during the past $10 \mathrm{yr}$, major benthic fauna kills were reported in the Romanian Black Sea littoral in 2001, 2005, and 2010 (Fig. 19a). Severe hypoxia was observed in 2001, and in 2010 during summer heat waves (see Sect. 3.4 and Fig. 6), when oxygen solubility was reduced by up to $50 \%$. Surface water temperatures of up to $30^{\circ} \mathrm{C}$ coupled with salinities of less than 10 associated with high discharge from the River Danube resulted in strong stratification and a rapid development of diatoms such as Leptocylindrus danicus and Cerataulina pelagica, and of the dinoflagellate Prorocentrum cordatum. Hypoxia effects were also registered on macrobenthic crustaceans such as Isopoda, Decapoda, and Tanaidaceea. A drastic decrease in the number of worms changed the structure of the epibenthic system (Teaca et al., 2006). In the hot summer of 2010 , despite diminishing eutrophication, oxygen concentrations as low as $34 \mu \mathrm{mol} \mathrm{L} \mathrm{L}^{-1}$ were recorded in the Constanta coastal area. The fishes affected belonged to communities that typically inhabit hardbottom regions (especially Blenniidae) and sediments (Gob- iidae) (Fig. 19a). The main species affected were Neogobius melanostomus, Pegusa lascaris, Mullus barbatus ponticus, Gaidropsarus mediterraneus, Ophidion rochei, Scorpaena porcus, and Syngnathus sp. Approximately three tonnes of dead fish were collected from the beaches according to local authorities.

In the Greek lagoons, historical records of fish kills date back to the 17th and 18th centuries. The fish kills were observed following stormy weather, and there was evidence of elevated concentrations of hydrogen sulfide, such as the intense odor of "rotten eggs" (Meletios, 1807). For Aetoliko Lagoon (b on panel VI of Fig. 1) it has been reported that during such an event, silverware turned black, gardens withered, and masses of dead fish were washed up onshore (Moller and Anders, 1986). Seven major events have been observed in the 20th and 21st centuries: in 1963, 1990, 1992, 1995, 1998, 2001, and 2008 (Dassenakis et al., 1994; Dimitriou et al., 2010; Gianni and Zacharias, 2011). For example, in 1992 after a storm, a "milky yellow" plume appeared following the shoaling of sulfide-rich bottom water and the generation of free sulfur. This plume then spread over the lagoon, and severe oxygen depletion took place in the surface water layer accompanied by high hydrogen sulfide concentrations (>100 ppm; i.e., $>2.9 \mathrm{mmol} \mathrm{L}^{-1}$ ) (Dassenakis et al., 1994). Approximately $100 \mathrm{t}$ of dead fish (mostly Mugilidae and Dicentrarchus labrax) were washed ashore or sank to the floor of the lagoon (Leonardos and Sinis, 1997). Three months later the system had almost returned to its normal state. Dassenakis et al. (1994) suggested that the meteorological conditions (S-SW winds) caused the mixing of welloxygenated surface water with anoxic, sulfide-rich bottom water, resulting in the catastrophic anoxic event. Similar events of fish kills due to mixing of $\mathrm{H}_{2} \mathrm{~S}$ into surface water have occurred for instance in dead-end canals (Luther et al., 2004). Although the main drivers of anoxia and fish kills in Aetoliko Lagoon seem to be oceanographic and anthropogenic, gas seepage cannot be excluded as a geological driver (see Sect. 3.7). Fish kills related to gas seepage and gas-charged sediments have been also reported in the nearshore environment of the Namibian shelf (Emeis et al., 2004).

The case of Amvrakikos Gulf (a on panel VI of Fig. 1) shows impressively how disregarding the hydrological setting can lead to the failure of large fish farms. In 1998, the rise of the hypoxic/anoxic interface caused the sudden death of $1000 \mathrm{t}$ of fish (Ferentinos et al., 2010, Fig. 19b). Potential mechanisms were the massive intrusion of dense seawater through the straits from the open sea, driven by differences in density or by the formation of a gravity-driven hyperpycnal flow at the mouth of the Arachthos River opposite the fish farms. High-density water filled the deeper parts of the eastern basin of the Gulf, raising the anoxic bottom layer. The inability of fish in fish cages to escape from anoxic water makes them particularly vulnerable to such events. 

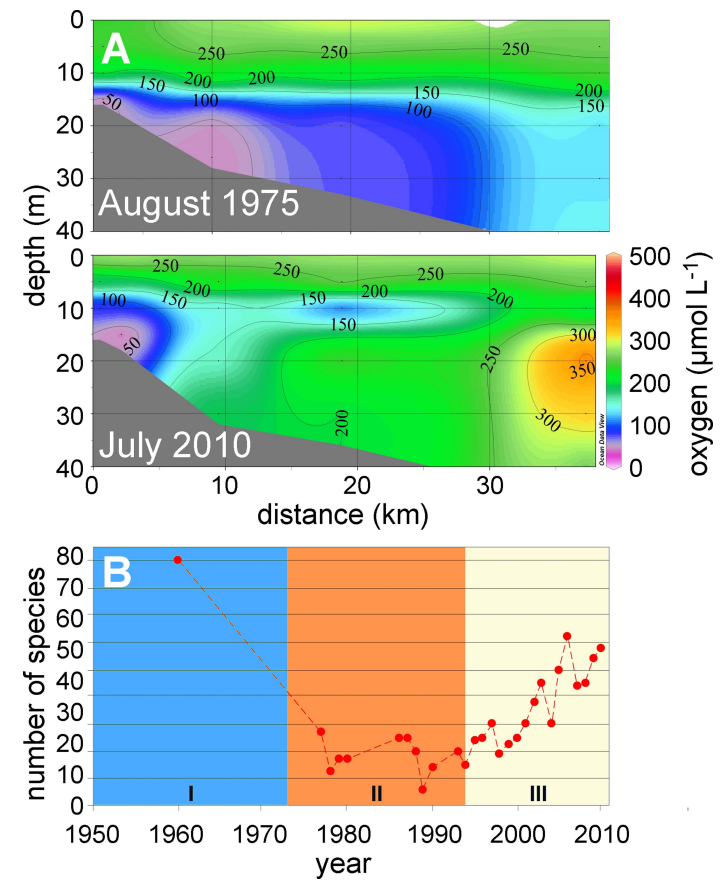

Fig. 20. (A) Distribution of oxygen concentration $\left(\mu \mathrm{mol} \mathrm{L}^{-1}\right)$ in Romanian coastal waters (transect East Constanta) in August 1975 and July 2010. (B) Temporal changes in the species diversity of the total macrobenthic community in the Romanian pre-Danubian sector (Period: I - pre-eutrophication, II - eutrophication, III - posteutrophication).

\subsubsection{Response of benthic communities to eutrophication-driven hypoxia - an example from the northwestern Black Sea shelf}

The combination of existing biological and hydrochemical data with new data, collected on the northwestern Black Sea shelf off the coast of Romania (b on panel III of Fig. 1) during the HYPOX project (see also Sect. 3.4), enabled assessment of the changes in the benthic community structure and functioning, and hence of the current state and trends in recovery of the shelf ecosystem from recurrent large-scale bottom-water hypoxia. During eutrophication in the 1970s and 1980s, seasonal hypoxia developed in the water column below the surface mixed layer. This resulted in vast hypoxic areas that extended offshore to water depths of up to $40 \mathrm{~m}$ (Fig. 20a, upper panel) and led to a dramatic reduction in benthic biodiversity. In hot summers like that of 2010, hypoxia still occurs in nearshore areas due to stratification (see Sect. 3.4), albeit with a shorter duration and a smaller spatial extent (Figs. 6 and 20a, lower panel). Mud worms like Melinna palmata were the winners in this situation of eutrophication and hypoxia, whereas filter feeders like Mytilus galloprovincialis and Acanthocardia paucicostata decreased in abundance and spatial coverage (Fig. 21). An increase in the accumulation of detritus in the sediments

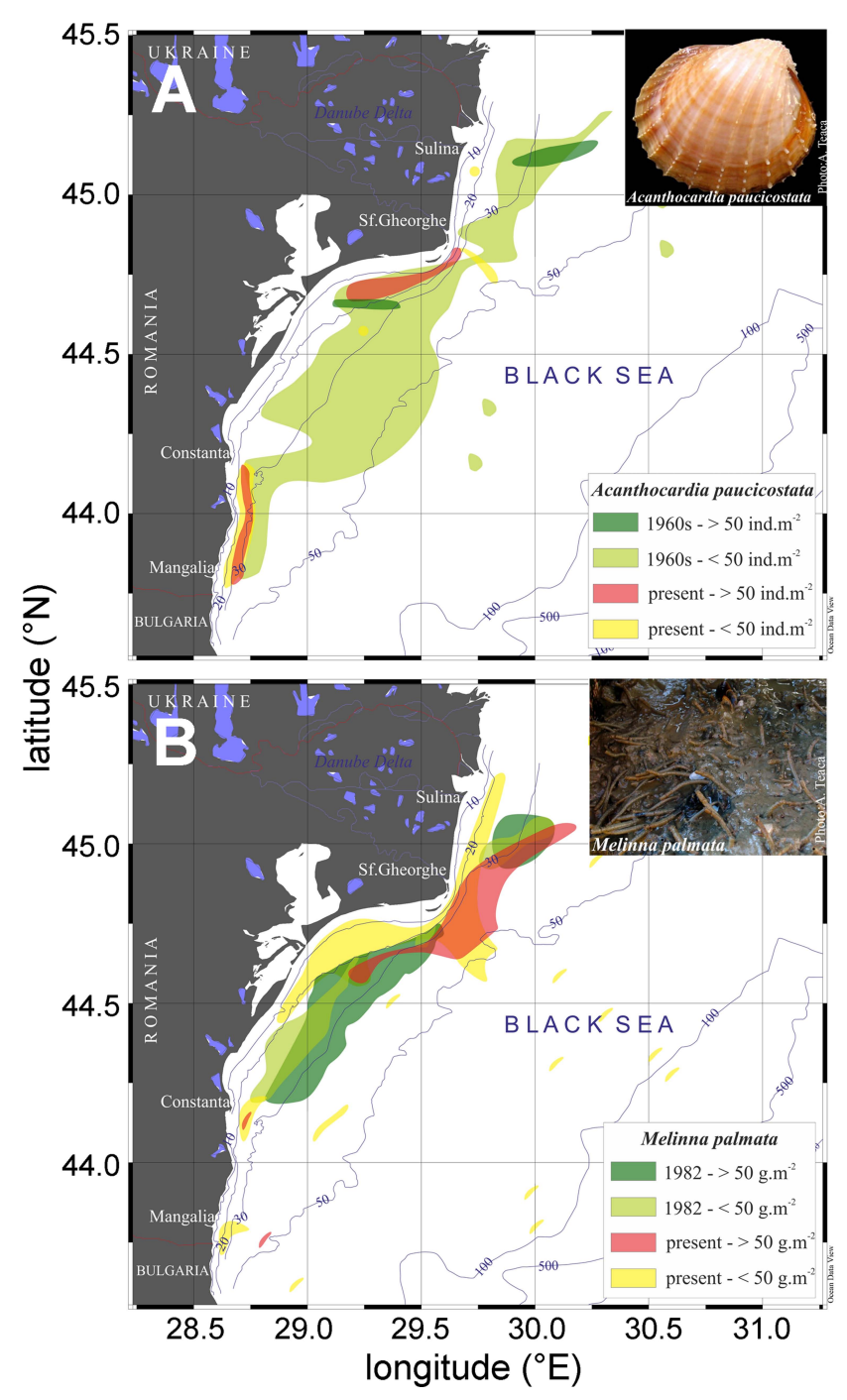

Fig. 21. The density distribution of the bivalve Acanthocardia paucicostata in the 1960s and after 2000 (A) and the biomass distribution of the polychaete Melinna palmata in the 1980s and after 2000 (B) along the Romanian Black Sea coast. Bivalves are the losers and polychaetes are the winners in a situation of increasing eutrophication and hypoxia.

during the 1970s and 1980s supported a massive development of mud worm populations. Bivalve communities became unable to cope with the sudden food supplies from heavy blooms and detritus at some point. Although mussel communities are able to withstand short periods of severe hypoxia by glycogen metabolism, they lose their filtering capacity (Mee et al., 2005) and succumb to persistent hypoxia. Compared to the pre-eutrophication period (Gomoiu, 1992), abundances of epibenthic species (crustaceans and some mollusks) decreased, while a massive development of endobenthic detritophagous organisms was observed. The expansion of the population of small organisms resulted in a diminution of biomass and impoverishment of the trophic 
base for demersal fishes (turbot, sole, mullet). A new benthic community dominated by mud worms became established along the Romanian coast, forming a sub-coenosis in the areas inhabited by the typical Mytilus community. In the Sf. Gheorghe area off the southern Danube branch we found a spectacular population development of the polychaete worms Prionospio multibranchiata, Capitella capitata, Polydora cornuta, and Dipolydora quadrilobata, the latter being a new species for the Romanian coast (Begun et al., 2010). These are opportunistic species on soft sedimentary and hard bottom substrates. In general, integrated over all key taxonomic groups, we found a decrease in the diversity of benthic macrofauna during the period of anthropogenic eutrophication (1970-1990) (Fig. 20b). The area affected by summer hypoxia extended from $3500 \mathrm{~km}^{2}$ in 1973, its first major recorded appearance, to $20000 \mathrm{~km}^{2}$ by the 1980s (Tolmazin, 1985). An ecological regime shift transformed the highly productive and eutrophic ecosystem into a less productive and degraded ecosystem during the early 1990s. For example, benthic communities that were spatially well distributed in the 1960s have become reduced and fragmented during the past $40 \mathrm{yr}$ (e.g., Phyllophora biocenosis; Zaitsev, 1992), and others have been suppressed by invasive species which occupied their habitats. Mya arenaria and Anadara inaequivalvis have modified the indigenous mollusk community comprising Lentidium and Cerastoderma (Gomoiu, 2001). Over the last $10 \mathrm{yr}$ we have observed a decline in eutrophication and a decrease in the number and intensity of hypoxic events (BSC, 2008) along with a slight recovery in the macrobenthic community structure in terms of species numbers in the Romanian pre-Danubian sector (Fig. 20b). On the path to recovery, however, fast-growing opportunistic species are occupying newly formed niches; e.g., ascidians are replacing filter-feeding mussels, and filamentous algae like Polysiphonia are hindering the recovery of macroalgae like Phyllophora by overgrowing. The recent data reveal a still fragile macrobenthic ecosystem that differs from the pre-eutrophication state and is susceptible to anthropogenic and environmental impacts. The combination of oxygen monitoring data (see Sect. 3.4) with benthic community data gathered within HYPOX confirms that the western coastal ecosystem has recuperated to some extent from an ecological collapse marked by excessive eutrophication, oxygen depletion and mass mortality, and has now reached a new, albeit fragile, stage of ecosystem recovery.

\subsubsection{Oxygen gradients shaping benthic communities - examples from the Bosporus outflow and the Crimean shelf in the Black Sea}

The convergence of the low-salinity surface waters of the Black Sea with the more saline waters of the Mediterranean, and the resulting rapid transition from oxic conditions to hypoxic and anoxic conditions, creates an ecological system that requires the organisms that prevail there to adopt spe-

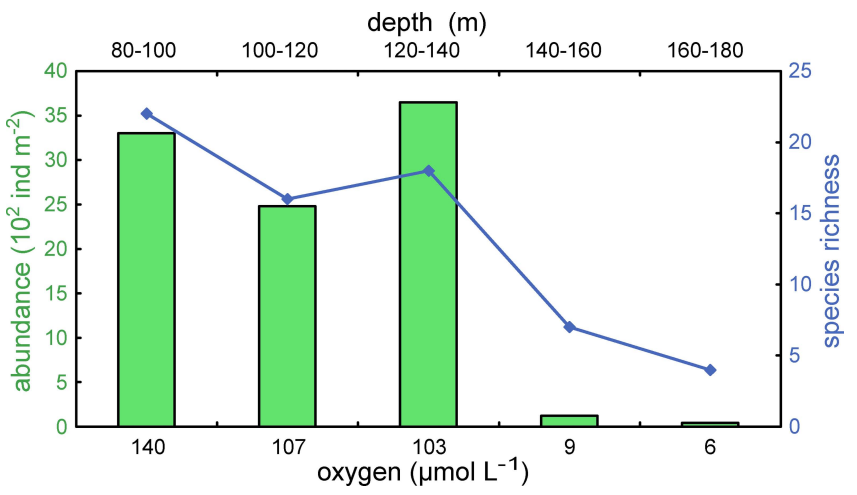

Fig. 22. Dependence of the abundance and species richness of the macrobenthos in the Bosporus area on water depth and on the dissolved-oxygen concentration measured just above the sediment.

cial adaptation strategies. During cruise $15 / 1$ of RV MARIA S. MERIAN in 2010 changes in macrobenthic community structure with depth, and hence along oxygen gradients were studied at the Bosporus outlet of the Black Sea (covering water depths of 80-170 m) and on the Crimean shelf (covering water depths of 70-146 m).

In the Bosporus area (a on panel III of Fig. 1) we found two distinct ecological communities, Modiolula phaseolina and Amphiura stepanovi-Terebellides stroemi, located to the northeast and the northwest of the outlet. The species richness and abundance of the macrobenthos diminished with decreasing oxygen content in the bottom-water (Fig. 22). No fully established bottom communities were found at oxygen concentrations below $10 \mu \mathrm{mol} \mathrm{L} \mathrm{L}^{-1}$. At stations with low oxygen concentrations, the macrobenthos was composed of only a few species of annelids. These included two polychaete species (Nephtys hombergii, Heteromastus filiformis) as well as oligochaete species. Both Heteromastus filiformis and Nephtys hombergii inhabited almost all depths studied, while the brittle star Amphiura stepanovi was restricted to oxygen concentrations higher than $10 \mu \mathrm{mol} \mathrm{L} \mathrm{L}^{-1}$.

While the benthic habitat at the Bosporus outlet is characterized by strong vertical gradients in oxygen, the Crimean shelf slope (depth $70-146 \mathrm{~m}$, d on panel III of Fig. 1) is additionally affected by rapid temporal changes in oxygen concentration (see Sect. 3.2). At the Crimean slope at water depths of $70-90 \mathrm{~m}$ and oxygen concentrations of approximately $290 \mu \mathrm{mol} \mathrm{L} \mathrm{L}^{-1}$, the only community-forming species found was the bivalve Modiolula phaseolina (a $K$-strategist), which made up $77 \%$ of the community, while smaller species, such as annelids (an $r$-strategist), contributed only $14 \%$. At the $100-150 \mathrm{~m}$ depth level, the oxygen concentration decreased to $140 \mu \mathrm{mol} \mathrm{L}^{-1}$ and the community structure changed: the proportion of annelids and other $r$-strategists increased to $42 \%$, whereas $M$. phaseolina made up only $29 \%$ of the benthic community. The $r$ strategists reproduce and grow fast and are therefore better 
adapted to unstable environments (e.g., rapidly changing oxygen concentrations) than $K$-strategists, which produce a lower number of offspring with lower growth rates (Pianka, 1970, 1978). The predominance of M. phaseolina at shallower depths agrees with earlier reports of mollusks or $K$ strategists as typical community-structure forming species in the Black Sea under stable oxic conditions. Comparing key species presently inhabiting the oxic-anoxic transition zone at the Crimean shelf to those in the 1950s reveals a decrease in the average size of the individuals. This occurred along with a strong decrease in biomass - from $43 \mathrm{~g} \mathrm{~m}^{-2}$ in 1957 (Kiseleva and Slavina, 1964) to $28 \mathrm{~g} \mathrm{~m}^{-2}$ in 2010 - while the abundance of the dominant species remained unchanged. This may indicate a rise in the depth of the oxic-anoxic transition zone in addition to the rapid temporal changes that have occurred.

\subsection{Effects on biogeochemical processes}

When oxygen deficiency occurs in a stratified water column, a segregation of redox-sensitive substances and biogeochemical transformations becomes established along redox gradients. When bottom-water oxygen decreases to hypoxic levels, early diagenetic processes in the sediment shift from aerobic to anaerobic pathways and the nature and magnitude of sediment-water exchange changes (Middelburg and Levin, 2009). Organic matter may be less degraded in systems with high organic matter rain rates due to the lower efficiency of anaerobic decomposition processes or the enhanced conservation of sedimentary bacterial biomass in the absence of eukaryotic grazers (e.g., Lee, 1992; Hulthe et al., 1998; Hartnett and Devol, 2003). Reduced substances may accumulate during longer periods of hypoxia, with dramatic feedback to benthic and pelagic organisms. We provide examples of pelagic biogeochemical processes in the Bosporus outflow ventilation area, and of benthic early diagenetic processes in the Romanian Black Sea shelf and Baltic Sea.

\subsubsection{Biogeochemical implications of oxygen intrusions in the redoxcline - an example from the Bosporus outflow area of the Black Sea}

In aquatic systems with frequent or permanent anoxia, such as the Baltic Sea, the Black Sea, and enclosed fjords, enhanced mixing of anoxic and oxic waters may occur; e.g., because of internal waves, during inflow events that inject oxic water into anoxic layers, or at the intersection of the oxycline with the sediment. The impact of mixing events on biogeochemical cycling and on the microbial community, which has not been well studied, was addressed in the Bosporus outflow area (a on panel IV of Fig. 1).

In Sect. 3.1 it was demonstrated that, even in highly stratified systems, redoxclines can be highly complex and dynamic in space and time. It was reasoned that the associated intense mixing of oxic and anoxic waters, and of their re- lated microbial communities, might affect the biogeochemical conversion processes taking place at the redoxcline. The Bosporus outflow area in the southwestern Black Sea offers a unique opportunity to study the effect of intrusions of oxic waters into anoxic water layers on water-column biogeochemisty. In this area, oxic saline water from the Mediterranean leaves the Bosporus Strait and, due to its excess density, cascades down the continental shelf to greater depths, where it mixes with the adjacent anoxic waters. Even after the oxygen has been consumed, these "Bosporus plume" waters can still be detected by temperature anomalies measured up to $\sim 80$ nautical miles off the mouth of the Bosporus (Konovalov et al., 2003). Studies carried out within HYPOX focused on the competition between abiotic and microbially mediated redox processes and the effect of this on the position and magnitude of chemical gradients. In November 2009 and in April 2010, a custom-built pump CTD was deployed to obtain continuous concentration profiles of redox-active elements at a vertical resolution of up to $0.5 \mathrm{~m}$ based both on sensor data and on wet-chemical analyses of samples delivered through a hose into the ship's laboratory. In contrast to other pump CTD systems (e.g., Friederich et al., 1990), the free-falling pump CTD used in this study was able to descend by its own negative buoyancy, which allowed samples to be obtained undisturbed by the ship's motion (Fig. 23e).

In November 2009, oxic Bosporus plume water was detected down to $350 \mathrm{~m}$ depth at several stations to the northeast of the Bosporus outlet (Fig. 23a). The water layers affected by the oxic plume were up to $250 \mathrm{~m}$ thick. In contrast to this, no Bosporus plume inflow was detected during the entire seven-day sampling campaign in April 2010 (Fig. 23b), although the moderate easterly winds that prevailed at that time are not considered likely to prevent the inflow of Mediterranean water through the Bosporus Strait (Latif et al., 1991). High-resolution nutrient profiles obtained in November 2009 revealed that the first appearance of reduced ions, such as ammonium and sulfide, in the Bosporus plumes was $25-100 \mathrm{~m}$ lower than at a nearby reference station where oxic plume water was not detected (Fig. 23c, d). Increased nitrite concentrations at the plume station indicated significant nitrogen turnover in both the oxic and anoxic layers. Using ${ }^{15} \mathrm{~N}$-labeling experiments, nitrification rates of 4-20 nmol L-1 $\mathrm{d}^{-1}$ were measured in the oxic plume water, whereas very high $\mathrm{N}_{2}$ production rates ( $>150 \mathrm{nmol} \mathrm{L}^{-1} \mathrm{~d}^{-1}$ ) were found to coincide with the first appearance of sulfide at greater depths, suggesting the occurrence of denitrification coupled with sulfide oxidation (Fig. 23 d). The presence of old, deoxygenated plume water at the reference station was indicated by temperature anomalies at $220 \mathrm{~m}$ depth. Again, microbial activity in this layer was reflected in higher nitrite concentrations, which coincided with lower concentrations of sulfide and ammonium.

Our results show that oxygen intrusions in the Bosporus outlet area cause a shift in the position of the oxic/anoxic interface and of the redoxcline. This suggests that lateral 


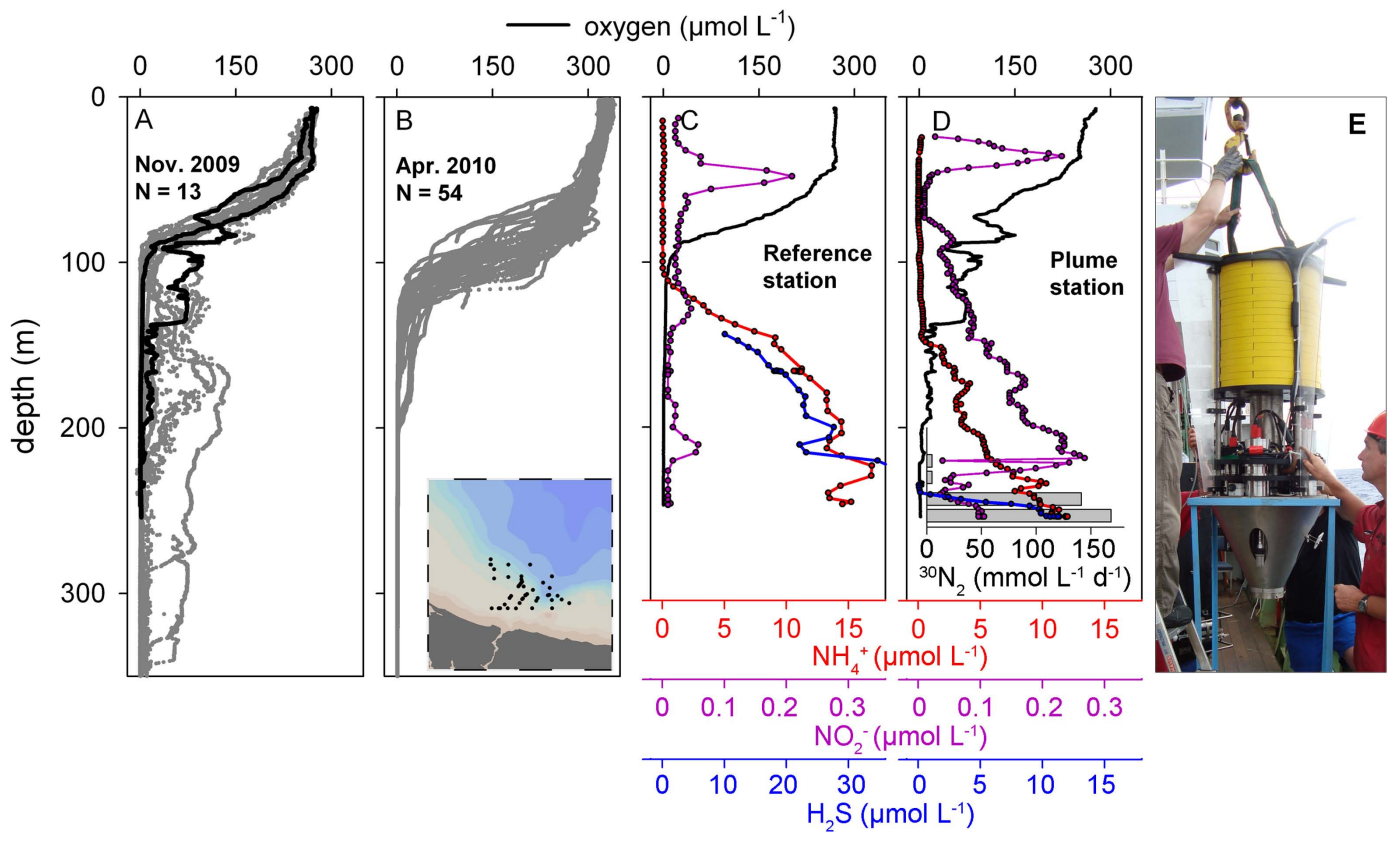

Fig. 23. A and B: Oxygen concentration profiles measured in November 2009 and April 2010 in the Bosporus outlet area (see inset map). The black curves show the examples illustrated in panels $(\mathbf{C})$ and $(\mathbf{D})$. $\mathbf{C}$ and $\mathbf{D}$ : Vertical distributions of oxygen, ammonium, nitrite, and sulfide at a reference station and a plume site affected by waters of Mediterranean origin. For the plume station, $\mathrm{N}_{2}$ production rates at the depth at which sulfide first occurs are provided (gray bars). (E) The free-falling pump CTD just before deployment. The sensors for temperature, salinity, and oxygen, and the inlet of the pump, protrude out of the downward-facing cone. The yellow-painted syntactic foam provides buoyancy to the upper part of the pump CTD. In free-falling mode the pump CTD descends slowly along a wire that runs through the center of the instrument.

mixing plays a significant role in maintaining a permanent suboxic zone in the Black Sea, as hypothesized by Murray et al. (1995) and Konovalov and Murray (2001). Lateral intrusions initially mix oxic compounds and reduced compounds or ions such as oxygen, nitrate and sulfide, which usually do not meet in quasi-diffusive horizontally layered systems.

While high-resolution profiles proved highly suitable for identifying and localizing the processes that occur in complex redoxclines, incubation experiments are necessary to quantify turnover conversion rates, as lateral advection complicates the calculation of fluxes and rates from concentration gradients. The elevated rates of nitrogen loss found in the plume waters once the oxygen was depleted may have important implications for large-scale nitrogen cycling. However, the sequence of microbial and chemical processes favored by the injected oxidizing potential and the associated reaction rates, and especially the amount of nitrogen that is lost from the ecosystem via denitrification, need further investigation. The unexpected absence of Bosporus plume waters in April 2010 emphasizes the fact that the regulation of the Bosporus inflow is not yet fully understood.

\subsubsection{Benthic nutrient regeneration under seasonally changing oxygen conditions - examples from the northwestern Black Sea shelf and the western Baltic Sea}

To illustrate the impact that dissolved-oxygen variability can have on benthic nutrient exchange fluxes, we return to the sites that are subject to seasonal bottom-water hypoxia (see Sect. 3.4). In many respects, the benthic environments of the Romanian Black Sea shelf and Boknis Eck in the western Baltic Sea are similar, despite the differences in geographic setting and coastal morphology. Both are shallow-water sites ( $\sim 30 \mathrm{~m}$ water depth) with sediments rich in organic carbon ( 2 and $5 \mathrm{wt} \%$ ), and at both sites bottom-water temperatures range from $<5{ }^{\circ} \mathrm{C}$ in March to $11^{\circ} \mathrm{C}$ in September, with bottom-water hypoxia developing in late summer (Figs. 6 and 7).

Total oxygen utilization (TOU) and nutrient fluxes were measured on the Romanian Black Sea shelf (Portita site, $28 \mathrm{~m}$ water depth, c on panel III of Fig. 1) using in situ benthic flux chambers and ex situ whole-core incubations. Under normal oxic conditions $\left(225 \mu \mathrm{mol} \mathrm{L}-1 \mathrm{O}_{2}\right.$ in the bottom water in May 2010), the measured TOU $\left(11.7 \mathrm{mmol} \mathrm{m}^{-2} \mathrm{~d}^{-1}\right)$ was lower than during the hypoxic conditions that prevailed in September 2010 (18.9 $\mathrm{mmol} \mathrm{m}^{-2} \mathrm{~d}^{-1}$; Fig. 24). Previous studies at the same location during eutrophication in 


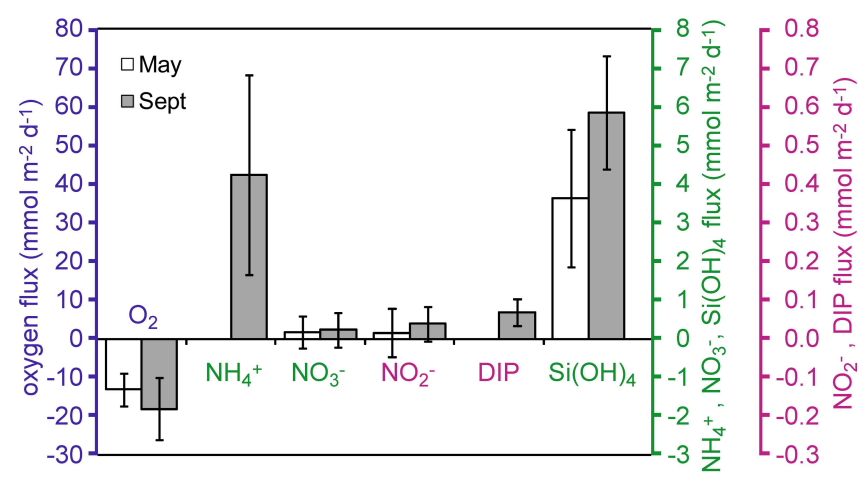

Fig. 24. Mean values of in situ and ex situ benthic total oxygen utilization $\left(\mathrm{mmol} \mathrm{m} \mathrm{m}^{-2} \mathrm{~d}^{-1}\right)$ and benthic nutrient fluxes in May 2010 $(n=6)$ and September $2010(n=7)$ measured at the site of the RCM mooring at Portita on the northwestern Black Sea shelf. Error bars represent the standard deviation of the flux measurements from the calculated mean value. Ammonia and phosphate fluxes in May were below their respective detection limits.

May 1997 reported comparable in situ oxygen uptake rates of $13.8 \mathrm{mmol} \mathrm{m}^{-2} \mathrm{~d}^{-1}$ (Friedrich et al., 2002). No release of $\mathrm{NH}_{4}^{+}$and $\mathrm{PO}_{4}^{3-}$ from the sediment to the overlying water was detected in May 2010, but concentrations of these ions became elevated in September when the bottom-water oxygen concentration was $<150 \mu \mathrm{mol} \mathrm{L}^{-1}$. $\mathrm{Si}(\mathrm{OH})_{4}$ fluxes were higher in September than in May ( $p=0.046$, which is marginally significant). In contrast, $\mathrm{NO}_{3}^{-}$and $\mathrm{NO}_{2}^{-}$showed no significant difference between seasons.

Broadly similar nutrient fluxes and seasonal patterns were observed at Boknis Eck (b on panel II of Fig. 1) during 2010 (based on fluxes calculated from porewater gradients; Dale et al., 2013). At the Romanian Black Sea shelf, the higher $\mathrm{NH}_{4}^{+}$and $\mathrm{PO}_{4}^{3-}$ fluxes in September 2010 can be attributed to a larger amount of fresh organic matter deposited on the sediment surface and to the occurrence of exceptionally high water temperatures during the summer of 2010, which resulted in higher bacterial metabolic activity. For Boknis Eck, Dale et al. (2013) identified additional processes and mechanisms to account for elevated nutrient fluxes in late summer. They suggested that the efflux of $\mathrm{NH}_{4}^{+}$and $\mathrm{PO}_{4}^{3-}$ from the sediments in later summer may be enhanced by the ebullition of methane gas bubbles, which acts as a pseudo-irrigation process (Dale et al., 2013). Using a non-steady state 1-D numerical reaction-transport model, Dale and coauthors further proposed that the phosphate-storing sulfide-oxidizing Beggiatoa bacteria that are present in the sediments at Boknis Eck (Preisler et al., 2007) release large amounts of $\mathrm{PO}_{4}^{3-}$ to the porewater when oxygen concentrations fall to low levels $(<10 \mu \mathrm{mol} \mathrm{L}-1)$, thus enhancing the mobilization of $\mathrm{PO}_{4}^{3-}$ from the sediments. The release of significant amounts of $\mathrm{NH}_{4}^{+}$and $\mathrm{PO}_{4}^{3-}$ can be expected to fuel primary productivity in the water column and exacerbate bottom-water hypoxia, thus providing positive feedback to benthic nutrient release at both the Black Sea shelf and Boknis Eck.

A more generic representation of the benthic response to seasonal hypoxia in coastal sediments can be obtained using the above-mentioned non-steady-state model developed for Boknis Eck (Dale et al., 2013). This model considers the transport and reaction of solutes and solids such as oxygen, $\mathrm{NH}_{4}^{+}, \mathrm{PO}_{4}^{3-}$, particulate organic matter $(\mathrm{POM})$, and iron-bound phosphorus in the sediments. Simulated POM degradation occurs via several pathways, including aerobic respiration and denitrification, through which organic $\mathrm{N}$ and $\mathrm{P}$ are mineralized as dissolved $\mathrm{NH}_{4}^{+}$and $\mathrm{PO}_{4}^{3-}$. Seasonal changes in water-column temperature, salinity, dissolved oxygen, POM flux to the seafloor, bioturbation, and bioirrigation are used to drive the model. Whole-core incubation experiments show that bioirrigation falls essentially to zero when irrigating fauna are exposed to hypoxia, but plays an important role in benthic nutrient exchange for the rest of the year (Dale et al., 2013). For the present discussion, the model is run until a seasonally cycling steady state is achieved in concentrations and reaction rates. To reduce the complexity of the model and to make it more relevant to other seasonally hypoxic sites, the modulation of dissolved $\mathrm{P}$ dynamics by sulfide-oxidizing Beggiatoa bacteria and the enhancement of solute transport by rising gas bubbles are both omitted from the model.

The model results (Fig. 25) demonstrate that under seasonally recurrent hypoxia the major pathways of POM mineralization switch between aerobic respiration in winter and spring and sulfate reduction in summer and autumn. Denitrification, iron reduction, and methanogenesis play a minor role in this example, but may be much more important at other locations (e.g., Martens and Klump, 1980; Canfield et al., 1993; Middelburg et al., 1996; Bohlen et al., 2011). Oxygen fluxes in the sediment are high in winter (January-March), when bioirrigating fauna are most active. Benthic oxygen uptake diminishes through spring and summer as bioirrigation rates and bottom-water oxygen concentrations decrease concomitantly until severely hypoxic conditions $\left(\mathrm{O}_{2} \sim 2 \mu \mathrm{mol} \mathrm{L}^{-1}\right)$ are established in September. Benthic aerobic respiration increases again in OctoberNovember, when wind-induced mixing ventilates the bottom waters (Hansen et al., 1999). Trends in $\mathrm{NH}_{4}^{+}$and $\mathrm{PO}_{4}^{3-}$ concentrations are different to the trend in oxygen concentration. The near-constancy of the porewater concentrations in the upper $10 \mathrm{~cm}$ in winter, at values equal to those in the bottom waters, is due to the non-local exchange of porewater with bottom water by bioirrigation. Solute pumping by indwelling fauna ameliorates the classic fingerprint of organic matter degradation in the surface sediment layers and accounts for the bulk of $\mathrm{NH}_{4}^{+}$and $\mathrm{PO}_{4}^{3-}$ flux from the sediment in winter. As bioirrigation rates decrease in spring and summer, $\mathrm{NH}_{4}^{+}$ and $\mathrm{PO}_{4}^{3-}$ begin to accumulate in the porewater. The absence of a surface oxidized layer in September and October, or the 


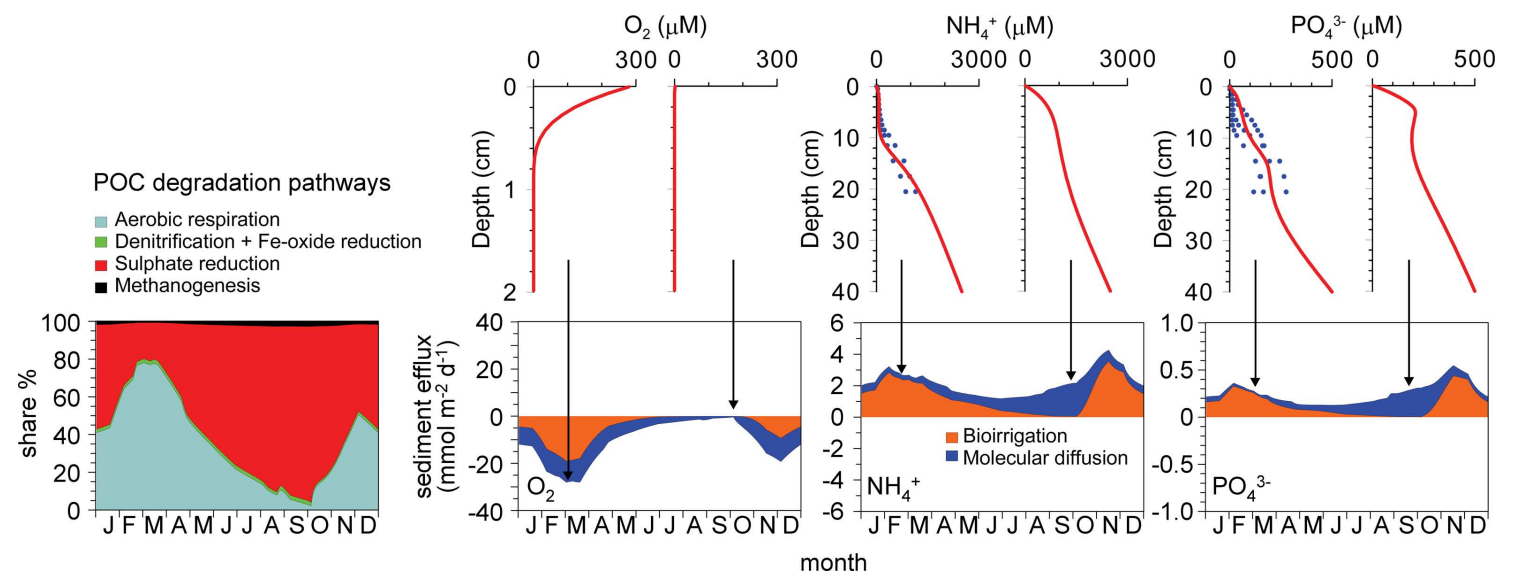

Fig. 25. Left-hand panel: model results showing the daily fraction of organic carbon mineralized by each degradation pathway at Boknis Eck (southwest Baltic Sea). Upper right-hand panels: representative depth concentration profiles of $\mathrm{O}_{2}, \mathrm{NH}_{4}^{+}$, and $\mathrm{PO}_{4}^{3-}$ during winter (high bioirrigation) and during hypoxia (low/zero bioirrigation) with measured winter concentrations from Boknis Eck (blue symbols). Lower right-hand panels: solute fluxes across the sediment-water interface $\left(\mathrm{mmol} \mathrm{m} \mathrm{m}^{-2} \mathrm{~d}^{-1}\right)$ by molecular diffusion and bioirrigation (negative values represent fluxes from the water column to the sediment).

reduction in its thickness, reduces the rate of nitrification and sequestration of $\mathrm{PO}_{4}^{3-}$ into iron oxyhydroxide minerals, and hence also reduces the retention capacity of the sediment for $\mathrm{NH}_{4}^{+}$and $\mathrm{PO}_{4}^{3-}$ (e.g., McManus et al., 1997).

The high diffusive flux rates of $\mathrm{NH}_{4}^{+}$and $\mathrm{PO}_{4}^{3-}$ into the water column during hypoxia corroborate the benthic measurements performed at Portita (Fig. 24) and demonstrate that sediments underlying seasonally hypoxic waters are important sites of preferential nutrient regeneration and return to the water column, as previous investigators have shown (Conley and Johnstone, 1995; Cowan and Boynton, 1996; Rozan et al., 2002; Viktorsson et al., 2013). Importantly, the results show that diffusive losses of $\mathrm{NH}_{4}^{+}$and $\mathrm{PO}_{4}^{3-}$ are important under hypoxic conditions, whereas irrigation fluxes are more important under the oxygenated conditions found in winter. An understanding of the intensity and depth of bioirrigation at seasonally hypoxic sites is thus critical for evaluating the potential impact of enhanced nutrient release to the water column when bioirrigation is diminished.

\section{Improving data quality and data access}

\subsection{Challenges in resolving gradual oxygen changes in the deep sea - an example from Fram Strait}

Water-column studies at HAUSGARTEN include the assessment of various physical and chemical parameters. Dissolved-oxygen concentrations in the near-bottom zone were monitored in situ by means of optical oxygen sensors ("optodes", AADI, Bergen, Norway) attached to moored, free-falling systems (bottom-landers, similar to the system shown in the left-hand panel of Fig. 3) deployed at the central HAUSGARTEN site ( $2500 \mathrm{~m}$ water depth, $\mathrm{f}$ on panel I of
Fig. 1), and ex situ by the Winkler titration of water samples taken at all permanent sampling sites during the annual summer expeditions to HAUSGARTEN. Whereas Winkler titrations have been conducted regularly since 2000 , continuous optode measurements with single-sensor and multisensor instruments did not begin until the summer of 2004 (no data are available from July 2005 to July 2006).

Despite the well-documented good performance of optodes (e.g., Tengberg et al., 2006; Uchida et al., 2008), the HAUSGARTEN data showed a number of puzzling characteristics that make them difficult to interpret (Fig. 26). Probably the most striking feature in the data is the episodic occurrence of significant drops in oxygen concentration (up to $100 \mu \mathrm{mol} \mathrm{L}^{-1}$ ) that can last for minutes to days. Similar anomalies have been reported for optode deployments in the deep central Atlantic and the northwestern Mediterranean Sea (Lo Bue et al., 2011). The detailed analysis of optode and current meter data performed by Lo Bue et al. (2011) showed that the drops in measured oxygen concentration correlated with low current speeds $\left(<10-12 \mathrm{~cm} \mathrm{~s}^{-1}\right)$ and stochastic flow direction patterns. In low-current regimes, the corrosion of metallic material in the vicinity of the oxygen sensors (e.g., bottom-lander frame, ballast weights) best explains the conspicuous drops in dissolved oxygen (Lo Bue et al., 2011). Optodes mounted $0.9 \mathrm{~m}$ above the seafloor, with an almost equal distance to the ballast weights and the ring of floats on top of the bottom-lander, always showed the lowest fluctuations. In agreement with the rather turbulent flow patterns that exist around the bottom-lander frame, not all the sensors of the multisensor instrument show the anomalies in parallel.

Another prominent feature of all optode measurements is a well-attenuated settling of the registered oxygen values within the first few weeks of the long-term deployments, indicating that the sensors need a long time to adapt to the 


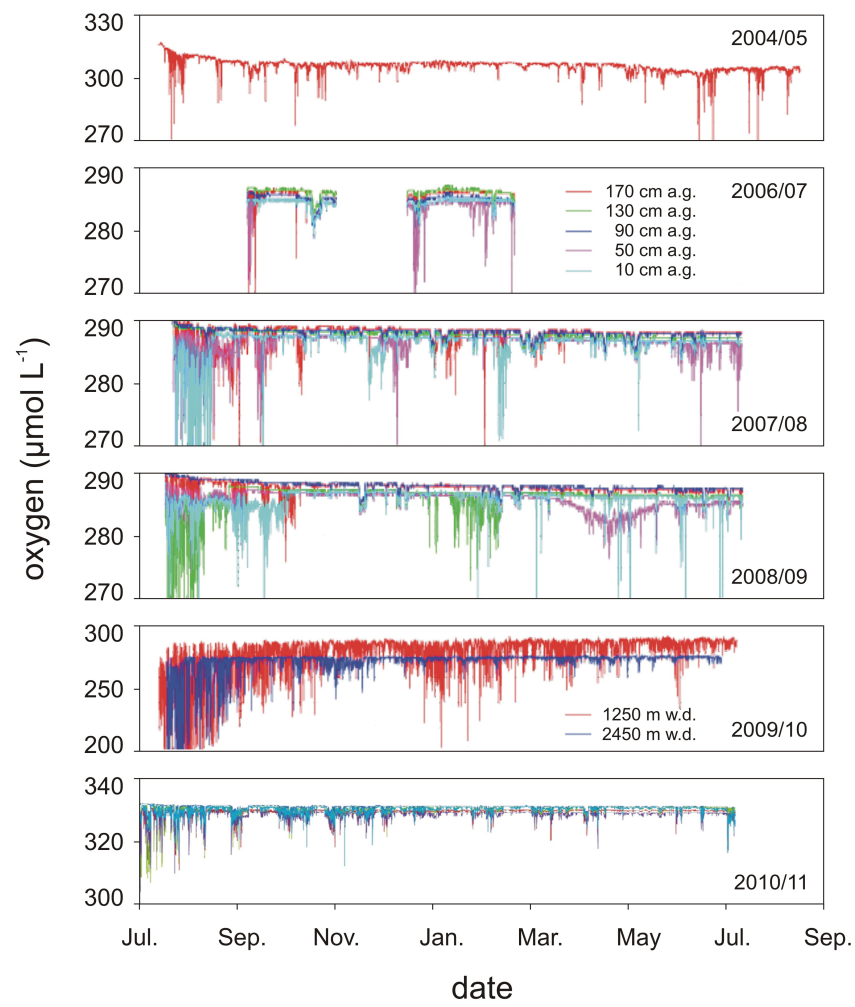

Fig. 26. Oxygen time-series records obtained using optical oxygen sensors ("optodes"; types 3830 and 4330, AADI, Bergen, Norway) from single-sensor and multisensor instruments deployed at the HAUSGARTEN observatory between July 2004 and July 2011 (a.g.: height of sensors above ground; w.d.: station water depth).

high pressure at $2500 \mathrm{~m}$ water depth and/or the extremely low water temperatures at the central HAUSGARTEN station $\left(\sim-0.8^{\circ} \mathrm{C}\right)$. However, whereas the multisensor instrument deployed between 2007 and 2008, and between 2008 and 2009, showed an initial drop in measured oxygen concentrations, single-sensor optodes deployed at the shallowest and the central HAUSGARTEN sites (1250 and $2500 \mathrm{~m}$ water depth, respectively) between 2009 and 2010 surprisingly exhibited the reverse phenomenon, with increases in measured oxygen concentration occurring immediately after deployment (Fig. 26).

Moreover, although all sensors were always thoroughly calibrated, optode measurements from different annual cycles often showed conspicuous offsets in oxygen concentration (up to $20 \mu \mathrm{mol} \mathrm{L}^{-1}$ ) that were clearly not attributable to natural variation. Neglecting all the conspicuous features mentioned above (i.e., episodic drops in oxygen concentration, the adaptation phase of the sensors, and offsets between deployments), optode data from the different deployments between 2004 and 2011 showed only a very low variation in oxygen concentration (a maximum of $2 \mu \mathrm{mol} \mathrm{L}^{-1}$ within one year). Sensor records showed slightly decreasing oxygen concentrations overall between 2007 and 2009, but a slight increase between 2009 and 2010 (Fig. 26). This observation makes it difficult to deduce whether the minor long-term trends registered by the optodes are real or the result of sensor drift.

Despite the good performance of the Aanderaa optodes in short-term and shallow-water applications, long-term deployments at the HAUSGARTEN Arctic deep-sea observatory indicate that this sensor type is probably not suitable for making long-term measurements in deep, polar waters, and in low-current environments in general. The various sensor peculiarities portrayed above apparently impede the resolution of minor variations in dissolved oxygen of the magnitude expected in the deep ocean. Oxygen concentrations determined by the Winkler titration of bottom-water samples during the expeditions to the HAUSGARTEN observatory are merely spot measurements and therefore, unfortunately, cannot help to verify the optode data. Continuous study of the temporal evolution of dissolved-oxygen concentrations in the deep ocean thus remains a big challenge, and one that apparently necessitates the development of new, improved sensors.

\subsection{Quality control of online oxygen monitoring data - examples from Koljoe Fjord and Loch Etive}

The stochastic nature of deep-water renewal events in the fjord systems studied in HYPOX (see Sect. 3.6) called for continuous monitoring in Koljoe Fjord (Sweden) (c on panel II of Fig. 1) and Loch Etive (Scotland) (a on panel V of Fig. 1). Both these sites are easily accessible, allowing cabled online observatories to be deployed. The experience gained with regard to appropriate instrumentation and the safeguarding of data quality is presented here to provide guidance for the future monitoring of coastal and landlocked sites.

Both the Koljoe Fjord and Loch Etive observatories consist of multisensor instruments (type "Seaguard" and "RDCP600"; AADI, Bergen, Norway) connected by an underwater cable to a station on land, and comprise custombuilt communication and power supply systems supplied by Develogic (Hamburg, Germany). The two observatories are illustrated schematically in Fig. 27 (Koljoe Fjord) and Fig. 9 (Loch Etive). Measurements are obtained at sub-hourly resolution using sensors manufactured by AADI (Bergen, Norway) and include oxygen (optode type 3830, 4330, and 4835) and standard oceanographic parameters (conductivity, temperature, sea level), as well as horizontal currents and 3-D current profiles (acoustic Doppler current velocimeters and profilers). The Koljoe Fjord observatory also served as a platform for the field testing of a new optical $\mathrm{CO}_{2}$ sensor (data not shown). Both observatories are equipped with automated real-time data retrieval to the PANGAEA database, as well as web-based data display and quality control systems (some details are provided in the next section and in Fig. 28).

Quality control of the time-series data obtained was recognized as vital to distinguish environmental trends from sensor artifacts. In the case of Koljoe Fjord, data for validation origi- 

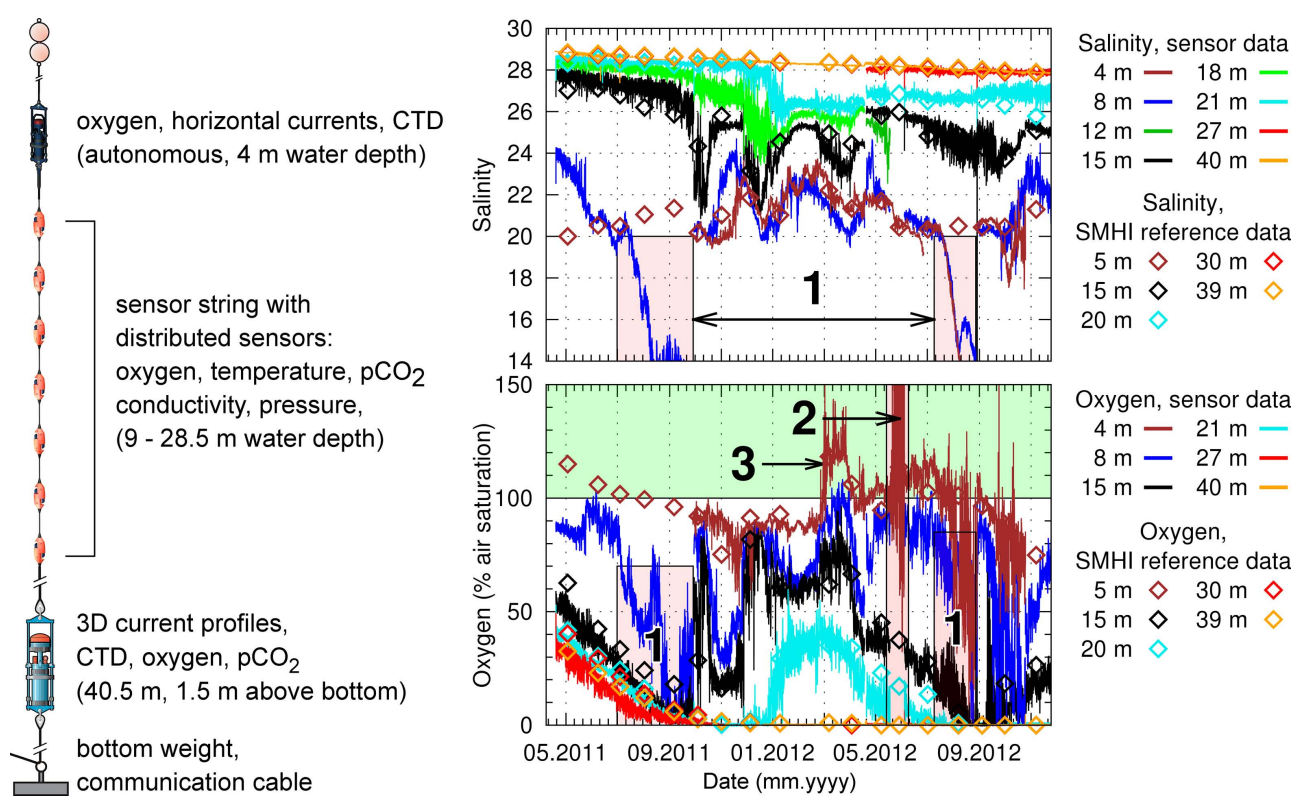

Fig. 27. Left-hand panel: schematic diagram of the cabled observatory at Koljoe Fjord. More than 30 sensors for measuring temperature, salinity, water level, turbidity, oxygen, and currents, including 3-D current profiles and backscatter from particles in the water column, are connected to data loggers (Seaguard and RDCP, AADI, Bergen, Norway). An offline self-logging shallow system (not shown) used for monitoring conductivity, temperature, and oxygen at $4 \mathrm{~m}$ depth was updated with sensors for $\mathrm{pH}, \mathrm{CO}_{2}$, DOM, Chl $a$ fluorescence, and horizontal current in October 2012. Right-hand panel: salinity and oxygen time series (curves; measurement interval $=0.5 \mathrm{~h}$ ), and SMHI monthly reference data (diamonds). The pink boxes mark periods of (1) strong biofouling by sessile fauna (mostly tunicates and mussels) that occurred during the summer months on sensors deployed at depths of 4 and $8 \mathrm{~m}$ in warm oxygenated surface water, and (2) biofouling by algae in late spring. Summer biofouling by fauna (1) resulted in severe underestimates of salinity and oxygen concentration as compared to the reference data, while spring biofouling by algae (2) led to strong peaks in the oxygen reading around midday due to photosynthetic activity on the surface of the oxygen optodes. The effects of biofouling were observed until the observatory had been recovered and cleaned. The increase in surface water oxygenation in spring 2012 (3) was due to a spring bloom of diatoms in the surface waters (the greenish area indicates oxygen concentrations above $100 \%$ air saturation). Gaps in the data are due to instrument maintenance. More detailed information is available at http://mkononets.dyndns-home.com:8080/.

nate from the nearby coastal monitoring station, which is visited monthly by the Swedish Meteorological and Hydrological Institute (http://www.smhi.se/oceanografi/oce_info_data/ SODC/download_sv.htm). Reference data at several discrete depths are provided for oxygen (Winkler titration), salinity, temperature, and a wide range of additional parameters. For the Loch Etive observatory, occasional water samples, and oxygen, conductivity, and temperature profiles measured by the Scottish Association for Marine Science, provide reference data. Wind measurements and additional weather data are available from nearby weather stations in the case of Koljoe Fjord, and from a shore station in the case of Loch Etive. Apart from temporary malfunctioning of the underwater hub and a lightning strike at the Loch Etive shore station, the sensors proved to work reliably on timescales of several months to years. Figure 27 shows that the sensors were able to detect dynamic changes in oxygen concentration (especially at intermediate depths) that standard monitoring approaches would not be able to resolve even if monitoring was carried out monthly, as is the case for Koljoe Fjord (the data obtained at the Loch Etive observatory are presented in
Sect. 3.6). Signal drift caused by biofouling, however, turned out to be an issue at both sites. Biofouling affected mainly the conductivity sensors (i.e., salinity measurements), but also the oxygen sensors in the upper part of the water column (down to $\sim 11 \mathrm{~m}$ ). When the sensors were retrieved for maintenance purposes, severe biofouling, involving mainly mussels and tunicates, was apparent, especially in summer. The effect of biofouling on the conductivity and oxygen readings was determined by comparing the sensor data with the corresponding reference data (e.g., oxygen recordings from 4 and $8 \mathrm{~m}$ water depth in July and August 2011, and in July and August 2012) and by the changes in sensor reading before and after cleaning. The effect of biofouling on conductivity readings resulted in the true salinity being underestimated by as much as $6-10$ units. For oxygen, readings were typically lowered by approximately $150-200 \mu \mathrm{mol} \mathrm{L}^{-1}$ when severe biofouling was encountered in late summer. In contrast, occasional excursions to higher concentrations (up to $600 \mu \mathrm{mol} \mathrm{L}^{-1}$ ) were observed at midday at both Koljoe Fjord (May 2012 at $4 \mathrm{~m}$ ) and Loch Etive (June 2010 at $14 \mathrm{~m}$; data not shown). We attribute these to the growth of biofilms of 
photosynthesizing algae on the sensors. No indication of drift was observed during the two-year observation period for the temperature sensors or for any sensors deployed at $16.5 \mathrm{~m}$ or deeper. At these depths biofouling was slight or absent, probably due to the limited availability of oxygen for respiration $\left(<90 \mu \mathrm{mol} \mathrm{L}^{-1}\right)$. In general, the effect of biofouling in Koljoe Fjord and Loch Etive agrees with previous reports on the performance of oxygen optodes and conductivity sensors (e.g., Tamburri, 2004; Tengberg et al., 2006; Martini et al., 2007; Jannasch et al., 2008; Gilbert et al., 2009).

Sensor readings and reference data agree well for sensors deployed either at the surface or in the deep water. For sensors installed at intermediate depths $(10-20 \mathrm{~m})$ in Koljoe Fjord, quality control was complicated by the extremely strong natural variability (up to $8^{\circ} \mathrm{C}, 5$ salinity units, and $200 \mu \mathrm{mol} \mathrm{O}_{2} \mathrm{~L}^{-1}$ within a period as short as 612 h; see Fig. 27, October 2011 and September 2011). These changes are associated with aspects of fjord hydrodynamics (i.e., wind-induced mixing and the vertical motion of density surfaces induced by tides and internal waves) that occur on timescales not accounted for by traditional monitoring. This impedes the use of monitoring data obtained by the Swedish authorities nearby for quality control purposes. Contamination with air is probably the reason for the small amounts of oxygen detected in some deep-water $(>30 \mathrm{~m})$ reference samples; at these depths sensor readings clearly indicate the presence of anoxic conditions after the oxygen was depleted in November 2011.

In summary, continuous measurements were found to add valuable information to standard monitoring, which is a prerequisite for the successful monitoring of bottom-water renewal events and for obtaining an in-depth understanding of the hydrodynamics of the system (see also Sect. 3.6). Although the relevant technologies appear to be fairly mature, the installation of permanent observatories involves a longterm commitment of resources and personnel, especially in shallow-water systems with high biological activity, as frequent maintenance cruises are necessary to keep systems and sensors running properly. At both sites, and in other stratified systems, profiling observatories similar to the system deployed in the Gotland Basin (see Sect. 3.1) could solve the biofouling problem by retracting the sensors to deep waters with low oxygen concentrations between profiles. As suggested by Glenn et al. (2000), observatories should be regarded as supplemental to existing standard monitoring programs, which are always needed to supply validation data, rather than a substitute for such monitoring programs. However, slight modifications to established monitoring programs at stations providing validation data for the observatories can provide a large amount of added value for a negligible amount of additional effort.

\subsection{Strategies for data dissemination and contribution to global earth observation}

The benefits provided by ocean and lake observations such as those obtained within HYPOX, and by the knowledge derived from these observations, depend crucially on how accessible these data are to potential users, both within and outside the scientific community. That is, these benefits depend on the appropriateness of the data-sharing and dissemination procedures adopted. One of the major motivations for setting up the HYPOX project was the perceived necessity of outlining procedures to integrate ocean and lake observations into global earth observation initiatives and to demonstrate the benefits of data sharing to the aquatic science community. Impediments to open and timely data dissemination are technological and scientific, but also cultural. The collection of data on aquatic systems is driven by scientists with approaches and information needs that are both highly diverse and specific. Even in a well-focused project like HYPOX, the processes being investigated were targeted on many spatiotemporal observation scales. The diversity of scientific approaches fosters a culture of data dissemination that is still largely focused on individual publications, while the value of data sharing and the publication of citable data sets is only now beginning to be valued by the aquatic science community. Consequently, institutions and individual scientists often have reservations about sharing their data, so that data are often not made generally accessible for long periods of time. To be made full use of, these data must be fully integrated into global earth observation activities, meaning that additional technical requirements need to be met.

HYPOX is typical of third-party funded, aquatic sciences projects in that it involved multiple partners from different disciplines working together for a limited period of time. Approaches that proved suitable for HYPOX may therefore also serve as an example for other projects and consortia. To harmonize data sharing and dissemination, a common data policy for the work carried out within the HYPOX project and beyond was established. This included agreement on granting open access to data not later than two years after collection, and the immediate provision of a basic set of parameters (temperature and salinity) to the EU project EGIDA ${ }^{3}$ for use in pioneering attempts on the integration of earth observations. From a technical point of view the most important data-sharing issues were the adoption of common standards and protocols and the establishment of agreement on standard workflows for data processing, including the implementation of protocols for the quality control and quality assurance of continuous real-time data (see previous section). To facilitate this, the HYPOX consortium agreed to use the established data infrastructure system PANGAEA ${ }^{4}$ as a data

\footnotetext{
${ }^{3}$ EU-FP7 project (http://www.egida-project.eu/).

${ }^{4}$ Information system for geo-referenced earth system data hosted by the Alfred Wegener Institute, Bremerhaven, and
} 


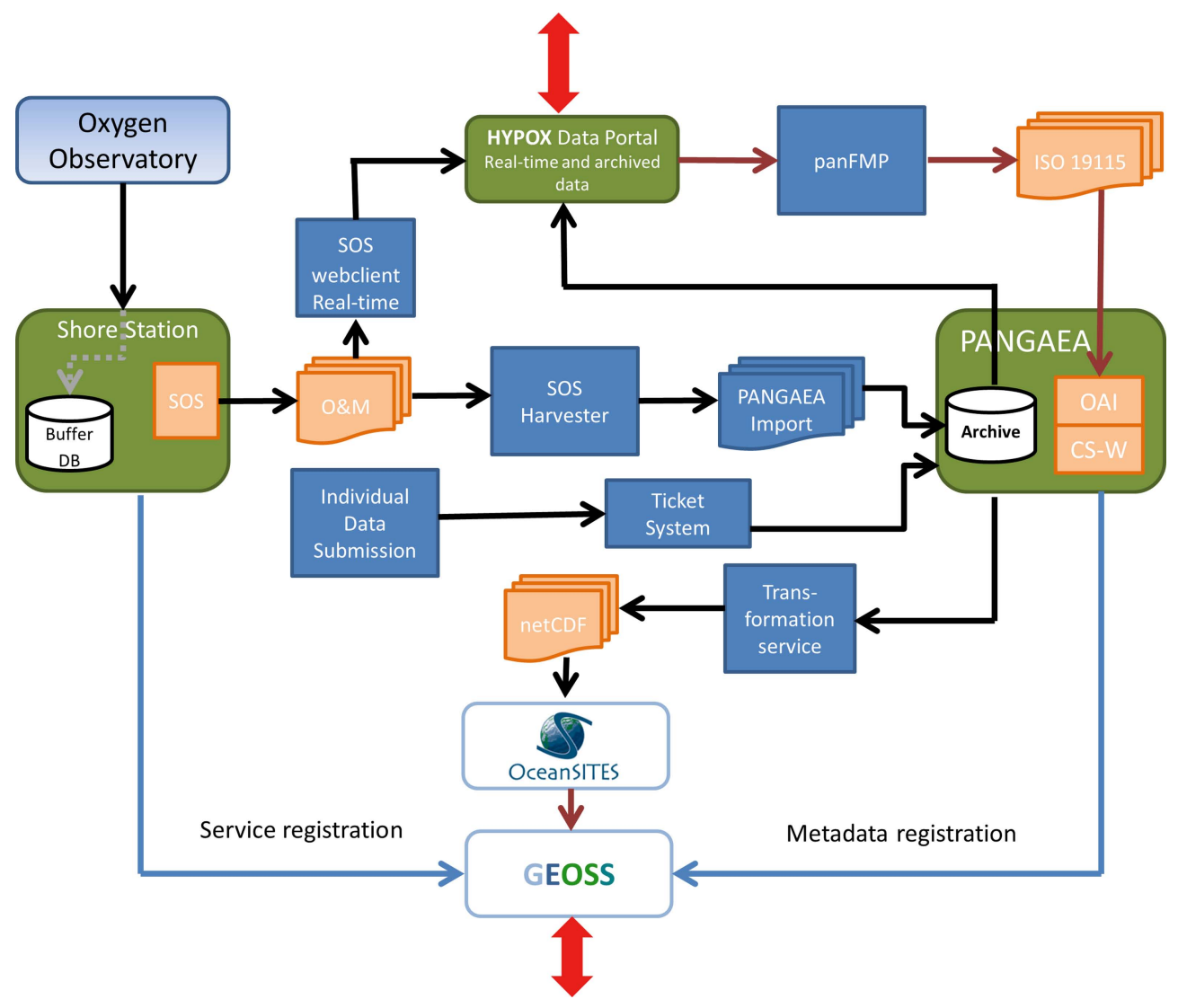

Fig. 28. Integration of the data flow from HYPOX sites to the central data archive Pangaea, and the link to other programs. The green boxes represent data buffers and permanent data archives, the blue boxes indicate processes involved in data flow and data transformation, and the reddish boxes represent the standards involved. Black arrows signify the flow of data and metadata from the cabled observatories in Koljoe Fjord and Loch Etive as well as from individual data sets submitted by HYPOX members. The HYPOX data portal is linked directly to the data archive and additionally receives data from the observatories in near real-time to allow immediate access to the most recent measurements. After transformation to netCDF format, the data are supplied via OceanSITES to GEOSS. The blue arrows represent additional services supplied to GEOSS by HYPOX, namely the provision of metadata and a georeferenced news feed, as well as the direct provision of data from cabled observatories. Interactive user access to data and metadata is possible via GEOSS and the HYPOX portal (red arrows), as well as through additional distributed web portals serving the specific needs of experts. See text for details and an explanation of the abbreviations used.

archive. PANGAEA served as the central hub for the collection and dissemination of data and metadata, and formed the interface with the global earth observation initiative GEOSS ${ }^{5}$ via the so-called GEOSS Common Infrastructure (GCI $)^{6}$. The global initiative GEOSS was started in 2005 with the aim of merging earth-related observations to provide a common information base. To this end, GEOSS acts as an information broker for the earth sciences, interfacing with different information systems and data providers. Fig. 28 shows the basic

MARUM, the Center of Marine Environmental Sciences, Bremen, Germany (http://www.pangaea.de).

${ }^{5}$ International initiative by the Group on Earth Observation (GEO) (www.earthobservations.org/geoss.shtml).

${ }^{6} \mathrm{~A}$ collection of registries for services and data formats that allows GEOSS and other brokering services to access registered data sets (http://www.earthobservations.org/gci_gci.shtml). architecture of the data infrastructure that was established jointly by HYPOX and PANGAEA. The data retrieval and access system makes use of standards that comply with the principles and concepts of Spatial Data Infrastructures (SDI). According to Kuhn (2005), an "SDI is a coordinated series of agreements on technology standards, institutional arrangements, and policies that enable the discovery and use of geospatial information by users and for purposes other than those it was created for". For HYPOX, data management system standards like ISO19115 ${ }^{7}$, Sensor Web Enablement ${ }^{8}$, the

\footnotetext{
${ }^{7}$ International standard for the description of metadata (www. iso.org/iso/catalogue_detail.htm?csnumber=26020).

${ }^{8}$ Open Geospatial Consortium standard describing a sensor data acquisition standard (www.opengeospatial.org/projects/ groups/sensorwebdwg).
} 
standard service OGC-CSW ${ }^{9}$, and OAI-PMH ${ }^{10}$ were implemented, and relevant guidelines, like INSPIRE ${ }^{11}$, were taken account of to ensure interoperability with GCI and GEOSS, as well as with other major data service providers. Four HYPOX services have been registered and are publicly available via the GEOSS registry portal: a geo-referenced news feed (HYPOX GeoRSS), an open archive initiative (OAI) service for harvesting the metadata of all HYPOX data sets in PANGAEA, and two sensor observation services for direct access to data from the cabled observatories of Koljoe Fjord and Loch Etive. In addition to these central data services, individual web portals have been established to serve the particular scientific needs of experts. As an example, the University of Gothenburg has set up a web page to continuously display incoming data from the Koljoe Fjord observatory ${ }^{12}$ in order to follow the evolution of fjord oxygenation and to validate observational results and decide whether processes like biofouling are affecting the measurements (see previous section). Links for downloading the Black Sea Argo float data are provided in Sect. 3.5.

In conclusion, a central data management system has been built up within HYPOX that fulfills the requirements of diverse data sets ranging from biological to physical data, and from discrete individual measurements to continuous streams of sensor data in real-time. The HYPOX data management system provides a sustainable service to data providers, project members, and associated initiatives, as well as to the end-users of the data.

\section{Conclusions}

Comprehensive observational studies of oxygen depletion were carried out in open seas, coastal waters, and landlocked water bodies within the three-year EU-FP7 project HYPOX. The various temporal and spatial scales of hypoxia were addressed by state-of-the-art monitoring strategies in order to properly describe the characteristics of hypoxia and facilitate a mechanistic understanding of its dynamics. Further, we assessed the consequences of hypoxia for the different ecosystem compartments, including higher organisms and biogeochemical processes. Our study demonstrates the capabilities, but also the limitations, of currently available approaches to monitoring hypoxia in the water column and bottom wa-

\footnotetext{
${ }^{9}$ Open Geospatial Consortium standard for catalog services that implements search functionalities and engines for spatial data using their metadata (www.opengeospatial.org/standards/cat).

${ }^{10}$ Protocol for metadata harvesting (www.openarchives.org/ $\mathrm{pmh} /)$.

${ }^{11} \mathrm{EU}$ directive published in 2007 (http://inspire.jrc.ec.europa. $\mathrm{eu} /)$.

${ }^{12}$ Data access and plotting web tool for Koljoe Fjord data, run by Mikhail Kononets at the University of Gothenburg (http://mkononets.dyndns-home.com:8080/ and http://mkononets. dyndns-home.com:8080/cgi-bin/recent_data_plots.script).
}

ters, as well as its causes and consequences. Here, we draw conclusions from our findings concerning appropriate monitoring approaches for various geological and hydrographical settings, taking into account the various requirements with respect to spatio-temporal resolution that are specific to the sites and research questions concerned.

A large variety of technologies for monitoring hypoxia is available both on the market and within the scientific community. One of the biggest challenges is to decide on the best-suited and most efficient way of resolving the temporal and spatial scales of the particular hypoxia phenomenon one wishes to monitor. The processes and scientific questions that are addressed directly determine the requirements for the deployed sensors in terms of spatial and temporal resolution, detection ranges, and stability. Successful assessment of ecosystem conditions will further depend crucially on the proper selection of monitoring sites, and needs to match periods when hypoxia occurs. In addition to oxygen, basic physical and biological parameters should always be recorded to better understand hypoxia drivers. As a basic requirement, this should include the application of standard oceanographic and biogeochemical sensors to measure $T, S$, $p$, local currents (or preferably vertical current profiles), turbidity, and photopigment fluorescence. Furthermore, stateof-the-art data-sharing and dissemination procedures need to be adopted to make data accessible and to connect to global earth observation efforts (Sect. 6.3).

\section{Monitoring rapid changes in the water column and in bottom waters}

Short-term temporal dynamics in oxygen distribution - e.g., fast fluctuations and sudden episodic events - cannot be resolved with repeated ship-based monitoring but call for timeseries approaches with high temporal resolution. Profiling moorings and multisensor strings were found to be appropriate for resolving temporal variability in water-column oxygenation and for identifying episodic events. In the permanently stratified water column of the Gotland Basin, the profiling mooring GODESS allowed thorough characterization of the redoxcline. The vertical oxygen distribution turned out to be highly complex and dynamic - with strong implications for diapycnal mixing and biogeochemical processes (Sect. 3.1). Stationary moorings with oxygen sensors attached at several depths, as installed in Swedish and Scottish fjord systems, proved highly suited to the monitoring of episodic changes in bottom-water oxygenation driven by a complex interplay of several drivers, including winds, tides, internal waves, precipitation, and air pressure (Sects. 3.6 and 6.2). The choice of either profiling or multisensor stationary mooring depends on the characteristics of oxygen dynamics at the monitoring site, the specific research question, and on technical considerations. Static moorings are robust and can provide observations at very high temporal resolution. Profiling moorings, however, have a higher energy demand and 
a greater risk of technical failure but allow for highest vertical resolution. Profiling moorings also permit sensors to be retracted to deeper waters between profiles in order to reduce biofouling, which was found to be less intense at depth (Sect. 6.2). If deep waters are anoxic, the oxygen sensors may also be conditioned and zero-calibrated between profiles to improve accuracy and sensitivity, as demonstrated in Sect. 3.3.

For observations on oxygen availability at the seafloor, static moorings or benthic platforms with sensors for oxygen and associated parameters only in the bottom water and adjacent layers proved sufficient. Using this approach, strong, rapid oscillations in bottom-water oxygenation were successfully resolved both in the Gotland Basin and the Crimean Shelf area, where dynamic oxyclines intersect with the seafloor (Sect. 3.2). Deployment of the benthic observatory GMM in a shallow Greek embayment revealed the potential of gas emissions from geologically active seabeds to act as geogenic drivers of oxygen depletion (Sect. 3.7).

Oxygen monitoring observatories, especially in coastal and landlocked waters, may be connected by cables to a land base for power and online data transmission. The associated long-term commitment of resources is substantial but allows for real-time data access that offers important opportunities. In the Scottish fjord system, real-time measurements facilitated identification of the complex forces driving bottomwater renewal events. This was achieved by a combined approach in which modeling results were directly compared to data almost in real-time. The insights obtained form a basis for forecasting bottom-water oxygenation and potentially even a basis for hypoxia mitigation measures (Sect. 3.6). Cabled observatories may also serve as hypoxia early warning systems. In the case of fish farms that are located in hypoxiaprone waters (see Sect. 5.1.1), real-time oxygen data may be used to appropriately schedule the harvesting of fish or the relocation of fish cages.

\section{Monitoring seasonal and multiannual trends}

Long-term variations and trends in oxygen in response to anthropogenic and climatic forcing (i.e., eutrophication, mesoscale climate variability, and global change) require monitoring on timescales of years to decades. Established long-term time series based on repeated standard CTD monitoring - e.g., on a monthly basis - are highly valuable and need to be sustained and intensified where possible. Although they fail to resolve short-term fluctuations (daily to weekly), they do allow seasonal patterns and multiannual trends in oxygen availability to be identified, and also allow the various drivers to be distinguished. This was demonstrated for time-series data obtained in the western Baltic Sea, the Black Sea basin, and Lake Zurich, where the effects of climatic forcing and eutrophication were successfully separated out. Time-series monitoring in the western Baltic Sea since the 1950s identified the temporal extension of the strat- ification period due to NAO variability as the current main driver of the year-to-year decreases in bottom-water oxygen concentration at Boknis Eck (Sect. 3.4). Measurements taken in the central Black Sea over the last 90 yr reflect the shoaling of the suboxic zone and a general decrease in pycnocline oxygenation since the 1970s as a consequence of eutrophication and climatic forcing (NAO) (Sect. 4.1). A 70-yr monitoring time series from Lake Zurich revealed that, despite reduced phosphate input, deep-water oxygenation continued to decline because climate-driven warming increased duration and intensity of water column stratification. Deep-water hypoxia in turn increased the release of phosphate from the sediments, tending to counteract the effect of sewage treatment measures (Sect. 4.2).

Established monitoring programs should be complemented with continuous sensor-based oxygen observations where possible. Even if long-term patterns and trends are well resolved, continuous recordings may add important information on short-term dynamics and the drivers responsible. One example is the assessment of the recovery of the ecosystem of the northwestern Black Sea shelf from large-scale, eutrophication-driven summer hypoxia (see Sect. 5.1.2). While conditions with respect to hypoxia have generally improved within the last few decades, a three-month time series of bottom-water oxygenation and additional oceanographic and biogeochemical parameters recorded on the northwestern Black Sea shelf revealed strong temporal dynamics in bottom waters in summer, including periods of oxygen deficiency. Hypoxic conditions still occur on short temporal scales as a consequence of hydrodynamic setting, and climatological as well as biological forcing (Sect. 3.4). This indicates that the shelf is naturally prone to hypoxia and that brief occurrences of summer hypoxia in bottom waters may have been common on the northwestern Black Sea shelf even before eutrophication had set in.

Measurements in Koljoe Fjord illustrate well the mutual benefit of standard monitoring and time-series recordings. The cabled observatory deployed within HYPOX complements an established monitoring program of the Swedish authorities. While the observatory greatly improves temporal coverage, the data obtained by monthly ship-based sampling proved essential for the quality control of the sensor data (Sect. 6.2). Mooring-based monitoring of long-term trends is also a potential solution for remote deep-water locations that can only be visited infrequently. This approach requires sensors with excellent long-term stability. The seven-year oxygen time series obtained at HAUSGARTEN, a seasonally ice-covered station west of Svalbard that is only accessed once per year, provided the opportunity to examine the feasibility of state-of-the-art oxygen sensing technology. Although optical oxygen sensors (optodes) have been successfully applied at many shallow-water sites, our results from the HAUSGARTEN site show that even state-of-the-art optodes may be of limited suitability for long-term measurements in deep, cold waters, especially at low current speeds. 
Continuous observation of oxygen in the deep ocean (e.g., in order to identify the gradual trends that might be expected to occur in response to global change) remains a big challenge that may require sensors with improved temporal stability or new calibration strategies (Sect. 6.1).

The sediment record can serve as an archive to assess the oxygenation history of aquatic systems up to geological timescales. Organic and inorganic proxies in sediments in combination with proper age models (e.g., based on varve counting or radiocarbon dating) proved to be powerful tools for reconstructing oxygenation characteristics and associated processes. In stratified Swiss lakes and in the Black Sea, the general patterns of eutrophication and hypoxia over the last century were identified using lipid biomarkers in the sediment. The sedimentary $\mathrm{Mn} / \mathrm{Fe}$ ratio was recognized as a semi-quantitative proxy for reconstructing oxygen maxima during turnover in Lake Zurich. The manganese record in the sediments of the Bosporus outflow area proved to be an effective proxy for tracing changes in the inflow of Mediterranean water into the Black Sea during the Holocene (Sect. 4.3).

\section{Monitoring areal patterns in water-column oxygenation}

Investigation of spatial patterns in water-column oxygenation requires surveys with ship-based equipment or autonomously operating technologies. Ship-based methods may be used for observations of specific phenomena in a confined area at the time covered by the monitoring cruise. Repeated CTD casts successfully provided snapshots of the extent of the "Bosporus plume" and the oxygenation of bottom waters across the Crimean shelf (Sect. 5.2.1 and Fig. 4a). Surveys with the towed multisensor platform MEDUSA were used to identify areas in Greek lagoons where water-column oxygenation changes in response to gas seepage (Sect. 3.7).

Profiling Argo floats are platforms that are completely independent of ships. They are ideal for investigating oxygen distribution patterns on basin-wide scales. Within HYPOX, ARGO-type floats equipped with oxygen sensors were deployed for the first time in the Black Sea; these proved to be powerful tools for resolving the impact of mesoscale processes on the basin-scale distribution of oxygen. The two floats successfully recorded patterns in water-column oxygen distributions and revealed strong differences between slope areas and the central basin, as well as strong seasonal changes (Sect. 3.5). The data obtained by the relatively slowdrifting floats obviously represent a combination of spatial and temporal patterns. This may be a limitation if only one float is used, but adds strength to the approach once large fleets of floats are equipped with oxygen sensors and good spatial coverage is continuously maintained.

\section{Observing the impact of oxygenation on biogeochemical processes and benthic communities}

Hypoxia and anoxia in aquatic systems have severe consequences for rates and pathways of biogeochemical processes, and impose stress on marine fauna and flora. The assessment of biogeochemical processes and element redox-cycling in stratified water columns requires instruments that combine state-of-the-art oxygen sensors and high resolution sampling devices to account for the complex and dynamic nature of the oxycline. A custom-built pump CTD allowed 300-m-long continuous profiles of oxygen and redox-sensitive elements to be obtained in the Bosporus outflow area. This revealed that oxidized compounds (e.g., $\mathrm{O}_{2}, \mathrm{NO}_{3}^{-}$) and reduced compounds (e.g., $\mathrm{H}_{2} \mathrm{~S}$ ) are mixed by lateral intrusions of Mediterranean waters with strong implications for the vertical zonation of reduced species and for nitrogen cycling (Sect. 5.2.1). The pump CTD may be operated in free-falling mode to decouple the instrument from ship movements. Measurements obtained in stratified Swiss lakes using trace-level oxygen microsensors attached to the sampling platform PIA recognized for the first time the presence of long 'tails' of submicromolar oxygen concentrations in the lower oxycline. This allowed high-precision sampling to be conducted for the investigation of specific redox cycling processes and their response to trace levels of oxygen (Sect. 3.3, Fig. 5).

Combined in situ and ex situ sediment flux incubations, analyses of pore-water constituents, and non-steady-state numerical reaction-transport modeling proved to be appropriate to investigate the impact of bottom-water oxygenation on benthic biogeochemistry. Investigations in seasonally hypoxic areas in the western Baltic and the northwestern Black Sea demonstrate that sediments underlying seasonally hypoxic waters are preferential sites for the release of reduced nitrogen compounds (e.g., $\mathrm{NH}_{4}^{+}$) and phosphate. Elevated rates of release of $\mathrm{NH}_{4}^{+}$and $\mathrm{PO}_{4}^{3-}$ may intensify primary productivity, the export of organic matter, and oxygen demand at depth. Non-diffusional transport processes (e.g., methane ebullition and bioirrigation) and their response to different levels of bottom-water oxygenation may significantly alter fluxes and need to be addressed (Sect. 5.2.2).

Responses of seafloor fauna to hypoxia are manifold, and include deterioration and mortality, recovery and adaptation, and the appearance of opportunistic and invasive species. Only selected aspects of these responses could be addressed in HYPOX. Ship-based sampling of benthic fauna is indispensable, at least for smaller size classes and infauna, and has to be combined with proper assessment of oxygen conditions in terms of concentration and temporal dynamics. Combining surveys of benthic communities with oxygen time-series measurements proved successful in assessing the status of the western Black Sea benthic ecosystem with regard to hypoxia. The recovery of this ecosystem after its earlier ecological collapse has now reached a new, fragile stage with a shift in the benthic communities towards opportunistic species with 
short life cycles and a shift in the baseline conditions relative to situation prior to eutrophication (Sect. 5.1.2). Investigations in areas with naturally changing oxygen conditions at the Crimean shelf and the Bosporus outlet showed that the established benthic communities are well adapted to low and fluctuating oxygen conditions (Sect. 5.1.3). Benthic imaging surveys by means of towed instruments or underwater vehicles allow assessment of the response of larger organisms to hypoxia on larger spatial scales, including observations of aberrant behavior. For this purpose, cameras were added to towed instruments, benthic crawlers, ROVs, and submersibles at several sites, but the results were not included in this study.

The research performed within HYPOX revealed a variety of unresolved technological, scientific, and logistic challenges that will need to be addressed in the future. These challenges include, but are not limited to: (1) the continuation of existing long-term time-series monitoring programs and the set-up of additional programs; (2) the installation of cabled and autonomous observatories to complement standard monitoring programs with observations at high temporal resolution; (3) a proper validation of observatory data using data from reference stations; (4) the integration and improvement of existing oxygen sensors (e.g., for monitoring oxygen distribution at trace levels and long-term gradual changes at the micromolar scale), including the definition of best practices for sensor calibration and monitoring strategies to safeguard comparability between modern and existing data sets; (5) the integrated assessment of the response of ecosystems to hypoxia, including community patterns, the adaptive behavior of organisms, and biogeochemical processes; (6) the development of model-based forecasting tools; and (7) the settingup of readily accessible databases for the dissemination of oxygen observations and the integration of these observations into global aquatic system observation initiatives. The success and efficiency of any long-term monitoring effort, be it autonomous observatories or classical monitoring, requires the long-term commitment of human and financial resources. Nevertheless, our comprehensive study within the three-year HYPOX project was able to address many aspects of hypoxia in aquatic systems, and revealed the vital need for dedicated oxygen monitoring at carefully selected locations using appropriate technologies to take a wide range of temporal and spatial scales into account.

Acknowledgements. We thank the HYPOX coordinator Antje Boetius for initiating and supporting the project. The editor Jack B. M. Middelburg and two reviewers provided valuable comments on the manuscript. This study was funded by the European Union FP7 project "HYPOX - In situ monitoring of oxygen depletion in hypoxic ecosystems of coastal and open seas and landlocked water bodies" (EC grant 226213). Additional funding was provided by the Max-Planck-Society, the Helmholtz Zentrum Geesthacht Center for Materials and Coastal Research, and the Alfred Wegener Institute Helmholtz Center for Polar and Marine
Research. This study is a contribution to the project "Land-Ocean Interactions in the Coastal Zone" (LOICZ).

The service charges for this open access publication have been covered by Research Centers of the Helmholtz Association.

Edited by: J. Middelburg

\section{References}

Adrian, R., O’Reilly, C. M., Zagarese, H., Baines, S. B., Hessen, D. O., Keller, W., Livingstone, D. M., Sommaruga, R., Straile, D., van Donk, E., Weyhenmeyer, G. A., and Winder, M.: Lakes as sentinels of climate change, Limnol. Oceanogr., 54, 2283-2297, 2009.

Anneville, O., Gammeter, S., and Straile, D.: Phosphorus decrease and climate variability: mediators of synchrony in phytoplankton changes among European peri-alpine lakes, Freshwater Biol., 50, 1731-1746, 2005.

Anneville, O., Souissi, S., Gammeter, S., and Straile, D.: Seasonal and inter-annual scales of variability in phytoplankton assemblages: Comparison of phytoplankton dynamics in three perialpine lakes over a period of 28 years, Freshwater Biol., 49, 98115, 2004.

BACC: Assessment of Climate Change in the Baltic Sea Basin, Springer, Berlin, 473 pp., 2008.

Bachmann, H.: Hydrobiologische Untersuchungen am Rotsee, Aquat. Sci., 5, 39-81, 1931.

Balzer, W., Grasshoff, K., Dieckmann, P., Haardt, H., and Petersohn, U.: Redox turnover at the sediment/water interface studied in a large bell jar system, Oceanol. Acta, 6, 337-344, 1983.

Bange, H. W., Dale, A., Hansen, H. P., Karstensen, J., Malien, F., Petereit, C., Laß, K., and Friedrichs, G.: Boknis Eck time series station (SW Baltic Sea): measurements from 1957 to 2010, LOICZ Inprint, 1, 16-22, 2011.

Beckers, J. M., Gregoire, M., Nihoul, J. C. J., Stanev, E., Staneva, J., and Lancelot, C.: Modelling the Danube-influenced northwestern continental shelf of the Black Sea. I: Hydrodynamical processes simulated by 3-D and boxmodels, Estuar. Coast. Shelf S., 54, 453-472, 2002.

Begun, T., Teaca, A., and Gomoiu, M. -T.: State of macrobenthos within Modiolus phaseolinus biocoenosis from Romanian Black Sea continental shelf, GeoEcoMarina, 16, 5-18, 2010.

Bell, W. H.: The Exchange of Deep Water in Howe Sound Basin, Marine Sciences Directorate, Pacific Region Environment Canada, Report 73-13, 109 pp., 1973.

Benton, M. J.: When Life Nearly Died: The Greatest Mass Extinction of All Time, Thames \& Hudson, London, 336 pp., 2005.

Bianchi, D., Galbraith, E. D., Carozza, D. A., Mislan, K. A. S., and Stock, C. A.: Intensification of open-ocean oxygen depletion by vertically migrating animals, Nat. Geosci., 6, 545-548, 2013.

Bloesch, J.: Sedimentation und Phosphorhaushalt im Vierwaldstättersee (Horwer Bucht) und im Rotsee, Aquat. Sci., 36, 71-186, 1974.

Bohlen, L., Dale, A. W., Sommer, S., Mosch, T., Hensen, C., Noffke, A., Scholz, F., and Wallmann, K.: Benthic nitrogen cycling traversing the Peruvian oxygen minimum zone, Geochimica et Cosmochimica Acta , 75, 6094-6111, 2011. 
Brewer, P. G. and Peltzer, E. T.: Limits to marine life, Science, 324, 347-348, 2009.

Brocks, J. J. and Summons, R. E.: Sedimentary hydrocarbons, biomarkers for early life, in: Treatise in Geochemistry, edited by: Holland, H. D. and Turekian, K., Elsevier, 65-115, 2003.

BSC: State of the environment of the Black Sea (2001-2006/7), in: Publications of the Commission on the Protection of the Black Sea Against Pollution (BSC) 2008-3, edited by: Oguz, T., Istanbul, Turkey, 83-98, 273-320, 2008.

Canfield, D. E., Kristensen, E., and Thamdrup, B.: Aquatic geomicrobiology, Advances in Mar. Biol., 48, 1-642, 2005.

Canfield, D. E., Jørgensen, B. B., Fossing, H., Glud, R., Gundersen, J., Ramsing, N. B., Thamdrup, B., Hansen, J. W., Nielsen, L. P., and Hall, P. O. J.: Pathways of organic carbon oxidation in three continental margin sediments, Mar. Geol., 113, 27-40, 1993.

Capet, A., Beckers, J. -M., and Grégoire, M.: Drivers, mechanisms and long-term variability of seasonal hypoxia on the Black Sea northwestern shelf- is there any recovery after eutrophication?, Biogeosciences, 10, 3943-3962, doi:10.5194/bg-10-3943-2013, 2013.

Chen, C., Liu, H., and Beardsley, R. C.: An unstructured, finite volume, three-dimensional, primitive equation ocean model: application to coastal ocean and estuaries, J. Atmos. Ocean. Tech., 20, 159-186, 2003.

Cociasu, A., Dorogan, L., Humborg, C., and Popa, L.: Long-term ecological changes in Romanian coastal waters of the Black Sea, Mar. Pollut. Bull., 32, 32-38, 1996.

Conley, D. J. and Johnstone, R. W.: Biogeochemistry of N, P and $\mathrm{Si}$ in Baltic Sea sediments: response to a simulated deposition of a spring diatom bloom, Mar. Ecol. -Prog. Ser., 122, 265-276, 1995.

Conley, D. J., Björck, S., Bonsdorff, E., Carstensen, J., Destouni, G., Gustafsson, B. G., Hietanen, S., Kortekaas, M., Kuosa, H., Meier, H. E. M., Müller-Karulis, B., Nordberg, K., Norkko, A., Nürnberg, G., Pitknen, H., Rabalais, N. N., Rosenberg, R., Savchuk, O. P., Slomp, C. P., Voss, M., Wulff, F., and Zillen, L.: Hypoxiarelated processes in the Baltic Sea, Environ. Sci. Technol., 43, 3412-3420, 2009.

Conversi, A., Umani, S. F., Peluso, T., Molinero, J. C., A., S., and Edwards, M.: The Mediterranean Sea regime shift at the end of the 1980s, and intriguing parallelisms with other European Basins, PLOS ONE, 5, e10633, doi:10.1371/journal.pone.0010633, 2010.

Cowan, J. L. W. and Boynton, W. R.: Sediment-water oxygen and nutrient exchanges along the longitudinal axis of Chesapeake Bay: seasonal patterns, controlling factors and ecological significance, Estuaries, 19, 562-580, 1996.

Dale, A. W., Bertics, V. J., Treude, T., Sommer, S., and Wallmann, K.: Modeling benthic-pelagic nutrient exchange processes and porewater distributions in a seasonally hypoxic sediment: evidence for massive phosphate release by Beggiatoa?, Biogeosciences, 10, 629-651, doi:10.5194/bg-10-629-2013, 2013.

Dassenakis, M., Krasakopoulou, E., and Matzara, B.: Chemical characteristics of Aetoliko lagoon, Greece, after an ecological shock, Mar. Pollut. Bull., 28, 427-433, 1994.

Davison, W.: Iron and manganese in lakes, Earth-Sci. Rev., 34, 119163, 1993.

Dellwig, O., Leipe, T., März, C., Glockzin, M., Pollehne, F., Schnetger, B., Yakushev, E. V., Böttcher, M. E., and Brumsack, H. -J.:
A new particulate $\mathrm{Mn}-\mathrm{Fe}-\mathrm{P}$-shuttle at the redoxcline of anoxic basins, Geochim. Cosmochim. Ac., 74, 7100-7115, 2010.

Diaz, R. J.: Overview of Hypoxia around the World, J. Environ. Qual., 30, 275-281, 2001.

Diaz, R. J. and Rosenberg, R.: Spreading dead zones and consequences for marine ecosystems, Science, 321, 926-929, 2008.

Dimitriou, E., Rousi, A., Tasioulis, J., and Koutsikopoulos, C.: Environmental parameters record during and after an anoxic crisis in the Etoliko Lagoon (Western Greece), in: 14th Hellenic Congress of Ichthyologists, Piraeus, 2010.

Edwards, A. and Edelsten, D. J.: Deep-water renewal of Loch Etive: a three basin Scottish fjord, Estuar. Coast. Mar. Sci., 5, 575-595, 1977.

Ekau, W., Auel, H., Pörtner, H.-O., and Gilbert, D.: Impacts of hypoxia on the structure and processes in pelagic communities (zooplankton, macro-invertebrates and fish), Biogeosciences, 7, 1669-1699, doi:10.5194/bg-7-1669-2010, 2010.

Emeis, K. C., Brüchert, V., Currie, B., Endler, R., Ferdelman, T., Kiessling, A., Leipe, T., Noli-Peard, K., Struck, U., and Vogt, T.: Shallow gas in shelf sediments of the Namibian coastal upwelling ecosystem, Cont. Shelf. Res., 24, 627-642, 2004.

Etiope, G., Papatheodorou, G., Christodoulou, D., Ferentinos, G., Sokos, E., and Faval, I. P.: Methane and hydrogen sulfide seepage in the NW Peloponnesus petroliferous basin (Greece): origin and geohazard, AAPG Bull., 90, 701-713, 2006.

Etiope, G., Christodoulou, D., Kordella, S., Marinaro, G., and Papatheodorou, G.: Offshore and onshore seepage of thermogenic gas at Katakolo Bay (Western Greece), Chem. Geol., 339, 115126, doi:10.1016/j.chemgeo.2012.08.011, 2013.

Fahrbach, E., Meincke, J., Osterhus, S., Rohardt, G., Schauer, U., Tverberg, V., and Verduin, J.: Direct measurements of volume transports through Fram Strait, Polar Res., 20, 217-224, 2001.

Feistel, R., Nausch, G., and Wasmund, N.: State and evolution of the Baltic Sea, 1952-2005, Wiley Interscience, Hoboken, NJ, USA, 703 pp., 2008.

Ferentinos, F., Papatheodorou, G., Geraga, M., Iatrou, M., Fakiris, E., Christodoulou, D., Dimitriou, E., and Koutsikopoulos, C.: Fjord water circulation and dysoxic/anoxic conditions in a Mediterranean semi-enclosed embayment in Amvrakikos Gulf, Greece, Estuar. Coast. Shelf S., 88, 473-481, 2010.

Filonov, A. E.: Thermic structure and intense internal waves on the narrow continental shelf of the Black Sea, J. Marine Syst., 24, 27-40, 2000.

Friederich, G. E., Codispoti,L. A., and Sakamoto, C. M.: Bottle and Pumpcast Data from the 1988 Black Sea Expedition Technical Report 90-3, Monterey Bay Aquarium Research Institution, Monterey, 1990.

Friedrich, J., Dinkel, C., Friedl, G., Pimenov, N., Wijsman, J., Gomoiu, M. -T., Cociasu, A., Popa,L., and Wehrli, B.: Benthic nutrient cycling and diagenetic pathways in the north-western Black Sea, Estuar. Coast. Shelf S., 54, 369-383, 2002.

Gianni, A. and Zacharias, I.: Anoxia, hydrogen sulfide and storm events in Aitoliko Lagoon, Greece, in: 3rd International CEMEPE and SECOTOX Conference, 19-24 June, Skiathos, 125130, 2011.

Gilbert S., Gundersen, K., Johengen, T., McKissack, T., McIntyre, M., Pinchuk, A., Purcell, H., Robertson, C., Schar, D., Smith, G. J., Tamburri, M., and Wells, D.: Performance demonstration statement for the Aanderaa Data Instruments' 4319 B Conductiv- 
ity Sensor. UMCES Technical Report Series. Ref. No. [UMCES] CBL 09-028, 2009.

Gillibrand, P. A., Cromey, C. J., Black, K. D., Inall, M. E., and Gontarek, S. J.: Identifying the Risk of Deoxygenation in Scottish Sea Lochs with Isolated Deep Water, SARF 017 - Final Report, SAMS, 47, 2006.

Glazer, B. T., Luther III, G. W., Konovalov, S. K., Friederich, G. E., Nuzzio, D. B., Trouwborst, R. E., Tebo, B. M., Clement, B., Murray, K., and Romanov, A. S.: Documenting the suboxic zone of the Black Sea viahigh-resolution real-time redox profiling, DeepSea Res. Pt. II, 53, 1740-1755, 2006.

Glenn, S. M., Dickey, T. D., Parker, B., and Boicourt, W.: Long-term real-time coastal ocean observation networks, Oceanography, 13, 24-34, 2000.

Gomoiu, M. -T.: Les conséquences négatives de la "floraison" des eaux à Exuviaella cordata OSTENF. du littoral roumain de la mer Noire, Rapp. Comm. int. Mer Médit., 24, 121-122, 1977.

Gomoiu, M. -T.: Marine eutrophication syndrome in the northwestern part of the Black Sea, in: Science of the Total Environment, edited by: Vollenweider, R. A., Elsevier, Amsterdam, 683-692, 1992.

Gomoiu, M. -T.: Impact of naval transport development on marine ecosystems and invasive species problems, J. Environ. Prot. Ecol., 2, 475-481, 2001.

Graf, G., Schulz, R., Peinert, R. and Meyer-Reil,L. -A.: Benthic response to sedimentation events during autumn to spring at a shallow-water station in the Western Kiel Bight, Marine Biology, 77, 235-246, 1983.

Gruber, N., Doney, S. C., Emerson, S. T., Gilbert, D., Kobayashi, T., Körtzinger, A., Johnson, G. C., Johnson, K. S., Riser, S. C., and Ulloa, O.: The Argo Oxygen Program: a White Paper to Promote the Addition of Oxygen Sensors to the International Argo Float Program, Version 5-1, Argo Steering Commitee, Paris, 2007.

Hannig, M., Lavik, G., Kuypers, M. M. M., Woebken, D., MartensHabbena, W., and Jürgens, K.: Shift from denitrification to anammox after inflow events in the central Baltic Sea, Limnol. Oceanogr., 52, 1336-1345, 2007.

Hansen, H. P., Giesenhagen, H. C., and Behrends, G.: Seasonal and long-term control of the bottom water oxygen deficiency in a stratified shallow water coastal system, ICES J. Mar. Sci., 56, 65-71, 1999.

Hartnett, H. E. and Devol, A. H.: Role of a strong oxygen-deficient zone in the preservation and degradation of organic matter: a carbon budget for the continental margins of northwest Mexico and Washington State, Geochim. Cosmochim. Ac., 67, 247-264, 2003.

Hasiotis, T., Papatheodorou, G., and Ferentinos, G.: A string of large and deep gas-induced depressions (pockmarks) offshore of Killini Peninsula, western Greece, Geo-Mar. Lett., 22, 142-149, 2002.

Haworth, E. Y., Tutin, W., and Lund, J. W. G.: Lake Sediments and Environmental History: Studies in Palaeolimnology and Palaeoecology in Honour of Winifred Tutin, University of Minnesota Press, Minneapolis, 1984.

HELCOM: Eutrophication in the Baltic Sea - An integrated thematic assessment of the effects of nutrient enrichment and eutrophication in the Baltic Sea region, Balt. Sea Environ. Proc. No. 115B, 148 pp., 2009.
Hofmann, A. F., Peltzer, E. T., Walz, P. M., and Brewer, P. G.: Hypoxia by degrees: establishing definitions for a changing ocean, Deep-Sea Res. Pt. I, 58, 1212-1226, 2011.

Hulthe, G., Hulth, S., and Hall, P. O. J.: Effect of oxygen on degradation rate of refractory and labile organic matter in continental margin sediments. Geochim. Cosmochim. Acta, 62, 1319-1328, 1998.

Humborg, C., Ittekkot, V., Cociasu, A., and v. Bodungen, B.: Effect of Danube River dam on Black Sea biogechemistry and ecosystem structure, Nature, 386, 385-388, 1997.

Idso, S. B.: On the concept of lake stability, Limnol. Oceanogr., 18, 681-683, 1973.

Jankowski, T., Livingstone, D. M., Bührer, H., Forster, R., and Niederhauser, P.: Consequences of the 2003 European heat wave for lake temperature profiles, thermal stability, and hypolimnetic oxygen depletion: implications for a warmer world, Limnol. Oceanogr., 51, 815-819, 2006.

Jannasch, H. W., Coletti, L. J., Johnson, K. S., Fitzwater, S. E., Needoba, J. A., and Plant, J. N.: The Land/Ocean Biogeochemical Observatory: a robust networked mooring system for continuously monitoring complex biogeochemical cycles in estuaries, Limnol. Oceanogr. -Meth., 6, 263-273, 2008.

Jones, G. A. and Gagnon, A. R.: Radiocarbon chronology of Black Sea sediments, Deep-Sea Res. Pt. I, 41, 531-557, doi:10.1016/0967-0637(94)90094-9, 1994.

Kamberis, E., Rigakis, N., Tsaila-Monopolis, S., Ioakim, C., and Sotiropoulos, S.: Shallow biogenic gas-accumulations in Late Cenozoic sands of Katakolon Peninsula, Western Greece, Special Publications, Geol. Soc. Greece, 9, 121-138, 2000.

Karakitsios, V. and Rigakis, N.: Evolution and petroleum potential of Western Greece, J. Petrol. Geol., 30, 197-218, 2007.

Keeling, R. F., Körtzinger, A., and Gruber, N.: Ocean deoxygenation in a warming world, Ann. Rev. Mar. Sci., 2, 199-229, 2010.

Kemp, W. M., Testa, J. M., Conley, D. J., Gilbert, D., and Hagy, J. D.: Temporal responses of coastal hypoxia to nutrient loading and physical controls, Biogeosciences, 6, 2985-3008, doi:10.5194/bg-6-2985-2009, 2009.

Kessler, J. D., Valentine, D. L., Redmond, M. C., Du, M., Chan, E. W., Mendes, S. D., Quiroz, E. W., Villanueva, C. J., Shusta, S. S., Werra, L. M., Yvon-Lewis, S. A., and Weber, T. C.: A persistent oxygen anomaly reveals the fate of spilled methane in the deep Gulf of Mexico, Science, 331, 312-315, 2011.

Kessler, J. D., Reeburgh, W. S., Southon, J., and Varela, R.: Fossil methane source dominates Cariaco Basin water column methane geochemistry, Geophys. Res. Lett., 32, L12609, 2005.

Kiseleva, M. I. and Slavina, O. J.: Bottom biocenoses off the west coast of the Crimea, Proc. of Sevastop. Biol. St., 15, 152-177, 1964 (in Russian).

Kirf, M. K., Dinkel, C., Schubert, C. J., and Wehrli, B.: Submicromolar oxygen profiles at the oxic-anoxic boundary of temperate lakes, Aquat. Geochem., 20, 39-57, doi:10.1007/s10498013-9206-7, 2014a.

Kirf, M. K., Røy, H., Holtappels, M., Fischer, J.P., Schubert, C. J., and Wehrli, B.: Redox gradients at the low oxygen boundary of lakes, Aquat. Sci., in review, 2014b.

Kohler, H. P., Ahring, B., Albella, C., Ingvorsen, K., Keweloh, H., Laczko, E., Stupperich, E., and Tomei, F.: Bacteriological studies on the sulfur cycle in the anaerobic part of the hypolimnion and 
in the surface sediments of Rotsee in Switzerland, FEMS Microbiol. Lett., 21, 279-286, 1984.

Konovalov, S. K. and Murray, J. W.: Variations in the chemistry of the Black Sea on a time scale of decades (1960-1995), J. Marine Syst., 31, 217-243, 2001.

Konovalov, S. K., Luther III, G. W., Friederich, G. E., Nuzzio, D. B., Tebo, B. M., Murray, J. W., Oguz, T., Glazer, B. T., Trouwborst, R. E., Clement, B., Murray, K. J., and Romanov, A. S.: Lateral injection of oxygen with the Bosporus plume: fingers of oxidizing potential in the Black Sea, Limnol. Oceanogr., 48, 2369-2376, 2003.

Konovalov, S. K., Murray, J. W., and Luther, G. W.: Basic processes of the Black Sea biogeochemistry, Oceanography, 18, 2835, 2005.

Konovalov, S. K., Murray, J. W., Luther, G. W., and Tebo, B. M.: Processes controlling the redox budget for the oxic/anoxic water column of the Black Sea, Deep-Sea Res. Pt. II, 53, 1817-1841, 2006.

Korotaev, G., Oguz, T., and Riser, S.: Intermediate and deep currents of the Black Sea obtained from autonomous profiling floats, Deep-Sea Res. Pt. II, 53, 1901-1910, 2006.

Kountoura, K. and Zacharias, I.: Temporal and spatial distribution of hypoxic/seasonal anoxic zone in Amvrakikos Gulf, Western Greece, Estuar. Coast. Shelf S., 94, 123-128, 2011.

Kuhn, W.: Introduction to Spatial Data Infrastructures, available at: http://www.docstoc.com/docs/2697206/ Introduction-to-Spatial-Data-Infrastructureskl, 2005.

Langmead, O., McQuatters-Gollop, A., Mee,L. D., Friedrich, J., Gilbert, A. J., Gomoiu, M. -T., Jackson, E.L., Knudsen, S., Minicheva, G., and Todorova, V.: Recovery or decline of the northwestern Black Sea: a societal choice revealed by socioecological modelling, Ecol. Model., 220, 2927-2939, 2009.

Latif, M. A., Ozsoy, E., Oguz, T., and Ünlüata, Ü.: Observations of the Mediterranean Inflow into the Black-Sea, Deep-Sea Res. Pt. I, 38, S711-S723, 1991.

Lee, C.: The use of stratified water bodies to compare intrinsic rates of decomposition in oxic and anoxic systems, Geochim. Cosmochim. Ac., 56, 3323-3335, 1992.

Lehmann, A., Getzlaff, K., and Harlaß, J.: Detailed assessment of climate variability in the Baltic Sea area for the period 1958 to 2009, Clim. Res., 46, 185-196, 2011.

Leipe, T., Dippner, J. W., Hille, S., Voss, M., Christiansen, C., and Bartholdy, J.: Environmental changes in the central Baltic Sea during the past 1000 years: inferences from sedimentary records, hydrography and climate, Oceanologia, 20, 23-41, 2008.

Lennartz, S.: Time-series analysis and development of a 1D box model to simulate trace gas concentrations at the Time Series Station Boknis Eck, Baltic Sea, MSc thesis, Technische Universität Braunschweig, 96 pp., 2013.

Leonardos, I. and Sinis, A.: Fish mass mortality in the Etolikon Lagoon, Greece: the role of local geology, Cybium, 21, 201-206, 1997.

Levin, L. A.: Oxygen minimum zone benthos: adaptation and community response to hypoxia, Annu. Rev. Oceanogr. Mar. Biol., $41,1-45,2003$.

Levin, L. A., Ekau, W., Gooday, A. J., Jorissen, F., Middelburg, J. J., Naqvi, S. W. A., Neira, C., Rabalais, N. N., and Zhang, J.: Effects of natural and human-induced hypoxia on coastal benthos, Biogeosciences, 6, 2063-2098, doi:10.5194/bg-6-2063-2009, 2009.
Livingstone, D. M.: Temporal structure in the deep-water temperature of four Swiss lakes: a short-term climatic change indicator?, Verhandlungen der Internationalen Vereinigung für theoretische und angewandte Limnologie, 25, 75-81, 1993.

Livingstone, D. M.: An example of the simultaneous occurrence of climate-driven "sawtooth" deep-water warming/cooling episodes in several Swiss lakes, Verhandlungen der Internationalen Vereinigung für theoretische und angewandte Limnologie, 26, 822826, 1997.

Livingstone, D. M.: Impact of secular climate change on the thermal structure of a large temperate central European lake, Climatic Change, 57, 205-225, 2003.

Livingstone, D. M. and Imboden, D. M.: The prediction of hypolimnetic oxygen profiles: a plea for a deductive approach, Can. J. Fish. Aquat. Sci., 53, 924-932, 1996.

Lo Bue, N., Vangriesheim, A., Khripounoff, A., and Soltwedel, T.: Anomalies of oxygen measurements performed with Aanderaa optodes, Journal of Operational Oceanography, 4, 27-37, 2011.

Luth, U., Luth, C., Stokozov, N. A. and Gulin, M. B.: The chemocline rise effect on the northwestern slope of the Black Sea, in: Methane Gas Seep Explorations in the Black Sea (MEGASEEBS), Project Report. Ber. Zentrum Meeres- u. Klimaforsch., edited by: Luth, U., Luth, C., and Thiel, H., Univ. Hamburg, Reihe E, 14, 59-77, 1998.

Luther III, G. W., Ma, S., Trouwborst, R., Grazer, B., Blickley, M., Scarborough, R., and Mensinger, M.: The role of anoxia, $\mathrm{H}_{2} \mathrm{~S}$, storm events in fish kills of dead-end canals of Delaware Inland Bays, Estuaries, 27, 551-560, 2004.

Manley, O.: Branching of Atlantic Water within the GreenlandSpitsbergen passage: an estimate of recirculation, J. Geophys. Res., 100, 20627-20634, 1995.

Marinaro, G., Etiope, G., Gasparoni, F., Calore, D., Cenedese, S., Furlan, F., Masson, M., Favali, F., and Blandin, J.: GMM - a gas monitoring module for long-term detection of methane leakage from the seafloor, Environ. Geol., 46, 1053-1058, 2004.

Marinaro, G., Etiope, G., Gasparoni, F., Furlan, F., and Bruni, F.: Gas seepage detection and monitoring at seafloor, in: 10th Offshore Mediterranean Conference and Exhibition, 23-25 March, Ravenna, Italy, http://shop.omc.it/ en-IT/gas-seepage-detection-and-monitoring-at-seafloor/ product-detail/?srch=marinaro\&submit=Search\&id_product $=$ 814, 2011.

Martens, C. S. and Klump, J. V.: Biogeochemical cycling in an organic-rich coastal marine basin - I. Methane sediment-water exchange processes, Geochim. Cosmochim. Ac., 44, 471-490, 1980.

Martini, M., Butman, B., and Mickelson, M. J.: Long-term performance of Aanderaa optodes and Sea-Bird SBE-43 dissolvedoxygen sensors bottom mounted at $32 \mathrm{~m}$ in Massachusetts Bay, J. Atmos. Ocean. Tech., 24, 1924-1935, 2007.

McManus, J., Berelson, W. M., Coale, K. H., Johnson, K. S., and Kilgore, T. E.: Phosphorus regeneration in continental margin sediments, Geochim. Cosmochim. Ac., 61, 2891-2907, 1997.

Mee, L. D.: The Black Sea in crisis: a need for concerted international action, AMBIO, 21, 278-286, 1992.

Mee, L. D., Friedrich, J., and Gomoiu, M. -T.: Restoring the Black Sea in times of uncertainty, Oceanography, 18, 32-43, 2005.

Meier, H. E. M., Andersson, H. C., Eilola, K., Gustafsson, B. G., Kuznetsov, I., Müller-Karulis, B., Neumann, T., and 
Savchuk, O. P.: Hypoxia in future climates: a model ensemble study for the Baltic Sea, Geophys. Res. Lett., 38, L24608, doi:10.1029/2011GL049929, 2011.

Meletios Metropolitan of Artas and Nafpaktos: Geography New and Old, 4, Venice, 200 pp., 1807.

Middelburg, J. J. and Levin, L. A.: Coastal hypoxia and sediment biogeochemistry, Biogeosciences, 6, 1273-1293, doi:10.5194/bg-6-1273-2009, 2009.

Middelburg, J. J., Soetaert, K., Herman, P. M. J., and Heip, C. H. R.: Denitrification in marine sediments: a model study, Global Biogeochem. Cy., 10, 661-673, 1996.

Moller, H. and Anders, K.: Marine Fishes; Fishes; Diseases; Parasites, Moller, Kiel, 365 pp., 1986.

Monteiro, P. M. S., van der Plas, A., Mohrholz, V., Mabille, E., Pascall, A., and Joubert, W.: Variability of natural hypoxia and methane in a coastal upwelling system: oceanic physics or shelf biology?, Geophys. Res. Lett., 33, L16614, doi:10.1029/2006GL026234, 2006.

Murray, J. W., Codispoti, L. A., and Friederich, G. E.: Oxidationreduction environments. The suboxic zone in the Black Sea, in: Aquatic Chemistry: Interfacial and Interspecies Processes, edited by: Huang, C. P., O'Melia, C. R., and Morgan, J. J., ACS Advances in Chemistry Series, 157-176, 1995.

Naeher, S., Smittenberg, R. H., Gilli, A., Kirilova, E. P., Lotter, A. F., and Schubert, C. J.: Impact of recent lake eutrophication on microbial community changes as revealed by high resolution lipid biomarkers in Rotsee (Switzerland), Org. Geochem., 49, 86-95, 2012.

Naeher, S., Schaeffer, P., Adam, P., and Schubert, C. J.: Maleimides in recent sediments - Using chlorophyll degradation products for palaeoenvironmental reconstructions, Geochim. Cosmochim. Ac., 119, 248-263, 2013a.

Naeher, S., Gilli, A., North, R. P., Hamann, Y., and Schubert, C. J.: Tracing bottom water oxygenation with sedimentary $\mathrm{Mn} / \mathrm{Fe}$ ratios in Lake Zurich, Switzerland, Chem. Geol., 352, 125-133, $2013 b$

Naeher, S., Niemann, H., Peterse, F., Smittenberg, R. H., Zigah, P. K., and Schubert, C. J.: Tracing the methane cycle with lipid biomarkers in Lake Rotsee (Switzerland), Org. Geochem., 66, 174-181, doi:10.1016/j.orggeochem.2013.11.002, 2014.

Nayar, A.: A lakeful of trouble, Nature, 460, 321-323, 2009.

Nealson, K. H. and Saffarini, D.: Iron and Manganese in anaerobic respiration environmental significance, Annu. Rev. Microbiol., 48, 311-343, 1994.

Neumann, T.: Climate-change effects on the Baltic Sea ecosystem: a model study, J. Marine Syst., 81, 213-224, 2010.

Nilsson, H. C. and Rosenberg, R.: Succession in marine benthic habitats and fauna in response to oxygen deficiency: analysed by sediment profile-imaging and by grab samples, Mar. Ecol. -Prog. Ser., 197, 139-149, 2000.

Nordberg, K., Filipsson, H.L., Gustafsson, M., Harland, R., and Roos, P.: Climate, hydrographic variations and marine benthic hypoxia in Koljöfjord, Sweden, J. Sea Res., 46, 187-200, 2001.

North, R. P., Livingstone, D. M., Hari, R. E., Niederhauser, P., Köster, O., and Kipfer, R.: The physical impact of the late 1980s climate regime shift on Swiss lakes and rivers, Inland Waters, 3, 341-350, 2013.

North, R. P., North, R. L., Livingstone, D. M., Köster, O., and Kipfer, R.: Long-term changes in hypoxia and soluble reactive phosphorus in the hypolimnion of a large temperate lake: consequences of a climate regime shift, Glob. Change Biol., 20, 3, 811-823, doi:10.1111/gcb.12371, 2014.

Oguz, T. and Gilbert, D.: Abrupt transitions of the top-down controlled Black Sea pelagic ecosystem during 1960-2000: evidence for regime-shifts under strong fishery exploitation and nutrient enrichment modulated by climate-induced variations, Deep-Sea Res. Pt. I, 54, 220-242, 2007.

Oguz, T., Dippner, J. W., and Kaymaz, Z.: Climatic regulation of the Black Sea hydro-meteorological and ecological properties at interannual-to-decadal time scales, J. Marine Syst., 60, 235-254, 2006.

O'Sullivan, P. E. and Reynolds, C. S.: The Lakes Handbook: Lake Restoration and Rehabilitation, Blackwell Science, Oxford, 2005.

Papatheodorou, G., Hasiotis, T., and Ferentinos, G.: Gas charged sediments in the Aegean and Ionian seas, Greece, Mar. Geol., 112, 171-184, 1993.

Pearson, T. H. and Rosenberg, R.: Macrobenthic succession in relation to organic enrichment and pollution of the marine environment, Oceanogr. Mar. Biol., 16, 229-311, 1978.

Peeters, F., Livingstone, D. M., Goudsmit, G. -H., Kipfer, R., and Forster, R.: Modeling 50 years of historical temperature profiles in a large central European lake, Limnol. Oceanogr., 47, 186197, 2002.

Petersen, C. G. J.: On the animal communities of the sea bottom in the Skagerak, the Christiania Fjord and the Danish waters, Report from the Danish Biological Station, 23, 1-28, 1915.

Pianka, E. R.: On $r$ and $K$ selection, Am. Nat., 104, 592-597, 1970.

Pianka, E. R.: Evolutionary Ecology, 2 Edn., Harper and Row, New York, 397 pp., 1978.

Pitkanen, H., Lehtoranta, J., and Raike, A.: Internal nutrient fluxes counteract decreases in external load: the case of the estuarial eastern Gulf of Finland, Baltic Sea, Ambio, 30, 195-201, 2001.

Preisler, A., de Beer, D., Lichtschlag, A., Lavik, G., Boetius, A., and Jørgensen, B. B.: Biological and chemical sulfide oxidation in a Beggiatoa inhabited marine sediment, ISME J., 1, 341-353, 2007.

Prien, R. D. and Schulz-Bull, D. E.: The Gotland Deep Environmental Sampling Station in the Baltic Sea, OCEANS, 2011 IEEE, Spain, 1-5, 2011.

Rabalais, N. N. and Gilbert, D.: Distribution and consequences of hypoxia, in: Watersheds, Bays and Bounded Seas, edited by: Urban, E., Sundby, B., Malanotte-Rizzoli, P., and Melillo, J. M., Island Press, Washington, DC, 209-226, 2009.

Reissmann, J., Burchard, H., Feistel, R., Hagen, E., Lass, H. U., Mohrholz, V., Nausch, G., Umlauf, L., and Wieczorek, G.: Stateof-the-art review on vertical mixing in the Baltic Sea and consequences for eutrophication, Prog. Oceanogr., 82, 47-80, 2009.

Rempfer, J., Livingstone, D. M., Forster, R., and Blodau, C.: Response of hypolimnetic oxygen concentrations in deep Swiss perialpine lakes to interannual variations in winter climate, Verhandlungen der Internationalen Vereinigung für theoretische und angewandte Limnologie, 30, 717-721, 2009.

Rempfer, J., Livingstone, D. M., Blodau, C., Forster, R., Niederhauser, P., and Kipfer, R.: The effect of the exceptionally mild European winter of 2006-2007 on temperature and oxygen profiles in lakes in Switzerland: a foretaste of the future?, Limnol. Oceanogr., 55, 2170-2180, 2010. 
Revsbech, N. P., Larsen, L. H., Gundersen, J., Dalsgaard, T., Ulloa, O., and Thamdrup, B.: Determination of ultra-low oxygen concentrations in oxygen minimum zones by the STOX sensor, Limnol. Oceanogr.-Meth., 7, 371-381, 2009.

Revsbech, N. P., Thamdrup, B., Dalsgaard, T., and Canfield, D. E.: Construction of STOX oxygen sensors and their application for determination of $\mathrm{O}_{2}$ concentrations in oxygen minimum zones, Method. Enzymol., 486, 325-341, 2011.

Riedel, B., Zuschin, M., and Stachowitsch, M.: Tolerance of benthic macrofauna to hypoxia and anoxia in shallow coastal seas: a realistic scenario, Mar. Ecol. -Prog. Ser., 458, 39-52, 2012.

Riser, S. and Johnson, K.: Net production of oxygen in the subtropical ocean, Nature, 451, 323-325, 2008.

Rodionov, S. N. and Overland, J. E.: Application of a sequential regime shift detection method to the Bering Sea ecosystem, ICES J. Mar. Sci., 62, 328-333, 2005.

Rozan, T. F., Taillefert, M., Trouwborst, R. E., Glazer, B. T., Ma, S. F., Herszage, J., Valdes, L. M., Price, K. S., and Luther, G. W.: Iron-sulfur-phosphorus cycling in the sediments of a shallow coastal bay: implications for sediment nutrient release and benthic macroalgal blooms, Limnol. Oceanogr., 47, 1346-1354, 2002.

Rudels, B., Meyer, R., Fahrbach, E., Ivanov, V. V., Osterhus, S., Quadfasel, D., Schauer, U., Tverberg, V., and Woodgate, R. A.: Water mass distribution in Fram Strait and over the Yermak Plateau in summer 1997, Ann. Geophys., 18, 687-705, 2000, http://www.ann-geophys.net/18/687/2000/.

Sale, J. W. and Skinner, W. W.: The vertical distribution of dissolved oxygen and the precipitation of salt water in certain tidal areas, J. Frankl. Inst., 184, 837-848, 1917

Schaller, T. and Wehrli, B.: Geochemical focusing of manganese in lake sediments - an indicator of deep-water oxygen conditions, Aquat. Geochem., 2, 359-378, 1996.

Schauer, U., Fahrbach, E., Osterhus, S., and Rohardt, G.: Arctic warming through the Fram Strait: oceanic heat transport from 3 years of measurements, J. Geophys. Res., 109, C06026, doi:10.1029/2003JC001823, 2004.

Schmidt, W.: Über Temperatur- und Stabilitätsverhältnisse von Seen, Geogr. Ann. A, 10, 145-177, 1928.

Schneider, P. and Hook, S. J.: Space observations of inland water bodies show rapid surface warming since 1985, Geophys. Res. Lett., 37, L22405, doi:10.1029/2010GL045059, 2010.

Schubert, C. J., Lucas, F., Durisch-Kaiser, E., Stierli, R., Diem, T., Scheidegger, O., Vazquez, F., and Müller, B.: Oxidation and emission of methane in a monomictic lake (Rotsee, Switzerland), Aquat. Sci., 72, 455-466, 2010.

Sinninghe Damsté, J. S., Kenig, F., Koopmans, M. P., Koster, J., Schouten, S., Hayes, J. M., and DeLeeuw, J. W.: Evidence for gammacerane as an indicator of water column stratification, Geochim. Cosmochim. Ac., 59, 1895-1900, 1995.

Skolka, V. H. and Cautis, I.: Floraison d'Exuviaella cordata Ostenfs. et ses conséquences sur la pêche maritime en Roumanie au cours de l'année 1969, IRCM Constanta, Cercetări Marine Recherches marines, 1, 59-82, 1971.

Skopintsev, B. A.: Formirovanie sovremennogo khimicheskogo sostava vod Chernogo morya (Formation of the Present Chemical Structure of the Black Sea), Gidrometeoizdat, Leningrad, 1975.

Smetacek, V., von Bodungen, B., Knoppers, B., Peinert, R., Pollehne, F., Stegmann, P., and Zeitzschel, B.: Seasonal stages characterizing the annual cycle of an inshore pelagic system, Rapp. p. -v. réun. - Cons. int. explor. mer, Succeeding: ICES marine science symposia International Council for the Exploration of the Sea, 183, 126-135, 1984.

Soltwedel, T., Bauerfeind, E., Bergmann, M., Budaeva, N., Hoste, E., Jaeckisch, N., Juterzenka, K. V., Matthießen, J., Mokievsky, V., Nöthig, E. M., Quéric, N., Sablotny, B., Sauter, E., Schewe, I., Urban-Malinga, B., Wegner, J., Wlodarska-Kowalczuk, M., and Klages, M.: HAUSGARTEN: multidisciplinary investigations at a deep-sea, long-term observatory in the Arctic Ocean, Oceanography, 18, 46-61, 2005.

Sorokin, Y. I.: On the primary production and bacterial activities in the Black Sea, Journal du Conseil Permanent International pour l'Exploration de la Mer, 29, 41-54, 1964.

Stadelmann, P.: Der Zustand des Rotsees bei Luzern, in: MaihofRotsee. Geschichte und Eigenart eines Quartiers, edited by: Quartierverein Maihof, Quartierverein Maihof, Luzern, 54-61, 1980 (in German).

Stanev, E. V., He, Y., Grayek, S., and Boetius, A.: Oxygen dynamics in the Black Sea as seen by Argo profiling floats, Geophys. Res. Lett., 40, 3085-3090, 2013.

Steckbauer, A., Duarte, C. M., Cartsensen, J., Vaquer-Sunyer, R., and Conley, D. J.: Ecosystem impacts of hypoxia: thresholds of hypoxia and pathways to recovery, Environ. Res. Lett., 6, 025003, doi:10.1088/1748-9326/6/2/025003, 2011.

Stefan, H. G. and Fang, X.: Model simulations of dissolved oxygen characteristics of Minnesota lakes: past and future, J. Environ. Manage., 18, 73-92, 1994.

Stefan, H. G., Hondzo, M., Fang, X., Eaton, J. G., and McCormick, J. H.: Simulated long-term temperature and dissolved oxygen characteristics of lakes in the north-central United States and associated fish habitat limits, Limnol. Oceanogr., 4, 1124-1135, 1996.

Stefan, H. G., Fang, X., and Hondzo, M.: Simulated climate change effects on year-round water temperatures in temperate zone lakes, Climatic Change, 4, 547-576, 1998.

Stolper, D. A., Revsbech, N. P., and Canfield, D. E.: Aerobic growth at nanomolar oxygen concentrations, P. Natl. Acad. Sci. USA, 107, 18755-18760, 2010.

Stramma, L., Johnson, G. C., Sprintall, J., and Mohrholz, V.: Expanding oxygen-minimum zones in the tropical oceans, Science, 320, 655-658, 2008.

Tamburri,M. N.: Performance Verification Statement for the Aanderaa Instruments Inc. Dissolved Oxygen Optode 3830/3930/3835. UMCES Technical Report Series. Ref. No. [UMCES] CBL 04-116, 2004.

Teaca, A., Begun, T., and Gomoiu, M. -T.: Recent data on benthic populations from hard bottom mussel community in the Romanian Black Sea coastal zone, GeoEcoMarina, 12, 43-51, 2006.

Tengberg, A., Hovdenes, J., Andersson, H. J., Brocandel, O., Diaz, R., Hebert, D., Arnerich, T., Huber, C., Koertzinger, A., Khripounoff, A., Rey, F., Roenning, C., Schimanski, J., Sommer, S., and Stangelmayer, A.: Evaluation of a lifetime-based optode to measure oxygen in aquatic systems, Limnol. Oceanogr. -Meth., 4, 7-17, 2006.

Thamdrup, B., Dalsgaard, T., and Revsbech, N. P.: Widespread functional anoxia in the oxygen minimum zone of the Eastern South Pacific, Deep-Sea Res. Pt. I, 65, 36-45, 2012. 
Tolmazin, D.: Changing Coastal oceanography of the Black Sea. I: Northwesternshelf, Prog. Oceanogr., 15, 217-276, 1985.

Uchida, H., Kawano, T., Kaneko, I., and Fukasawa, M.: In-situ calibration of optode-based oxygen sensors, J. Atmos. Ocean. Tech., 25, 2271-2281, 2008.

Ünlüata, Ü., Oguz, T., Latif, M. A., and Özsoy, E.: On the physical oceanography of the Turkish straits, in: NATO ASI, edited by: Pratt, L. J., 25-60, 1990.

Vaquer-Sunyer, R. and Duarte, C. M.: Thresholds of hypoxia for marine biodiversity, P. Natl. Acad. Sci. USA, 105, 15452-15457, 2008.

Viktorsson, L., Ekeroth, N., Nilsson, M., Kononets, M., and Hall, P. O. J.: Phosphorus recycling in sediments of the central Baltic Sea, Biogeosciences, 10, 3901-3916, doi:10.5194/bg-10-39012013, 2013.

Ward, B. B., Kilpatrick, K. A., Novelli, P. C., and Scranton, M. I.: Methane oxidation and methane fluxes in the ocean surface layer and deep anoxic waters, Nature, 327, 226-229, 1987.

Weslawski, J. M., Kwasniewski, S., and Stempniewicz, L.: Warming in the Arctic may result in the negative effects of increased biodiversity, Polarforschung, 78, 105-108, 2009.

Yunev, O. A., Vedernikov, V. I., Basturk, O., Yilmaz, A., Kideys, A. E., Moncheva, S., and Konovalov, S. K.: Long-term variations of surface chlorophyll a and primary production in the open Black Sea, Mar. Ecol. -Prog. Ser., 230, 11-28, doi:10.3354/meps230011, 2002.
Yunev, O. A., Carstensen, J., Moncheva, S., Khaliulin, A., Ærtebjerg, G., and Nixon, S.: Nutrient and phytoplankton trends on the western Black Sea shelf in response to cultural eutrophication and climate changes, Estuar. Coast. Shelf S., 74, 63-76, 2007.

Zaitsev, Y. P.: Recent changes in the trophic structure of the Black Sea, Fish. Oceanogr., 1, 2, 180-198, 1992.

Zhang, J., Gilbert, D., Gooday, A. J., Levin, L., Naqvi, S. W. A., Middelburg, J. J., Scranton, M., Ekau, W., Peña, A., Dewitte, B., Oguz, T., Monteiro, P. M. S., Urban, E., Rabalais, N. N., Ittekkot, V., Kemp, W. M., Ulloa, O., Elmgren, R., Escobar-Briones, E., and Van der Plas, A. K.: Natural and human-induced hypoxia and consequences for coastal areas: synthesis and future development, Biogeosciences, 7, 1443-1467, doi:10.5194/bg-7-14432010, 2010.

Zimmermann, U., Forster, R., and Sontheimer, H.: Long-Term Change in the Water Quality of Lake Zurich, Upper Lake Zurich and the Lake of Walenstadt, City of Zurich Water Supply, Technical Report, 1991, (in German).

Züllig, H.: Pigmente phototropher Bakterien in Seesedimenten und ihre Bedeutung für die Seenforschung, Aquat. Sci., 47, 87-126, 1985, (in German). 